Helena Assaf Teixeira de Souza Mota Lima

Simulação da Injeção Alternada de Água-Emulsão-Água

Considerando Efeitos Capilares em Modelos

De Reservatórios Estratificados

Dissertação de Mestrado

Dissertação apresentada como requisito parcial para obtenção do grau de Mestre pelo Programa de Pósgraduação em Engenharia Mecânica da PUC-Rio.

Orientador: Prof. Márcio da Silveira Carvalho Co-orientadora: Dra. Ranena Verónica Ponce Flores

Rio de Janeiro 
Helena Assaf Teixeira de Souza Mota Lima

\section{Simulação da Injeção Alternada de Água-Emulsão-Água Considerando Efeitos Capilares em Modelos \\ De Reservatórios Estratificados}

Dissertação apresentada como requisito parcial para obtenção do grau de Mestre pelo Programa de Pós-graduação em Engenharia Mecânica do Centro Técnico Científico da PUC-Rio. Aprovada pela Comissão Examinadora abaixo assinada.

Prof. Márcio da Silveira Carvalho Orientador Departamento de Engenharia Mecânica - PUC - Rio

Dra. Ranena Verónica Ponce Flores Co-orientadora Departamento de Engenharia Mecânica - PUC - Rio

Dr. Arturo Rodrigo Ferreira Pardo Petróleo Brasileiro

Dr. Márcio Arab Murad Laboratório Nacional de Computação Científica

Prof. Márcio da Silveira Carvalho Coordenador Setorial do Centro Técnico Científico - PUC-Rio

Rio de Janeiro, 30 de setembro de 2016. 
Todos os direitos reservados. É proibida a reprodução total ou parcial do trabalho sem autorização da universidade, da autora e do orientador.

\section{Helena Assaf Teixeira de Souza Mota Lima}

Helena Assaf Teixeira de Souza Mota Lima graduou-se em Engenharia Civil pela Universidade Federal do Rio de Janeiro [2003].

Ficha catalográfica

Lima, Helena Assaf Teixeira de Souza Mota

Simulação da injeção alternada de água-emulsãoágua considerando efeitos capilares em modelos de reservatórios estratificados/ Helena Assaf Teixeira de Souza Mota Lima; orientador: Márcio da Silveira Carvalho; co-orientadora: Ranena Verónica Ponce Flores. - 2016.

100 f.: il. (color.); 29,7 cm

Dissertação (mestrado) - Pontifícia Universidade Católica do Rio de Janeiro, Departamento de Engenharia Mecânica, 2016.

Inclui bibliografia

1. Engenharia Mecânica - Teses. 2. Emulsão, 3. Recuperação Avançada de Óleo, 4. Controle de Mobilidade, 5. Simulação de Reservatórios. I

Carvalho, Márcio da Silveira. II. Ponce Flores, III. Pontifícia Universidade Católica do Rio de Janeiro. Departamento de Engenharia Mecânica. IV. Título. 


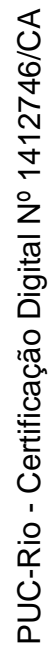

À minha família. 


\section{Agradecimento}

A minha família, em especial meu marido e meus filhos, pelo incentivo, suporte e companheirismo em todas as etapas deste trabalho e pela compreensão pelas minhas ausências e noites em claro durante este tempo.

Ao meu orientador, Professor Márcio da Silveira Carvalho, pela confiança, apoio e direcionamento durante a realização deste trabalho. E à minha co-orientadora, Dra. Ranena Verónica Ponce Flores, pela paciência, dedicação incansável, parceria e orientação constante e fundamental para a conclusão desta dissertação.

A PETROBRAS pelo suporte e liberação em tempo parcial para essa pesquisa. E aos meus gerentes Antônio Pinto, Tiago Homem, Thiago Pessoa, Roberta Mendes e colegas de trabalho pela ajuda e compreensão pelos períodos de afastamento das atividades profissionais.

À minha amiga Karime Glitz, por todo apoio e dedicação de me incentivar a encarar este desafio, ajudar e ensinar a programação dos gráficos e figuras, pela troca de ideias desde o início do mestrado e pela detalhada revisão desta dissertação.

Aos meus colegas de Mestrado e aos profissionais do Laboratório de Microhidrodinâmica e Escoamento em Meios Porosos pela ajuda que sempre me dedicaram. 


\section{Resumo}

Lima, Helena Assaf Teixeira de Souza Mota; Carvalho, Márcio da Silveira, Ponce Flores, Ranena Verónica. Simulação da Injeção Alternada de ÁguaEmulsão-Água considerando Efeitos Capilares em Modelos de Reservatórios Estratificados. Rio de Janeiro, 2016. 100p. Dissertação de Mestrado - Departamento de Engenharia Mecânica, Pontifícia Universidade Católica do Rio de Janeiro.

O aumento do fator de recuperação e o uso de métodos de recuperação avançada no atual cenário de novos patamares de preços representam um enorme desafio para a indústria do petróleo. Neste contexto, o uso de emulsões óleo-água como um método de recuperação avançada torna-se bastante atrativo. Diversos trabalhos mostraram um aumento no volume de óleo produzido através da injeção de emulsões óleo-água. Resultados de pesquisas experimentais indicam que a injeção de emulsões pode ser utilizada como agente de controle de mobilidade, bem como reduzindo a saturação residual de óleo. A aplicação do método de injeção alternada água-emulsão-água (WAE) requer o entendimento do escoamento de emulsões no meio poroso e dos mecanismos responsáveis pela melhora na recuperação. Este entendimento tanto na escala de poros como na escala de reservatórios permite incorporação destes mecanismos na modelagem para simulação de fluxo de reservatórios. No presente trabalho foi feita a incorporação dos efeitos gravitacionais no modelo desenvolvido para o escoamento de emulsões em meios porosos através da parametrização das curvas de permeabilidade relativa em função da concentração de gotas e do Número de Capilaridade. O processo WAE foi avaliado através de simulações em duas e três dimensões (2D/3D) utilizando um conjunto de camadas do segundo modelo comparativo do SPE10. Com simulações 2D e 3D foi possível realizar um estudo de sensibilidade do processo em relação ao momento da injeção de emulsão, o tamanho do banco, e as faixas de vazão e respectivos números de capilaridades de atuação da emulsão.

\section{Palavras-chave}

Emulsão; Recuperação Avançada de Óleo; Controle de Mobilidade; Simulação de Reservatórios. 


\section{Abstract}

Lima, Helena Assaf Teixeira de Souza Mota; Carvalho, Márcio da Silveira (advisor), Ponce Flores, Ranena Verónica (co-advisor). Flow simulation of macro-emulsion flooding at stratified reservoirs considering capillary effects. Rio de Janeiro, 2016. 100p. MSc. Dissertation - Departamento de Engenharia Mecânica, Pontifícia Universidade Católica do Rio de Janeiro.

In the current crude oil price scenario, the increase in oil recovery factor and the use of enhanced recovery methods represent a major challenge for the Oil Industry. In this context, the use of oil-water emulsion flooding as an enhanced recovery method becomes very attractive. Several studies have shown a significant potential to increase oil volume recovery by the injection of oil-water emulsions. Experimental results indicate that the emulsions injection can be used as a mobility control agent, resulting in a more uniform fluid displacement in the reservoir and lower residual oil saturation. Based on these experimental results, the most relevant parameters for emulsion injection performance effectiveness are droplet size, the local concentration of the dispersed phase of the emulsion and the local capillary number. The application of water alternating emulsion injection (WAE) method requires understanding of the flow of emulsions in porous media and the mechanisms responsible for the improved recovery. The understanding of this process in both porous scale and reservoir scale is fundamental to model emulsion injection effects in reservoir flow simulation. In this work, the gravitational effects was incorporated in the macroscopic model to represent flow of emulsions in porous media by relative permeability curves parametrization as function of emulsion concentration and of the local capillary number. The WAE process was evaluated in two and three dimensional simulations (2D / 3D) using a set of layers of the second SPE 10 comparative model. With 2D and 3D simulations, it was possible to explore a WAE injection performance sensitivity analysis considering the time at which the emulsion injection is started, the size of emulsion bank, and the injection flow rates and consequently the flow their capillary number.

\section{Keywords}

Emulsion; Enhanced Oil Recovery; Mobility Control, Reservoir Simulation 


\section{Sumário}

1 Introdução 17

1.1. Descrição geral do problema 17

$\begin{array}{ll}\text { 1.2. Objetivo } & 18\end{array}$

$\begin{array}{lr}\text { 1.3. Roteiro } & 19\end{array}$

2 Injeção de Emulsão em Meios Porosos $\quad 20$

2.1. Conceitos Básicos de Escoamento em Meios Porosos 20

2.2. Injeção de Água em Meio Porosos 24

2.3. Métodos de Recuperação Avançada 26

2.3.1. Emulsões 28

2.3.2. Injeção de emulsões em meios porosos 28

3 Modelagem de Escoamento de Emulsões em Meios Poroso 38

3.1. Modelo de Escoamento monofásico em um no meio poroso 38

3.2. Modelo de Escoamento Bifásico Água Óleo 40

3.3. Escoamento de Emulsões 43

3.4. Solução do Sistema de Equações Diferenciais 46

$\begin{array}{ll}4 \text { Resultados } & 48\end{array}$

4.1. Modelo de Reservatório 48

4.2. Simulações 2D 50

4.3. Simulações 3D com 4 camadas 58

4.3.1. Simulações 3D com 4 camadas na mesma formação reservatório 59

4.3.2. Simulações 3D com 4 camadas na interface entre duas formações reservatório

5 Comentários finais 95

5.1. Sugestões 96

6 Referências bibliográficas $\quad 98$ 


\section{Lista de figuras}

Figura 2-1 - Representação esquemática de um meio poroso preenchido com água e óleo. (Disponível em: www.sinmec.ufsc.br/) 21

Figura 2-2 - llustração do método de recuperação de petróleo mediante injeção de água. (Disponível em www.maxwell.vrac.pucrio.br)

Figura 2-3 - llustração de Viscous fingering entre poços injetor e produtor (Adaptado de www.large.stanford.edu)

Figura 2-4 - Gráfico evidenciando mostrando o acréscimo na produção de óleo e a redução na produção de água decorrente de um piloto de campo de injeção de emulsão água óleo. (Mc Auliffe, 1973) 29

Figura 2-5 - Imagens de emulsões água óleo escoando através de um capilar (Cobos et al., 2009)

Figura 2-6 - Imagens mostrando a mudança nos padrões de escoamento em um meio poroso após a injeção de emulsão (Guillen et al., 2012a)

Figura 2-7 - Ilustração de experimento realizado com diferentes amostras em paralelo e gráficos mostrando o efeito da injeção de emulsão (Guillen et al., 2012a)

Figura 2-8 - Resultados ilustrando o aumento do óleo adicional obtido com injeção WAE para o Número de Capilaridade menor (Guillen et 2012b)

Figura 2-9 - Gráficos com as permeabilidades relativas água-óleo e emulsão-óleo (Engelke et al. 2013)

Figura 2-10 - Resultado da simulação com acréscimo de fator de recuperação decorrente da injeção WAE (Ponce et al. 2014)

Figura 2-11 - Resultados de simulação de reservatórios de injeção WAE com remobilização de óleo como observado nos experimentos (Ponce et al., 2014)

Figura 4-1 - Distribuição da porosidade do modelo na figura superior e na parte inferior são evidenciados os canais fluviais (http://www.spe.org/web/csp/datasets/set02.htm)

Figura 4-2 - Permeabilidades relativas dos sistemas óleo-água e óleoemulsão utilizadas nas simulações dos casos

Figura 4-3 - Curvas de evolução do fator de recuperação de óleo (FR); com o período da injeção de emulsão sinalizada versus volume poroso (VP) injetado para os Casos 1 (IA), 2 (WAE - faixa ampla), 3 (WAE - faixa restrita) e 4 (WAE - faixa média). 
Figura 4-4 - Curvas de corte de água (WCUT) e a pressão de fundo no injetor (IBP), com o período da injeção de emulsão sinalizada versus volume poroso (VP) injetado para os Casos 1 (IA), 2 (WAE faixa ampla), 3 (WAE - faixa restrita) e 4 (WAE - faixa média).

Figura 4-5 -Curvas de evolução do fator de recuperação de óleo; com o período da injeção de emulsão sinalizada versus volume poroso injetado para os Casos 1 (IA), 4 (WAE 0,3/0,2/1,5), 5 (WAE $0,1 / 0,2 / 1,7)$ e 6 (WAE 0,2/0,2/1,6).

Figura 4-6 -Curvas de corte de água e a pressão de fundo no injetor, com o período da injeção de emulsão sinalizada versus volume poroso injetado para os Casos 1 (IA), 4 (WAE 0,3/0,2/1,5), 5 (WAE $0,1 / 0,2 / 1,7)$ e 6 (WAE 0,2/0,2/1,6).

Figura 4-7 - Curvas de evolução do fator de recuperação de óleo contra o volume poroso injetado para os Casos 1 (IA), 6 (WAE 0,2/0,2/1,6), 7 (WAE 0,2/0,1/1,7) e 8 (WAE 0,2/0,05/1,75).

Figura 4-8 - Curvas do corte de água e a pressão de fundo no injetor contra o volume poroso injetado para os Casos 1 (IA), 6 (WAE 0,2/0,2/1,6), 7 (WAE 0,2/0,1/1,7) e 8 (WAE 0,2/0,05/1,75).

Figura 4-9 - Mapas de saturação de água, concentração de emulsão e Número de Capilaridade do Caso 4 (WAE 0,3/0,2/1,5) para a injeção de 0,5VP (a) 0,7VP (b) e 2,0VP (c)

Figura 4-10 - Validação do código tridimensional implementado no modelo black-oil programado no simulador de código aberto MRST do SINTEF com simulador comercial.

Figura 4-11 - Curvas de evolução do fator de recuperação de óleo para os Casos A (IA), B (WAE 0,4/1,2/3,4), C (WAE 0,4/0,2/4,4) e D (WAE 0,4/0,4/4,2).

Figura 4-12 - Curvas de evolução do corte de água e da pressão de fundo no poço injetor para os Casos A (IA), B (WAE 0,4/1,2/3,4), C (WAE 0,4/0,2/4,4) e D (WAE 0,4/0,4/4,2).

Figura 4-13 - Mapas de porosidade e saturação de óleo das camadas $\mathrm{k}=3$ a 6 dos Casos $A$ (injeção de água) e D (WAE 0,4/0,4/4,2) durante a injeção de 1, 2 e 5 VP de fluidos.

Figura 4-14 Mapa de saturação de óleo da quarta camada do modelo e seções do mesmo no meio do grid para o Caso A (injeção de água) durante a injeção de 1 VP.

Figura 4-15 Mapa de saturação de óleo da quarta camada do modelo e seções do mesmo no meio do grid para o Caso D (WAE 0,4/0,4/4,2) durante a injeção de $1 \mathrm{VP}$.

Figura 4-16 - Mapas de saturação de óleo para seções (i,j) localizadas no poço injetor, no meio do domínio e no poço produtor - Caso $A$ (injeção de água) e Caso $D($ WAE 0,4/0,4/4,2) durante a injeção de 1 , 2 e 5 VP de fluidos. 
Figura 4-17 - Curvas de evolução do fator de recuperação de óleo para os Casos A (IA), D (WAE 0,4/0,4/4,2), E (WAE 0,2/0,4/4,4), e F (WAE 2,0/0,4/2,6).

Figura 4-18 - Curvas de evolução do corte de água da pressão de injeção no poço injetor para os Casos A (IA), D (WAE 0,4/0,4/4,2), E (WAE 0,2/0,4/4,4), e F (WAE 2,0/0,4/2,6).

Figura 4-19 - Mapas de porosidade e de saturação de óleo das camadas $\mathrm{k}=3$ a 6 dos Casos $\mathrm{A}$ (injeção de água) e $\mathrm{E}$ (WAE 0,2/0,4/4,4) durante a injeção de 1, 2 e 5 VP de fluidos.

Figura 4-20 - Mapas de saturação de óleo para seções (i,j) localizadas no poço injetor, no meio do domínio e no poço produtor - Caso $A$ (injeção de água) e $E(\operatorname{WAE} 0,2 / 0,4 / 4,4)$ durante a injeção de 1 , 2 e 5 VP de fluidos.

Figura 4-21 - Mapas de porosidade e de saturação de óleo das camadas $\mathrm{k}=3$ a 6 dos Casos $\mathrm{A}$ (injeção de água) e $\mathrm{F}$ (WAE 2,0/0,4/2,6) durante a injeção de 2,5, 4 e 5 VP de fluidos.

Figura 4-22 - Mapas de saturação de óleo para seções (i,j) localizadas no poço injetor, no meio do domínio e no poço produtor - Caso A (injeção de água) e Caso $\mathrm{F}$ (WAE 2,0/0,4/2,6) durante a injeção de 2,5 4 e 5 VP de fluidos.

Figura 4-23 - Curvas de evolução do fator de recuperação de óleo para os Casos G (IA), H (WAE 0,4/1,2/3,4), I (WAE 0,4/0,2/4,4) e J (WAE 0,4/0,4/4,2).

Figura 4-24 - Curvas de evolução do corte de água e pressão de injeção no poço injetor para os Casos $\mathrm{G}$ (IA), H (WAE 0,4/1,2/3,4), I (WAE 0,4/0,2/4,4) e J (WAE 0,4/0,4/4,2).

Figura 4-25 - Curvas de evolução do fator de recuperação de óleo para os Casos G (IA), H (WAE 0,4/1,2/3,4), H_ciclo e J (WAE $0,4 / 0,4 / 4,2)$.

Figura 4-26 - Curvas de evolução do corte de água e da pressão de injeção no poço injetor para os Casos G (IA), H (WAE 0,4/1,2/3,4), H_ciclo e J (WAE 0,4/0,4/4,2).

Figura 4-27 - Mapas de porosidade e de saturação de óleo das camadas $\mathrm{k}=34$ a 37 dos Casos $\mathrm{G}$ (injeção de água) e J (WAE $0,4 / 0,4 / 4,2$ ) durante a injeção de 1,2 e 5 VP de fluidos.

Figura 4-28 - Mapas de saturação de óleo para seções (i,j) localizadas no poço injetor, no meio do domínio e no poço produtor - Caso $G$ (injeção de água) e Caso J (WAE 0,4/0,4/4,2) durante a injeção de 1 , 2 e 5 VP de fluidos.

Figura 4-29 - Curvas de evolução do fator de recuperação de óleo para os Casos G (IA), J (WAE 0,4/0,4/4,2), K (WAE 0,2/0,4/4,4) e L (WAE 2,0/0,4/2,6). 
Figura 4-30 - Curvas de evolução do corte de água e da pressão de injeção no poço injetor para os Casos G (IA), J (WAE 0,4/0,4/4,2), K (WAE 0,2/0,4/4,4) e L (WAE 2,0/0,4/2,6).

Figura 4-31 - Mapas de porosidade e de saturação de óleo das camadas $\mathrm{k}=34$ a 37 dos Casos $\mathrm{G}$ (injeção de água) e $\mathrm{K}$ (WAE $0,2 / 0,4 / 4,4$ ) durante a injeção de 1,2 e 5 VP de fluidos.

Figura 4-32 - Mapas de saturação de óleo para seções (i,j) localizadas no poço injetor, no meio do domínio e no poço produtor - Caso $G$ (injeção de água) e Caso K (WAE 0,2/0,4/4,4) durante a injeção de 1 , 2 e 5 VP de fluidos.

Figura 4-33 - Mapas de porosidade e de saturação de óleo das camadas $\mathrm{k}=34$ a 37 dos Casos $\mathrm{G}$ (injeção de água) e K (WAE 2,0/0,4/2,6) durante a injeção de 2,5, 4 e 5 VP de fluidos.

Figura 4-34 - Mapas de saturação de óleo para seções (i,j) localizadas no poço injetor, no meio do domínio e no poço produtor - Caso $G$ (injeção de água) e Caso L (WAE 2,0/0,4/2,6) durante a injeção de 2,5, 4 e 5 VP de fluidos.

Figura 4-35 - Curvas de evolução do fator de recuperação de óleo para os Casos G (IA_Qref), J (WAE_Qref), M (WAE_Qref/5), N (WAE_5xQref)

Figura 4-36 - Curvas de evolução do corte de água para os Casos $G$ (IA_Qref), J (WAE_Qref), M (WAE_Qref/5), N (WAE_5xQref)

Figura 4-37 - Mapas de porosidade e de saturação de óleo das camadas k=34 a 37 dos Casos $\mathrm{G}$ (injeção de água) e M (WAE_Qref/5) durante a injeção de 1, 2 e 5 VP de fluidos.

Figura 4-38 - Mapas de saturação de óleo para seções (i,j) localizadas no poço injetor, no meio do domínio e no poço produtor - Caso G (injeção de água) e Caso M (WAE_Qref/5) durante a injeção de 1, 2 e 5 VP de fluidos.

Figura 4-39 - Mapas de porosidade e de saturação de óleo das camadas k=34 a 37 dos Casos $\mathrm{G}$ (injeção de água) e N (WAE_5xQref) durante a injeção de 1, 2 e 5 VP de fluidos.

Figura 4-40 - Mapas de saturação de óleo para seções (i,j) localizadas no poço injetor, no meio do domínio e no poço produtor - Caso G (injeção de água) e Caso N (WAE_5xQref) durante a injeção de 1, 2 e 5 VP de fluidos. 


\section{Lista de tabelas}

Tabela 4-1 - Quadro comparativo das simulações 2D (camada $\mathrm{k}=1$ )

Tabela 4-2 - Quadro comparativo das simulações 3D (4 camadas $\mathrm{k}=3,4,5$ e 6 )

Tabela 4-3 - Quadro comparativo das simulações 3D (4 camadas $\mathrm{k}=34,35,36$ e 37) com vazão constante

Tabela 4-4 - Quadro comparativo das simulações 3D (4 camadas $\mathrm{k}=34,35,36$ e 37) com sensibilidade a vazão .75 


\section{Lista de Símbolos}

$C_{e}$ - Concentração da fase dispersa (gotas)

$c_{i}$ - Compressibilidade da fase "i"

$c_{r}$ - Compressibilidade da rocha

$f_{w}$ - Fluxo fracionário, fração entre o fluxo de água e o fluxo total

$E_{R}-$ Eficiência de Recuperação

$E_{A}$ - Eficiência de varrido Areal

$E_{V V}-$ Eficiência de varrido vertical

$E_{D}-$ Eficiência de Deslocamento

$\mathrm{g}$ - Aceleração da Gravidade

K - Permeabilidade absoluta

$k_{f}$ - Permeabilidade Efetiva

$k_{r i}$ - Permeabilidade Relativa à fase "i"

$k_{r e}-$ Permeabilidade relativa à emulsão

$k_{r e}\left(S_{\text {Ore }}\right)$ - Permeabilidade relativa à emulsão na saturação de óleo residual à emulsão

$k_{r o}$ - Permeabilidade relativa ao óleo

$k_{r w}$ - Permeabilidade relativa à água

$k_{r w}\left(S_{\text {Orw }}\right)$ - Permeabilidade relativa à água na saturação de óleo residual

$k_{r o}\left(S_{w i}\right)$ - Permeabilidade relativa ao óleo na saturação de água inicial

$p$ - Pressão global

$p_{i}$ - Pressão da fase "i"

$p_{\text {cow }}$ - Pressão capilar óleo-água

M - Razão de mobilidades

$N C_{a}$ - Número de Capilaridade

$\vec{n}$ - Vetor normal apontando para fora do limite $\partial \Omega$

$n_{o}$ - Expoente de Corey para o óleo

$n_{w}$ - Expoente de Corey para a água

$n_{e}$ - Expoente de Corey para a emulsão

$q$ - Termo de fonte ou sumidouro

$S_{f}$ - Saturação do fluido

$S_{O r}$ - Saturação de óleo residual a injeção do fluido deslocante

$S_{\text {Ore }}$ - Saturação de óleo residual a injeção de emulsão

$S_{\text {Orw }}$ - Saturação de óleo residual a injeção de água 
$S_{w i}$ - Saturação de água inicial

$\vec{v}$ - Velocidade do fluido ou velocidade de Darcy

$V_{f}$ - Volume ocupado pelo fluido

z- Posição vertical

$\varnothing$ - Porosidade

$\mu_{f}$ - Viscosidade do fluido;

$\mu_{o}$ - Viscosidade do óleo;

$\mu_{w}$ - Viscosidade da água;

$\sigma$ - Tensão interfacial entre as fases óleo e água

$\rho_{f}$ - Massa específica de um fluido

$\lambda_{f}$ - Mobilidade de um fluido

$\Omega$ - Volume de controle

$\partial \Omega$ - Superfície do volume de controle 


\section{Lista de Siglas}

EOR - Enhanced Oil Recovery - Recuperação Avançada de Petróleo

FR - Fator de Recuperação

IA - Injeção de Água

IMEX - Three-phase, Black-Oil Reservoir Simulator

IMPES - implicit method pressure explicit saturation- Método implícito na pressão e explícito na saturação

MRST - MATLAB Reservoir Simulation Toolbox

O/A - emulsão óleo em água

STARS - Steam Thermal and Advanced Process Reservoir Simulator

TPFA - Two-point flux approximation- Aproximação de fluxo entre dois pontos

$\mathrm{VP}$ - Volume poroso

VT - Volume total

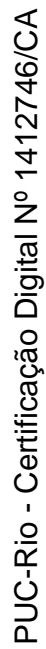

WAE - Water-Alternating-Emulsion - Injeção Alternada de água e emulsão

WCUT - Water Cut - Corte de água 


\section{Introdução}

\section{1.}

\section{Descrição geral do problema}

A injeção de água é o método mais utilizado na recuperação secundária de petróleo no mundo. Entretanto, os fatores de recuperação de óleo, mesmo na recuperação secundária, podem não ser elevados. A razão desfavorável de mobilidades entre o fluido deslocante e o deslocado, bem como a heterogeneidade do reservatório são fatores que favorecem a formação dos caminhos preferenciais e, consequentemente, fatores de recuperação mais reduzidos.

Diferentes métodos de recuperação avançada são utilizados na indústria com o objetivo de minimizar os problemas associados a baixa recuperação de óleo com a injeção de água e aumentar o fator de recuperação de óleo.

Diversos trabalhos mostraram um aumento no volume de óleo produzido através da injeção de emulsões óleo-água. Destaca-se que a injeção de emulsões como método de recuperação avançada pode tornar-se atrativa pelo potencial uso das emulsões produzidas (águas de produção) após condicionamento no processo de injeção.

Vale destacar que a injeção de água produzida pode vir a trazer problemas de perda de injetividade, especialmente, pela presença de sólidos no fluido produzido, daí a necessidade de processo de tratamento adequado para este fim.

O método da injeção de emulsões óleo-água só se mostrou efetivo para uma determinada faixa de condições de operação e características da emulsão injetada.

A aplicação deste método requer o entendimento do escoamento de emulsões no meio poroso e dos mecanismos responsáveis pela melhora na recuperação. Este entendimento tanto na escala de poros como na escala de reservatórios permite a incorporação destes mecanismos na modelagem para simulação de fluxo de reservatórios. Ponce et al. $(2014,2016)$ desenvolveram um modelo macroscópico para o escoamento de emulsões em meios porosos através 
da parametrização das curvas de permeabilidade relativa em função da concentração de gotas e do Número de Capilaridade. Estas implementações foram feitas no modelo black-oil de simulação de reservatórios programado no código aberto MATLAB Reservoir Simulation Toolbox (MRST) do SINTEF (Asrnes et al, 2007).

Visando avaliar o modelo de escoamento de emulsões com efeitos capilares e de concentração da fase dispersa da emulsão em reservatórios estratificados, assim como, o potencial do uso de emulsões para o aumento da eficiência de varrido vertical, faz-se necessária a incorporação dos efeitos gravitacionais no modelo proposto por Ponce et al. (2016), bem como a avaliação deste modelo em reservatórios estratificados.

\section{2 .}

\section{Objetivo}

O objetivo deste trabalho é incorporar os termos gravitacionais ao modelo disponível na literatura para descrever o efeito da injeção de emulsão água-óleo na recuperação de petróleo de forma a obter um modelo mais completo para a simulação na escala de reservatório e utilizá-lo na análise do processo de injeção de emulsões em reservatórios heterogêneos.

Utilizou-se como base o modelo desenvolvido por Ponce et al. (2016) que descreve mecanismos de controle de mobilidade e eficiência de deslocamento observados no escoamento de emulsões através de mudanças apropriadas nas curvas de permeabilidade relativa, e incorpora na parametrização das curvas de permeabilidade relativa a dependência do Número de Capilaridade.

No presente trabalho foram incorporados os efeitos gravitacionais no modelo de escoamento de emulsões (com dependência da concentração da fase dispersa da emulsão e do Número de Capilaridade) no intuito de realizar simulação em três dimensões e com isso avaliar o modelo em reservatórios estratificados bem como o potencial do uso de emulsões para aumentar o fator de recuperação.

O modelo desenvolvido foi usado no estudo do processo de injeção alternada água-emulsão-água (WAE - Water-Alternating-Emulsion) para a produção de óleo em modelos em duas e três dimensões (2D e 3D) com geometrias mais próximas de um reservatório real. 


\section{3.}

Roteiro

O trabalho está dividido em 5 capítulos. No capítulo 1, o problema é descrito, e são apresentados o objetivo e roteiro desta dissertação.

No segundo capítulo, faz-se uma breve revisão de conceitos básicos de fluxo em meios porosos e injeção de água, bem como a revisão bibliográfica dos resultados experimentais da injeção de emulsões e a modelagem deste método.

O capítulo 3 descreve os modelos matemáticos de escoamento bifásico água-óleo e de escoamento de emulsões no meio poroso, bem como a solução numérica deste sistema de equações.

Os resultados numéricos obtidos são apresentados e discutidos no capítulo 4. Finalmente, no capítulo 5 são apresentadas as conclusões e comentários finais do trabalho. 


\section{2 Injeção de Emulsão em Meios Porosos}

Neste capítulo é feita uma breve revisão de conceitos básicos de escoamento em meios porosos para fundamentar o entendimento das eficiências obtidas com a injeção de água. Posteriormente apresenta-se uma revisão bibliográfica dos resultados experimentais da injeção de emulsões, bem como a modelagem deste método de recuperação avançada em simuladores de reservatórios.

\section{1.}

\section{Conceitos Básicos de Escoamento em Meios Porosos}

Petróleo é uma mistura de compostos químicos orgânicos (hidrocarbonetos) que podem ser encontrados em estado sólido, líquido (fase óleo) ou gasoso (fase gás), a depender das condições de pressão e temperatura a que estão submetidos. (Thomas, 2001).

Um reservatório de petróleo é a acumulação desta mistura de hidrocarbonetos nos espaços vazios de uma rocha porosa, chamado de meio poroso.

Segundo Rosa (2006), a porosidade é uma das mais importantes propriedades das rochas na engenharia de reservatórios, uma vez que define a capacidade de armazenamento de fluidos no reservatório. A porosidade é definida como a razão entre o volume de vazios (volume poroso - VP) e o volume total (VT) da rocha reservatório, ou seja:

$$
\emptyset=\frac{V P}{V T}
$$

onde:

$\varnothing$ é a porosidade

VP é o volume poroso

VT é o volume total 
No entanto, o espaço vazio da rocha pode estar preenchido por diferentes fluidos. Define-se a saturação de um fluido em um meio poroso como o percentual do volume poroso ocupado por este fluido, assim:

$$
S_{f}=\frac{V_{f}}{V P}
$$

onde:

$S_{f}$ é a saturação de um fluido

$V_{f}$ é o volume ocupado pelo fluido

A Figura 2-1 ilustra um meio poroso com a matriz sólida (rocha) e dois líquidos imiscíveis, óleo e água.

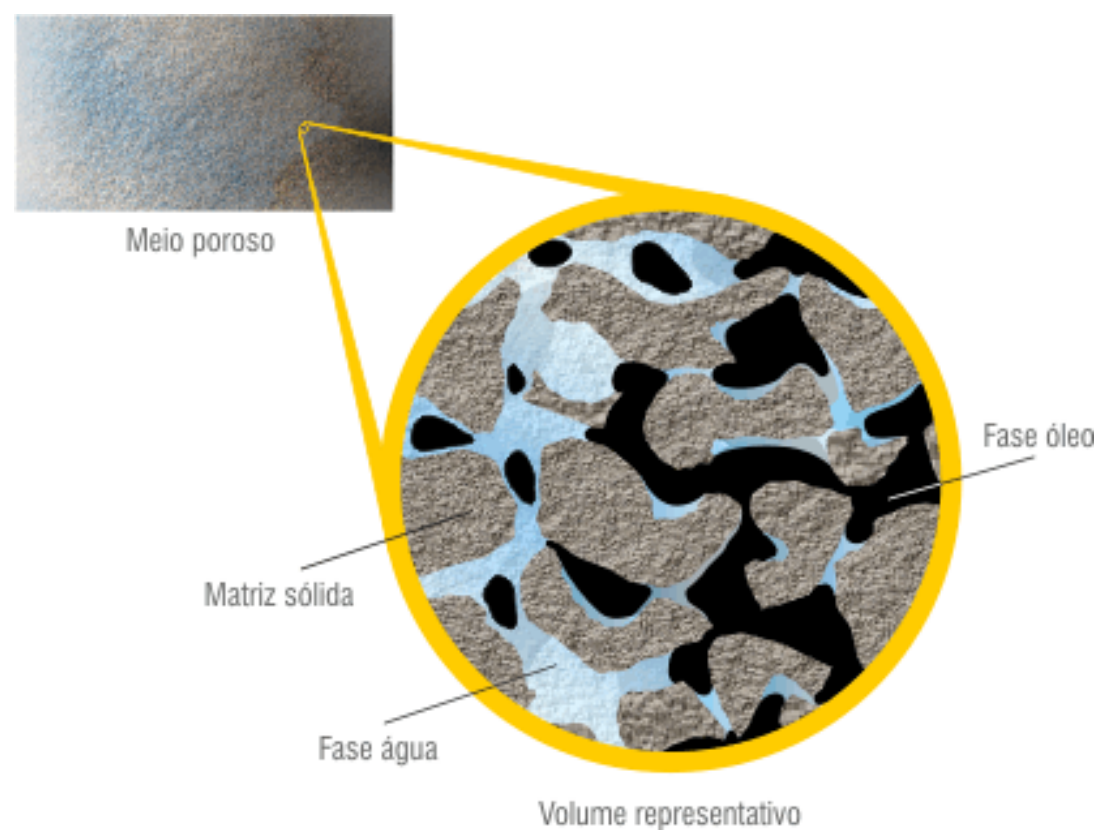

Figura 2-1 - Representação esquemática de um meio poroso preenchido com água e óleo. (Disponível em: www.sinmec.ufsc.br/)

Para produção dos fluidos contidos em uma rocha-reservatório faz-se necessária uma certa quantidade de energia. A energia natural ou primária é aquela contida inicialmente nos fluidos decorrente das situações e circunstâncias pelas quais passou a jazida para sua formação. (Rosa et al., 2006)

Para que haja a produção dos fluidos presentes no reservatório é necessário que outro material venha a substituir o espaço poroso ocupado pelo fluido a ser produzido. Dois são os principais efeitos para provocar esta produção: a descompressão e o deslocamento de um fluido por outro. São exemplos de 
mecanismos de produção: mecanismo de gás em solução, de capa de gás e influxo de água.

Cada mecanismo representa uma força motriz capaz de deslocar o óleo desde o meio poroso até os poços produtores do campo. Chama-se de recuperação primária a quantidade de óleo que pode ser retirada do reservatório unicamente com sua energia natural.

A recuperação secundária é aquela na qual se obtém uma produção adicional de óleo através da suplementação de energia de forma artificial. Os objetivos da recuperação secundária são aumentar a eficiência de recuperação e acelerar a produção de óleo. A injeção de água é o método mais utilizado na recuperação secundária de petróleo no mundo.

Para estudar o deslocamento de um fluido imiscível (óleo) por outro fluido (água, por exemplo) é preciso conhecer as características e parâmetros das rochas e dos fluidos em questão para avaliar a eficiência do processo de injeção.

Destaca-se, entre eles: (Rosa,2006)

a. Permeabilidade absoluta (K): é uma medida do meio poroso de se deixar atravessar por fluidos (saturação 100\%), ou seja, uma medida de condutividade de fluidos através do meio;

b. Permeabilidade efetiva de fluido $\left(k_{f}\right)$ (na presença de outro): quando existem dois ou mais fluidos no meio poroso a permeabilidade efetiva de um dos fluidos é menor que a permeabilidade absoluta por conta da presença de outro fluido.

c. Permeabilidade relativa ao fluido $\left(k_{r i}\right)$ : é a relação entre a permeabilidade efetiva e a permeabilidade absoluta. Pode ser representada de forma percentual variando entre zero (inexistência de fluxo) a 100\% (meio poroso saturado de um único fluido);

d. Massa específica do fluido $\left(\rho_{f}\right)$ : é a relação entre a massa e o volume do fluido. Esta é dependente da composição do fluido e das condições de pressão e temperatura do reservatório.

e. Viscosidade do fluido $\left(\mu_{f}\right)$ : é uma medida da sua resistência ao fluxo. Esta é dependente da composição do fluido e das condições de pressão e temperatura do reservatório.

f. Mobilidade de um fluido $\left(\lambda_{f}\right)$ : é definida como a razão entre a permeabilidade relativa a esse fluido e sua viscosidade nas condições de reservatório. 
Com estas características definidas, é possível obter parâmetros importantes como a Razão de Mobilidades ( $M)$, que é a relação entre as mobilidades do fluido deslocante (água) e do fluido deslocado (óleo). Assim, temos que:

$$
M=\left(\frac{k_{w} / \mu_{w}}{k_{o} / \mu_{o}}\right)
$$

onde:

$M$ é a razão de mobilidade

$k_{w}$ é a permeabilidade efetiva a água

$k_{o}$ é a permeabilidade efetiva ao óleo

$\mu_{w}$ é a viscosidade da água

$\mu_{o}$ é a viscosidade do óleo.

Quando não estão disponíveis valores experimentais das curvas de permeabilidade relativa podem ser usados diferentes métodos analíticos para descrever o comportamento de permeabilidades relativas. O modelo mais utilizado para sua obtenção é o modelo de Corey no qual a permeabilidade relativa de cada fase é função da saturação normalizada da própria fase (Corey, 1954).

As equações utilizadas neste modelo são:

$$
\begin{aligned}
& k_{r w}=k_{r w}\left(S_{o r}\right) \cdot\left(\frac{S_{w}-S_{w i}}{1-S_{w i}-S_{o r}}\right)^{n_{w}} \\
& k_{r o}=k_{r o}\left(S_{w i}\right) \cdot\left(\frac{1-S_{w}-S_{o r}}{1-S_{w i}-S_{o r}}\right)^{n_{o}}
\end{aligned}
$$

onde:

$k_{r w}$ é a permeabilidade relativa à água

$k_{r w}\left(S_{\text {Orw }}\right)$ é a permeabilidade relativa à água na saturação de óleo residual $S_{O r}$ é a saturação de óleo residual a injeção do fluido deslocante

$S_{w}$ é a saturação de água

$S_{w i}$ é a saturação de água inicial

$n_{w}$ é o expoente de Corey para a água

$k_{r o}$ é a permeabilidade relativa ao óleo

$k_{r o}\left(S_{w i}\right)$ é a permeabilidade relativa ao óleo na saturação de água inicial $n_{o}$ é o expoente de Corey para o óleo 
Outro conceito importante para o entendimento do problema é o número de capilaridade ( $\mathrm{NCa}$ ) associado ao deslocamento de um fluido em um meio poroso. Este é dado por:

$$
N C_{a}=\frac{\mu_{d} \cdot v}{\sigma}
$$

onde:

$\mu_{d}$ - viscosidade do fluido deslocante (água);

$v$ - velocidade de Darcy;

$\sigma$ - tensão interfacial entre as fases óleo e água.

O número de capilaridade representa a razão entre as forças viscosas associadas ao escoamento da fase deslocante e a força capilar entre as fases. $\mathrm{O}$ aumento de $\mathrm{NCa}$ desloca o balanço para o lado das forças viscosas e, consequentemente, diminui a saturação da fase deslocada no poro.

\section{2.}

\section{Injeção de Água em Meio Porosos}

A injeção de água é o método mais utilizado na recuperação secundária de petróleo no mundo. Entretanto, os fatores de recuperação de óleo mesmo na recuperação secundária podem ser baixos. A razão desfavorável de mobilidades entre o fluido deslocante e o deslocado, bem com a heterogeneidade do reservatório são fatores que favorecem a formação dos caminhos preferenciais e consequentemente baixos fatores de recuperação. (Farias, 2013)

Na Figura 2-2 é apresentada uma ilustração do método de recuperação de petróleo pela injeção de água.

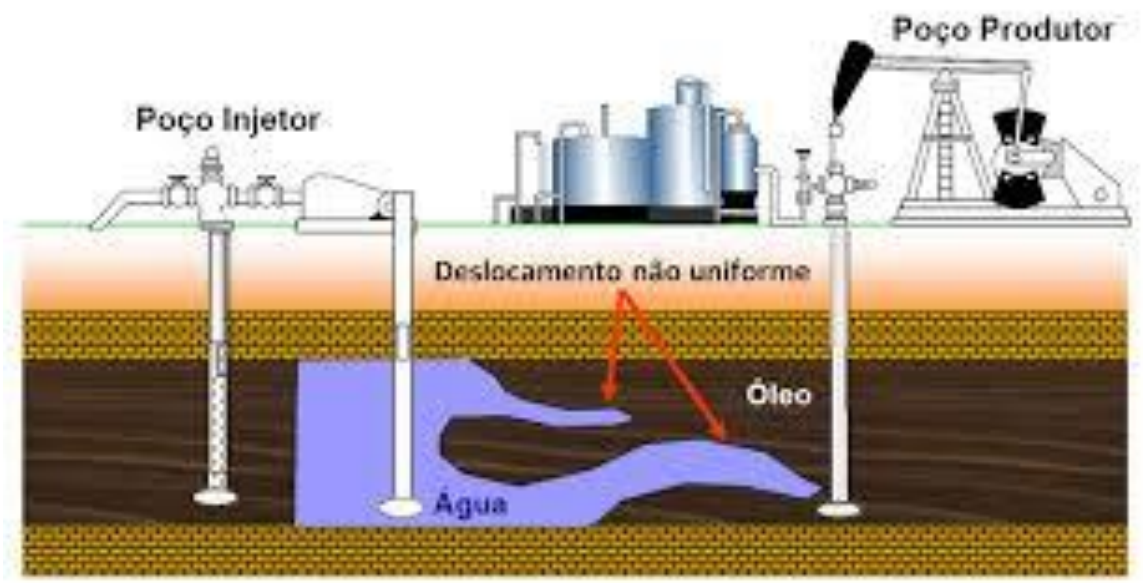

Figura 2-2 - Ilustração do método de recuperação de petróleo mediante injeção de água.

(Disponível em www.maxwell.vrac.puc-rio.br) 
A eficiência do método de recuperação $\left(E_{R}\right)$ secundário para a produção de óleo (a injeção de água, por exemplo) é função do produto de três fatores: eficiência de varrido horizontal ou areal; eficiência de varrido vertical e eficiência de deslocamento. (Rosa et al., 2006)

$$
E_{R}=E_{A} \cdot E_{V V} \cdot E_{D}
$$

A eficiência de varrido horizontal ou areal $\left(E_{A}\right)$ é a relação entre a área de fato varrida entre os poços produtores e injetores em relação a área total entre eles, e esta por sua vez é uma função das heterogeneidades na direção horizontal, do número de capilaridade e da razão de mobilidade entre o fluido injetado e o deslocado.

Uma alta razão de mobilidade alta $(M>1)$ leva ao aparecimento de um fenômeno conhecido como viscous fingering, ou digitação viscosa. A frente de deslocamento torna-se instável, formando caminhos preferenciais para a fase aquosa, como ilustrado na Figura 2-3. A água injetada chega aos poços produtores com grande parte do reservatório não sendo varrido.

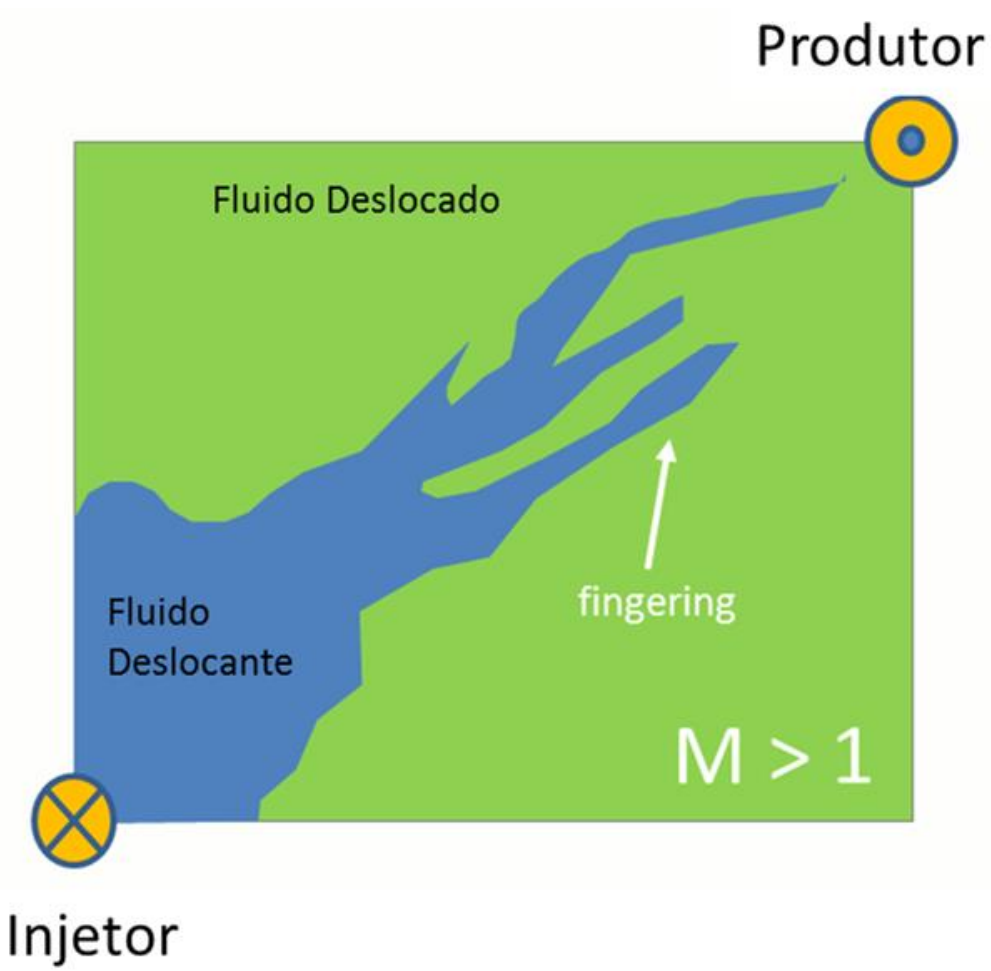

Figura 2-3 - Ilustração de Viscous fingering entre poços injetor e produtor (Adaptado de www.large.stanford.edu) 
A Eficiência de varrido vertical $\left(E_{V V}\right)$ é a relação entre a área vertical invadida pelo fluido deslocante e a área vertical total da seção transversal. Esta eficiência é dependente da heterogeneidade vertical, da inclinação de suas camadas, da diferença de densidade entre os fluidos, da razão entre as permeabilidades vertical e horizontal, e da razão de mobilidade.

A eficiência de descolamento $\left(E_{D}\right)$ está relacionada à microescala, associada à quantidade de óleo residual que permanece no espaço poroso mesmo na região varrida pelo fluido injetado. A eficiência de deslocamento está ligada diretamente ao padrão de fluxo das fases em escala microscópica no meio poroso.

A eficiência de deslocamento é definida como a relação entre o volume de óleo deslocado e o volume de óleo presente no reservatório.

$$
E_{D}=\frac{V P\left(S_{o}-S_{o r}\right)}{V P}=\frac{S_{o}-S_{o r}}{S_{o}}
$$

onde:

$S_{O r}$ é a saturação de óleo residual após a injeção do fluido deslocante

$S_{O}$ é a saturação de óleo inicial

\section{3. \\ Métodos de Recuperação Avançada}

Para minimizar os problemas da recuperação secundária e obter fatores de recuperação mais elevados existem os métodos especiais de recuperação ou métodos de recuperação avançada (EOR - Enhanced Oil Recovery).

São exemplos de métodos de recuperação avançada:

- métodos miscíveis, como a injeção de $\mathrm{CO}_{2}$ ou gás pobre a alta pressão entre outros;

- métodos térmicos, como injeção de fluidos quentes e combustão in situ;

- métodos químicos, como a injeção de polímeros, emulsões, álcali, etc.

Segundo Rosa (2006), para a maioria dos métodos de recuperação avançada, o custo dos fluidos a serem injetados, bem como os custos operacionais, são altos. Por isso, faz-se necessário a realização de estudos 
geológicos e de engenharia (testes de laboratório, simulação numérica) e projeto piloto no reservatório que receberá a aplicação do método para a determinação da sua viabilidade técnica e econômica com segurança.

O controle de mobilidade em reservatórios, que leva a um aumento da eficiência de varrido, pode ser feito basicamente de duas maneiras:

- aumento da viscosidade do fluido deslocante para melhorar a razão de mobilidade; e

- redução da permeabilidade relativa da água pelo emprego de algum agente capaz de bloquear o fluxo dessa fase em áreas já previamente lavadas.

A melhoria de razão de mobilidade pode ser obtida, por exemplo, através da adição de polímeros à água de injeção. Nesse caso, os problemas mais importantes são a ocorrência de adsorção parcial do produto pela rochareservatório, a perda de parte do poder de viscosificação pelo cisalhamento do polímero ao passar pelo sistema de injeção e o grande espaço requerido pelas plantas de mistura e depósitos de produto. Geralmente são projetos de alto custo que demandam grandes modificações nas instalações de produção. (Farias, 2013)

Pesquisas mostram um aumento no volume de óleo produzido após a injeção de emulsões óleo em água em rochas (reservatório e de afloramentos) que estavam sendo produzidas mediante a injeção continua de água. (McAuliffe, 1973).

Em processos de injeção alternada de água-emulsão-água (WAE - Water Alternating Emulsion), a produção adicional de óleo é explicada pelo bloqueio dos caminhos preferenciais da água pelas gotas da emulsão, o desvio do escoamento para áreas previamente não varridas pela água e a consequente estabilização da frente de injeção. (Cobos et al. 2009; Guillen et al., 2012; Engelke et al. 2013 e Farias, 2013).

A injeção de emulsões torna-se atrativa como método de recuperação avançada devido ao seu custo reduzido, maior resistência a altas temperaturas (que injeção de polímeros) e potencial uso das emulsões produzidas (águas de produção) após condicionamento no processo de injeção.

Para explorar as vantagens deste método de recuperação, faz-se necessário o entendimento do escoamento de emulsões no meio poroso e dos mecanismos responsáveis pela melhora na recuperação.

No item a seguir são discutidos modelos para a descrição do escoamento de emulsões no meio poroso bem como mencionados resultados de pesquisas 
que indicam que a injeção de emulsões pode ser utilizada como agente de controle de mobilidade permitindo um deslocamento mais uniforme do fluido no reservatório, bem como a redução do óleo residual aumentando assim também a eficiência de deslocamento de óleo.

\subsection{1. \\ Emulsões}

Uma emulsão é uma dispersão em que um líquido é disperso em uma fase líquida contínua e imiscível a ele. A estabilização das gotas de líquido disperso é feita através de agentes denominados surfactantes. Os surfactantes têm função de diminuir a tensão interfacial entre os fluidos e evitar a coalescência das gotículas da fase dispersa no interior da fase contínua. Na indústria do petróleo, emulsões são comumente encontradas ao longo de todas as etapas da cadeia produtiva.

As emulsões podem ser classificadas como microemulsões (dispersão de gotas de tamanho menor do que a longitude de onda da luz visível) e macroemulsões (dispersão de gotas com diâmetros em geral maiores que $0,1 \mu \mathrm{m}$ - (Becher, 2001).

Em função das naturezas das fases, as emulsões podem ser classificadas como: emulsão óleo em água $(\mathrm{O} / \mathrm{A})$, gotas de óleo dispersas em água; emulsão água em óleo $(\mathrm{A} / \mathrm{O})$, gotas de água dispersas em óleo e emulsão múltipla, de gotas de água dentro de gotas de óleo dispersas em água (A/O/A) (Kokal,2005).

No presente trabalho, de agora em diante, entenda-se a palavra emulsão como uma macroemulsão óleo em água $(\mathrm{O} / \mathrm{A})$.

As emulsões e microemulsões (Bera, 2015) podem ser encontradas em diversos processos de recuperação avançada de petróleo. Existem técnicas nas quais soluções com surfactante são injetadas para diminuir a tensão interfacial entre o óleo e a água, o que pode levar a formação de emulsão in situ, e assim mobilizar o óleo remanescente no meio poroso.

\subsection{2.}

\section{Injeção de emulsões em meios porosos}

A injeção de emulsões diluídas de óleo em água em reservatórios portadores de óleo viscoso pode contribuir significativamente para o bloqueio parcial de áreas já lavadas pela água de injeção mediante a captura parcial das 
gotas de óleo emulsionadas. Além disso, a presença de um surfactante na fase contínua diminui a tensão interfacial causando a diminuição da saturação de óleo residual devido ao aumento do número de capilaridade por redução da pressão capilar. Essas emulsões podem ser obtidas, após tratamento adequado, a partir da água produzida pelo campo. A água produzida com baixo teor de sólidos pode ser considerada uma emulsão de óleo em água salina. (Farias, 2013)

McAuliffe (1973) fez uma série de experimentos em arenitos Berea, Alhambra e Boise com objetivo de avaliar o potencial da injeção de emulsões óleo em água no controle da digitação viscosa em campos de petróleo.

Os resultados desse estudo motivaram um teste de injeção de emulsões no campo de Midway-Sunset nos EUA. Nesse projeto foi injetado um volume de 33000 bbl de emulsão óleo em água a 14\% (3\% do volume poroso estimado da área). Os resultados foram monitorados através das vazões de óleo e água nos poços produtores próximos (Figura 2-4), salinidade da água produzida e uso de traçadores radioativos adicionados no banco de água injetado após o tratamento com a emulsão.

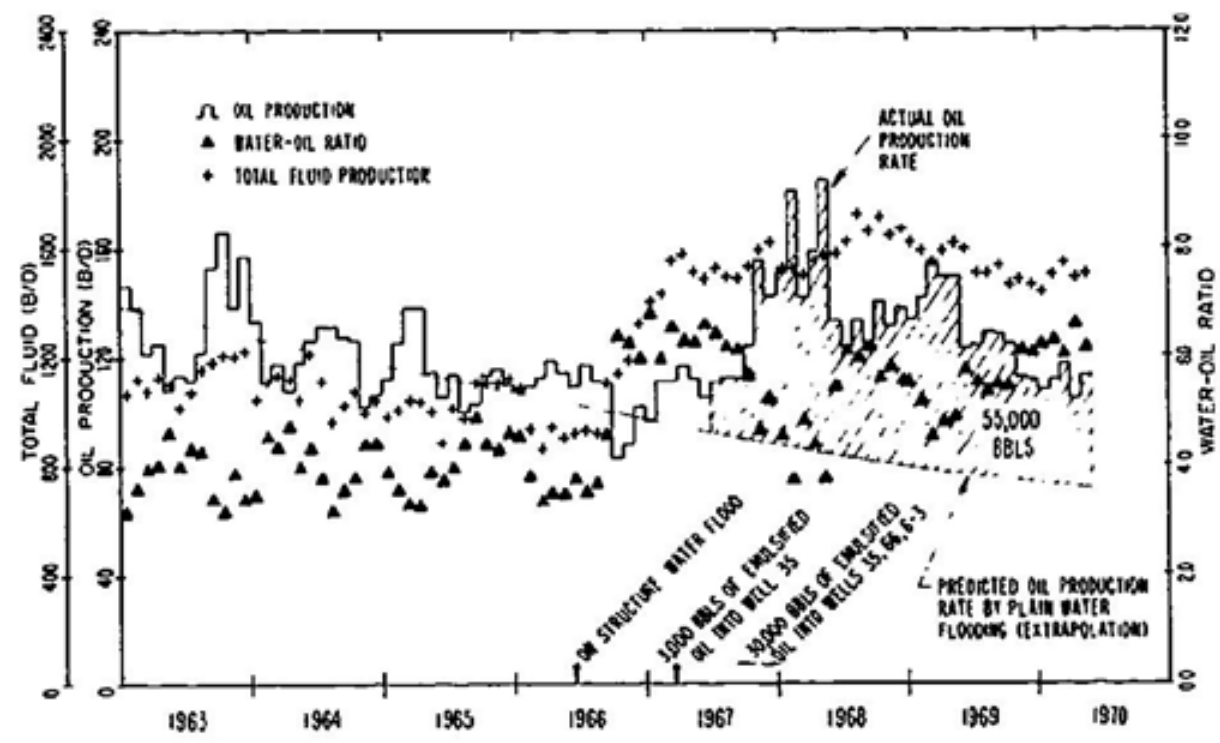

Figura 2-4 - Gráfico evidenciando mostrando o acréscimo na produção de óleo e a redução na produção de água decorrente de um piloto de campo de injeção de emulsão água óleo. (Mc Auliffe, 1973)

Entre os resultados de McAuliffe (1973), destacam-se que:

- Houve diminuição na vazão de água dos poços produtores monitorados, indicando que a emulsão atuou eficientemente no bloqueio das zonas com elevado grau de formação de fingers viscosos. O ganho de óleo acumulado foi 
estimado em 55000 bbl calculado através da diferença entre a produção de óleo realizada e o modelo de declínio dos poços;

- O retorno dos traçadores indicou que a emulsão alterou o padrão de fluxo no reservatório, pois o traçador foi detectado em poços originalmente pouco afetados pela injeção nos poços onde a emulsão foi aplicada;

- Foram detectados aumentos nas salinidades das águas produzidas pelos produtores da área, indicando que a emulsão ampliou o varrido do reservatório.

Cobos et al. (2009) mostram o comportamento do escoamento de emulsões através de um capilar que serve como modelo de uma garganta de poro. Neste trabalho é feita uma revisão do importante papel da emulsão em muitos processos de recuperação avançada (EOR), particularmente nos métodos químicos e é apresentada uma visualização e medição de pressão de emulsões óleo em água escoando através de um capilar (Figura 2-5).
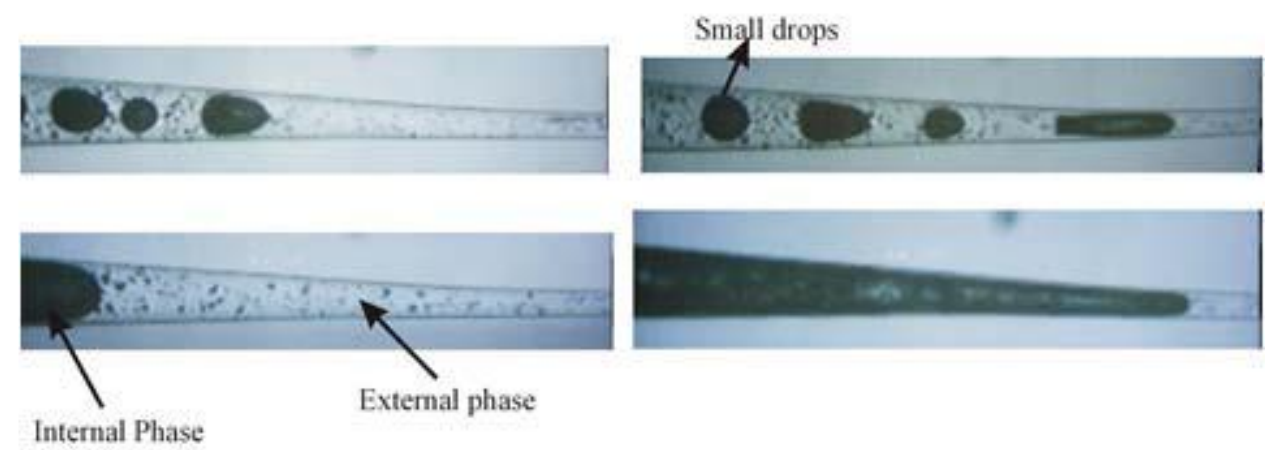

Figura 2-5 - Imagens de emulsões água óleo escoando através de um capilar (Cobos et al., 2009)

Cobos et al. (2009) analisaram emulsões com gotas grandes e pequenas, com diferentes distribuições do tamanho de gotas. As principais conclusões foram que o escoamento da emulsão é dominado pelo efeito de bloqueio das gotas maiores que o capilar e que as gotas da emulsão que possuíam tamanho similar ao das gargantas reduziam a mobilidade da fase contínua. Para caracterizar esta redução de mobilidade os autores mediram a queda de pressão durante a injeção de água e emulsão, na mesma vazão. Observou-se que para gotas muito menores que o tamanho dos poros o fator de redução da mobilidade tende a 1 e independe da vazão de injeção.

Este mecanismo de redução da mobilidade da água está associado à injeção de emulsão óleo em água. Esta mudança na mobilidade da água pode ser representada pela redução da permeabilidade relativa a água. Arhuoma et 
al.(2009b) desenvolveram um modelo para o escoamento para a injeção de soluções alcalinas em reservatórios de óleo pesado com formação de emulsão óleo em água in situ. No modelo, duas fases aquosas, água e a solução alcalina, e dois componentes oleosos, óleo cru e a emulsão óleo em água eram considerados. Uma pseudoreação no modelo gerava a emulsão in situ. Eles determinaram as permeabilidades relativas através de técnicas semianalíticas que desprezavam os efeitos de pressões capilares.

A metodologia utilizada por Arhuoma et al(2009b) consistia na interpolação entre as curvas de permeabilidade relativa da água e da emulsão. Quando necessário estes modelos incorporavam correlações de viscosidade relacionadas à concentração de emulsão (Arhuoma et al.,2009a). Adicionalmente, mudanças na interação rocha-fluido assim como absorção química também foram incluídas no modelo de injeção de soluções alcalinas. Eles encontraram um bom ajuste para esta sendo a principal explicação para a melhoria da eficiência de recuperação.

De forma similar, Wang, J. e M. Dong (2009) conduziram testes de injeção de soluções alcalinas/surfactantes em sandpacks usando óleo pesado para demostrar a efetividade de melhora no varrido pela geração de emulsão in situ. Os dados experimentais foram utilizados para calibrar a simulação de fluxo que incluía a geração in situ de emulsão e o escoamento desta. E com os parâmetros ajustados realizaram simulações em escala de campo.

Guillen et al. (2012a) estudaram o efeito da injeção WAE em meios porosos com diferentes permeabilidades. Os autores registraram o efeito da emulsão na escala de poros num meio poroso não consolidado. Nos experimentos, as gotas de óleo injetadas na emulsão puderam ser observadas bloqueando as gargantas de poros e ocasionando mudança no padrão do escoamento (Figura 2-6). Foi observada uma melhora na eficiência de deslocamento através da redução de saturação de óleo residual com a mobilização de óleo que inicialmente não fora removido pela injeção de água. 

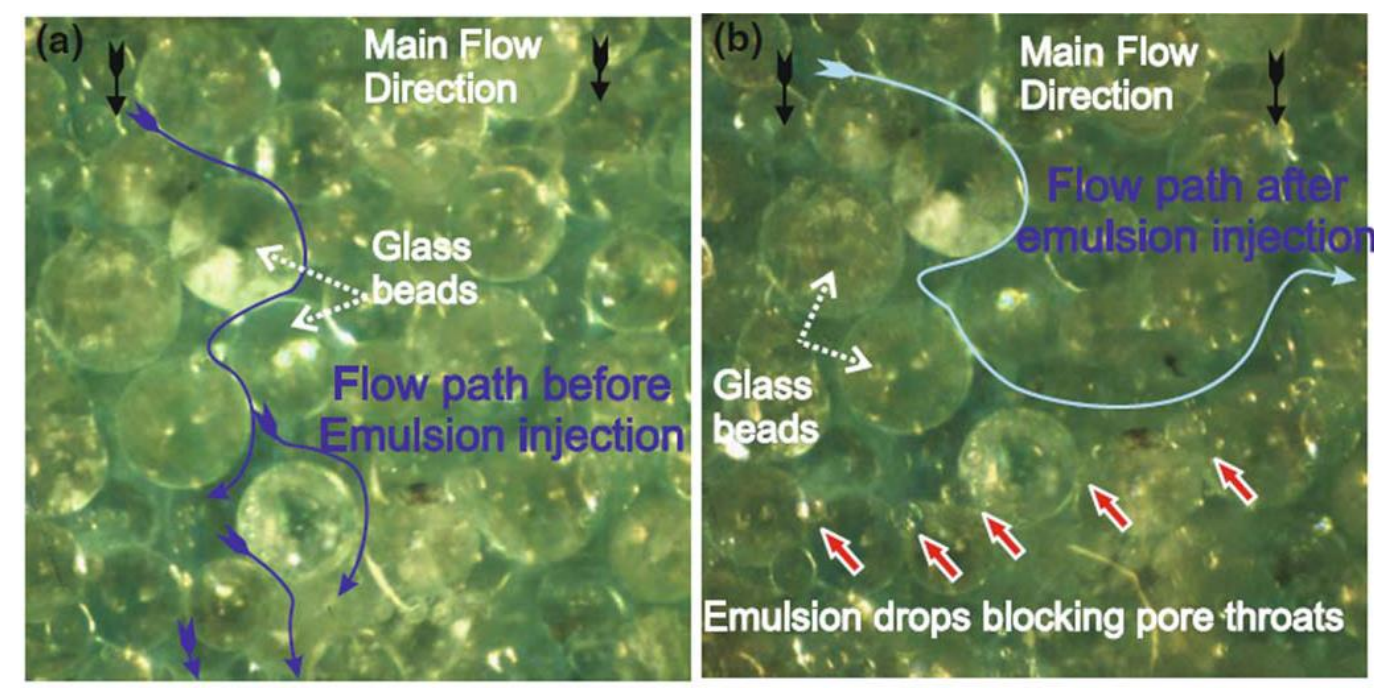

Figura 2-6 - Imagens mostrando a mudança nos padrões de escoamento em um meio poroso após a injeção de emulsão (Guillen et al., 2012a)

Outros experimentos apresentados por Guillen et al. (2012a), realizados em amostras de arenitos de diferentes permeabilidades montadas em paralelo, mostraram que a injeção de emulsão interfere no volume deslocado de óleo em diferentes escalas, tanto na escala de poros quanto na escala macro atuando no controle da mobilidade e permitindo um deslocamento mais uniforme do fluido no reservatório. A Figura 2-7 mostra a bancada experimental utilizada pelos autores para injeção de emulsão em amostras em paralelo assim como os resultados obtidos, pode-se observar que com a injeção da emulsão foi possível melhorar o varrido inclusive na amostra de menor permeabilidade 


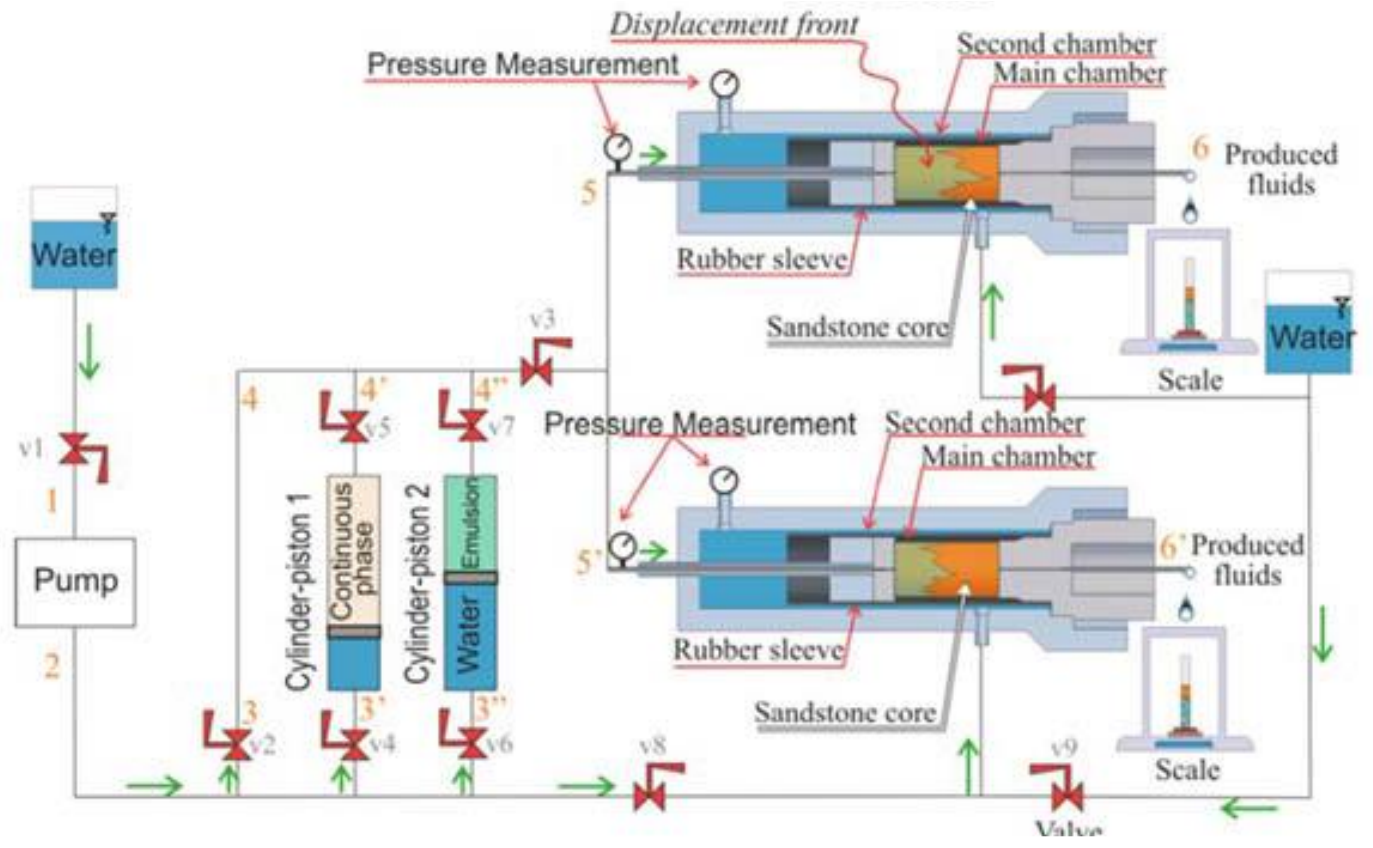

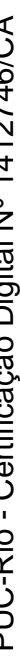

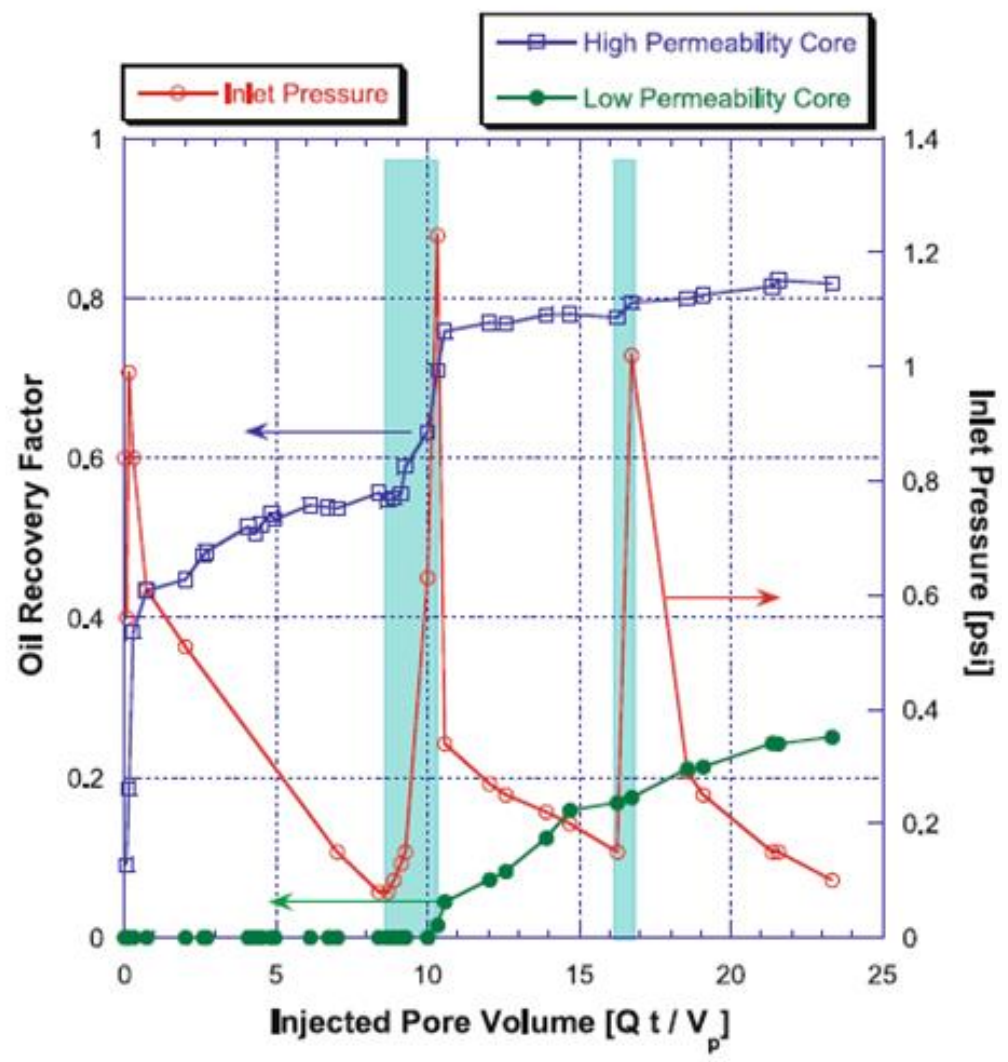

Figura 2-7 - Ilustração de experimento realizado com diferentes amostras em paralelo e gráficos mostrando o efeito da injeção de emulsão (Guillen et al., 2012a)

Guillen et al. (2012b) observaram que o fator de redução de mobilidade varia em função do Número de Capilaridade (vazão de injeção), comportamento semelhante foi observado por Romero et al.(2011). Os resultados experimentais 
de injeção WAE através de duas amostras rochosas de porosidade e permeabilidade muito similares mostraram, para diferentes vazões equivalentes a números de capilaridade iguais a $2 \times 10^{-5}$ e $2 \times 10^{-4}$, que quanto menor for o Número de Capilaridade mais efetivo é o controle da mobilidade e que, em função das características do fluido e do meio poroso, pode-se estimar um Número de Capilaridade crítico, onde a partir deste a redução da mobilidade ocorre de maneira mais significativa. (Figura 2-8)
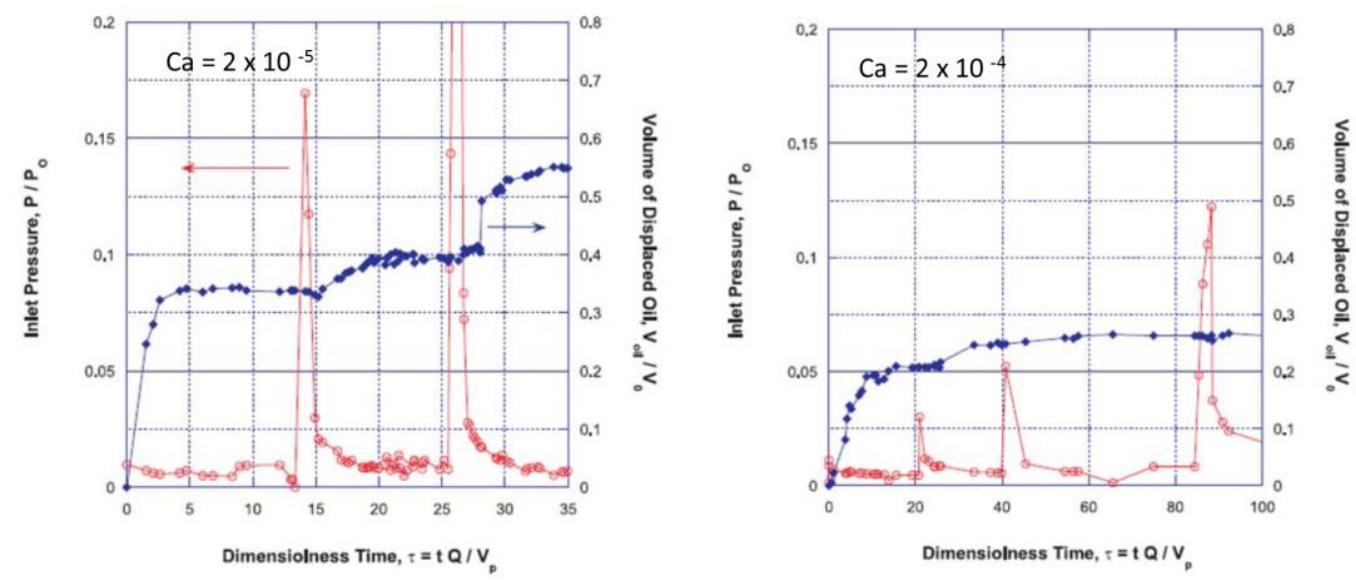

Figura 2-8 - Resultados ilustrando o aumento do óleo adicional obtido com injeção WAE para o Número de Capilaridade menor (Guillen et 2012b)

Farias (2013) avaliou o uso de emulsões diluídas de óleo em água como método de controle de mobilidade. Foi desenvolvido um extenso programa experimental em sandpacks de areia de sílica e amostras de arenito (Berea e Bentheimer) de forma a comparar as recuperações finais de óleo, perfis de pressão de injeção e razões água-óleo acumuladas nos casos de injeção de água, injeção de surfactantes e macroemulsões. Um estudo paramétrico foi feito de forma a identificar a influência da vazão de injeção, distribuição de tamanhos de gotas de óleo emulsionadas, concentração de óleo e permeabilidade no desempenho das emulsões injetadas. Os resultados obtidos indicaram ganhos na produção de óleo e redução da razão água-óleo acumulada.

Engelke et al.(2013) obteve experimentalmente curvas de permeabilidades relativas para os sistemas óleo-água e óleo-emulsão para emulsões com diferentes diâmetros de gota em amostras de arenitos (Berea). Pode-se observar tanto a redução da saturação de óleo residual quanto a mudança no formato e pontos terminais das curvas representando respectivamente o efeito na emulsão na eficiência de deslocamento e na eficiência de varrido (Figura 2-9). 
Desta forma, Engelke et al.(2013) obteve previsões com simulação de reservatório utilizando estas curvas parametrizadas para representar os efeitos da emulsão. Os resultados indicaram que a injeção de emulsão poderia atrasar a chegada de água e aumentar o volume de óleo recuperado em relação a injeção de água.

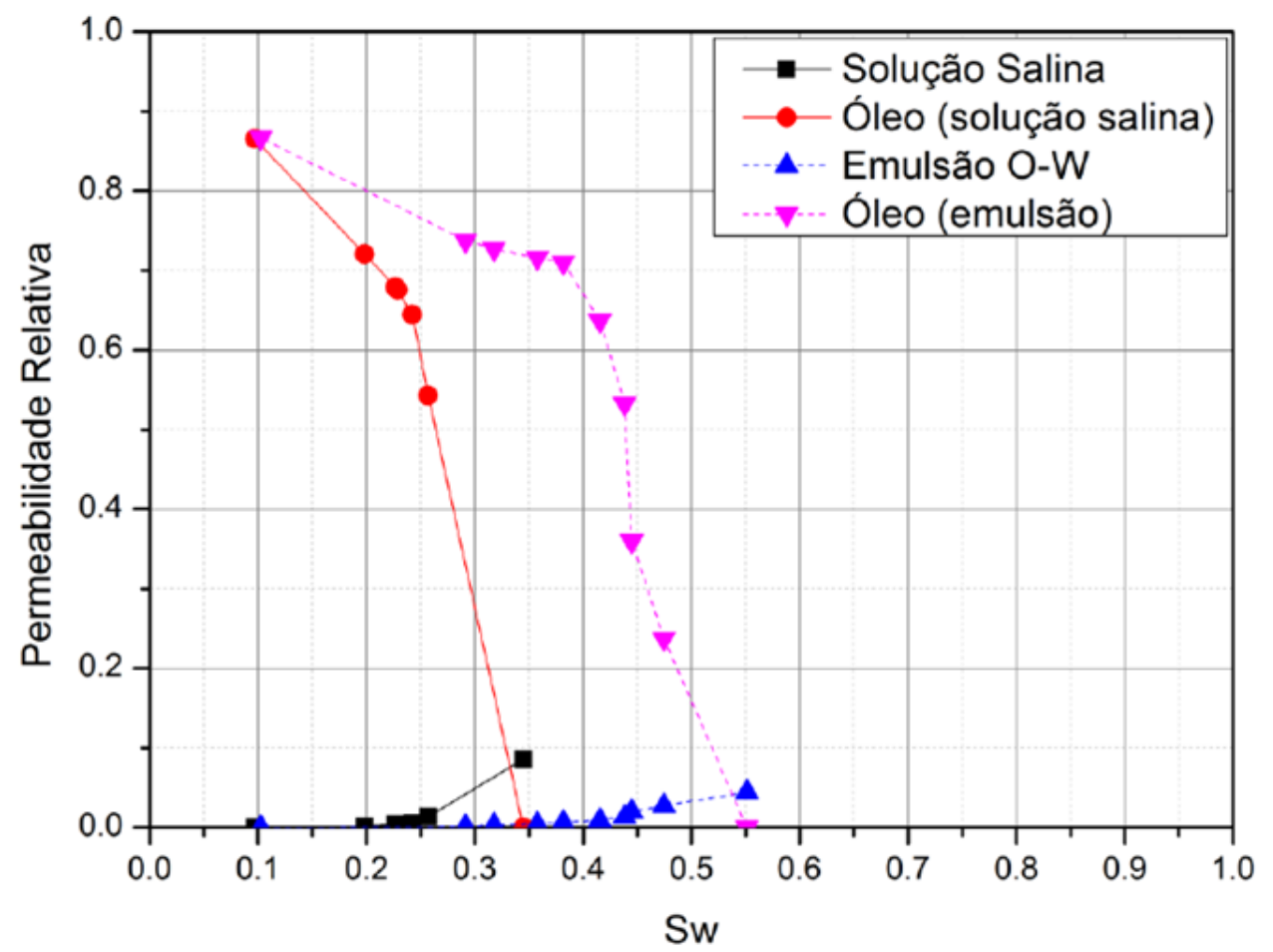

Figura 2-9 - Gráficos com as permeabilidades relativas água-óleo e emulsão-óleo (Engelke et al. 2013)

Os mecanismos de mobilização de óleo com redução de óleo residual e melhora do varrido macroscópico promovidos pela injeção de emulsões precisam ser compreendidos e modelados para permitir a previsão de escoamento de reservatórios em cenários de injeção de emulsão.

Ponce et al.(2014) propuseram um modelo simplificado para representar os efeitos observados experimentalmente por Guillen et al. (2012a,b) e Engelke et al.(2013) durante a injeção de emulsões mediante a interpolação linear entre as curvas de permeabilidade relativa óleo-água e óleo-emulsão em função da concentração local da fase dispersa da emulsão.

Desta maneira foi realizada a modelagem dos mecanismos de eficiência de deslocamento e controle de mobilidade e implementada em um simulador comercial (CMG-STARS ${ }^{\mathrm{TM}}$ ). Neste trabalho as curvas de permeabilidades 
relativas do sistema óleo-emulsão foram geradas mediante modificações das curvas do sistema óleo-água.

O mecanismo do controle de mobilidade da emulsão foi representado mediante a redução do valor de permeabilidade relativa da fase água na saturação de óleo residual enquanto que o mecanismo de eficiência de deslocamento da emulsão foi representado mediante a redução da saturação de óleo residual. Desta forma foi possível simular vários casos, considerando baixos números de capilaridade e ainda isolar e comparar a contribuição de cada um dos efeitos: eficiência de deslocamento versus eficiência de varrido. Os resultados mostraram que a eficiência de deslocamento (redução da saturação de óleo residual) é bem mais impactante que o controle de mobilidade de varrido, embora esta última também tenha algum efeito.

Nas Figura 2-10 e Figura 2-11 são ilustrados os resultados obtidos. A primeira é um gráfico com o acréscimo de fator de recuperação em relação ao caso de injeção de água com alteração na saturação de óleo residual nas curvas de permeabilidade relativa. Na segunda figura são mostrados os resultados da simulação evidenciando a remobilização de óleo na região lavada, como foi observado nos experimentos descritos anteriormente.

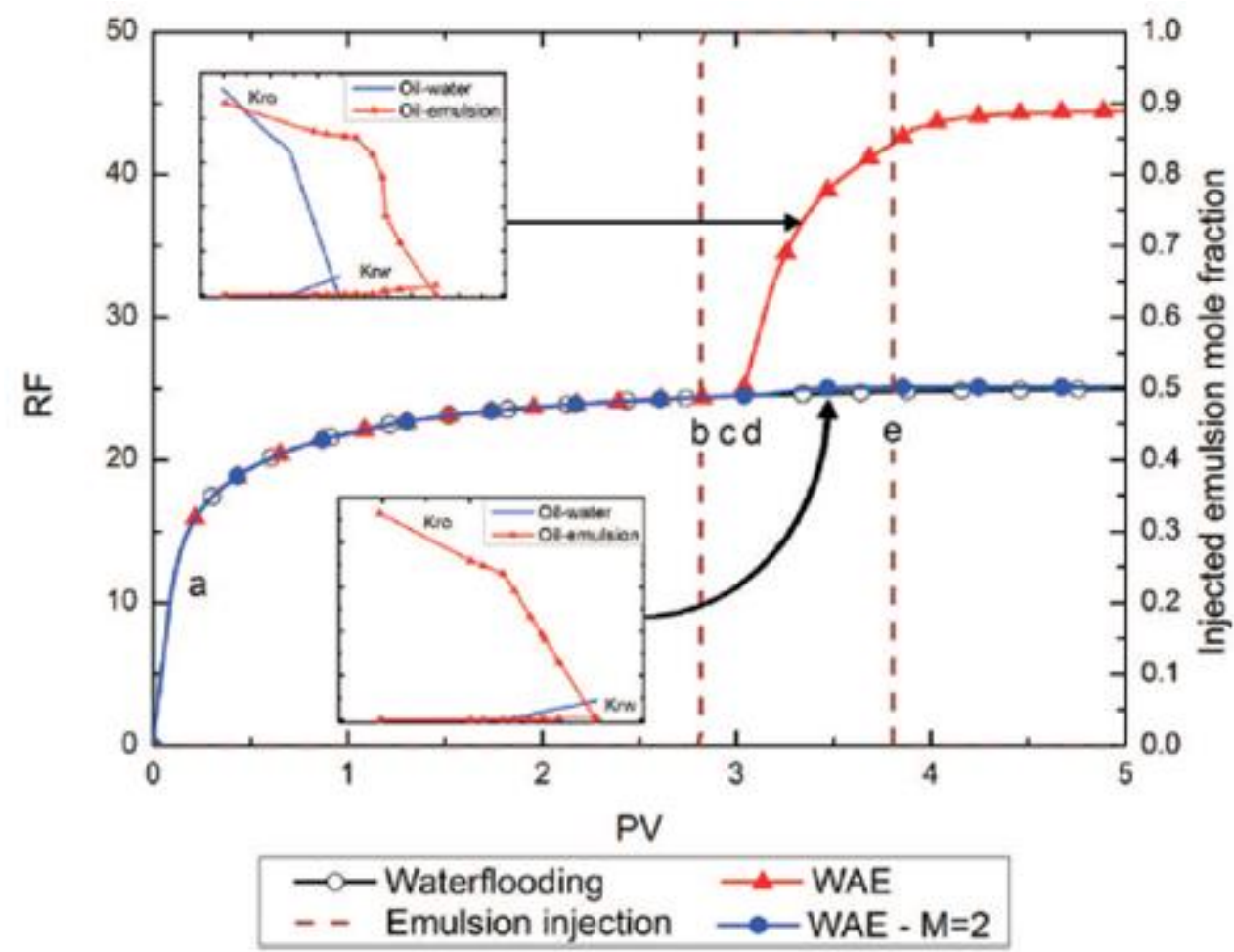

Figura 2-10 - Resultado da simulação com acréscimo de fator de recuperação decorrente da injeção WAE (Ponce et al. 2014) 


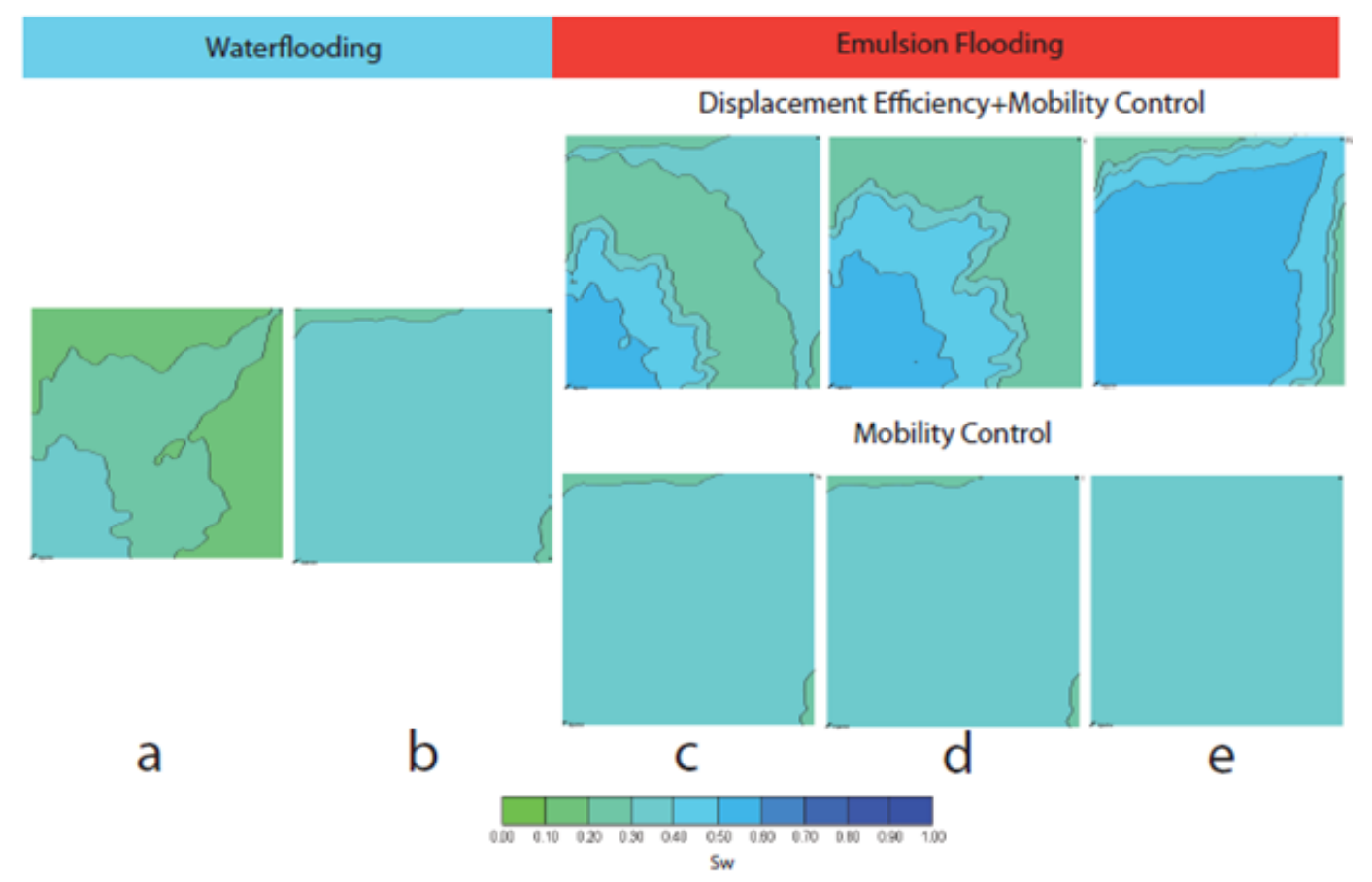

Figura 2-11 - Resultados de simulação de reservatórios de injeção WAE com remobilização de óleo como observado nos experimentos (Ponce et al., 2014)

Devido à necessidade de adicionar os efeitos capilares no modelo de escoamento de emulsões proposto, Ponce et al. (2016), ampliaram o modelo anterior para incorporar na parametrização das curvas de permeabilidade relativa a dependência do Número de Capilaridade. Para implementar corretamente esse modelo os autores modificaram o modelo black-oil programado no código aberto MRST do SINTEF e avaliaram o processo de injeção WAE na primeira camada do segundo modelo do SPE10.

No presente trabalho foram implementados no modelo desenvolvido por Ponce et al., (2016) os termos gravitacionais das equações de pressão e saturação que serão apresentadas no próximo capítulo. 


\section{3 Modelagem de Escoamento de Emulsões em Meios Poroso}

O escoamento de um fluido em um meio poroso é descrito por meio da conservação de sua massa no meio. $O$ balanço entre a advecção e a acumulação de massa envolve parâmetros característicos como a massa específica, a viscosidade e a compressibilidade do fluido, bem como a diferença de pressão e a permeabilidade do meio. Os conceitos de massa específica $(\rho)$ e viscosidade do fluido $(\mu)$ já foram apresentados anteriormente. A compressibilidade é a medida de quanto o fluido muda de volume quando é submetido a mudança de pressão. O modelo de fluido mais simples assume incompressibilidade, ou seja, a variação de pressão não é suficiente para que haja variação na massa específica. A seguir serão descritas as equações de escoamento em meios porosos de fluido incompressível em reservatórios isotérmicos, portanto serão negligenciadas variações na massa específica e temperatura.

Os fluidos são compostos por um ou mais componentes. O termo componente refere-se a uma espécie química única. Um componente pode estar presente em diferentes fases. Várias fases líquidas podem estar presentes no meio poroso, mas apenas uma fase gasosa pode existir. Em fluxos miscíveis, as fases são livres para se misturar e massa pode ser transferida de uma fase para outra.

A descrição das equações que descrevem o escoamento em meios porosos será iniciada pelo modelo de fluxo em meios porosos mais simples onde existe apenas uma fase. (Collins, 1976 e Dullien, 1994)

\subsection{Modelo de Escoamento monofásico em um no meio poroso}

A conservação de massa de um fluido de um meio poroso é descrita por:

$$
\int_{\Omega} \frac{\partial(\emptyset \rho)}{\partial t} d \Omega+\int_{\partial \Omega}(\rho \vec{v}) \cdot \vec{n} \partial \Omega=\int_{\Omega} q d \Omega
$$

onde:

$\vec{v}$ é velocidade do fluido 
$q$ é um termo de uma possível fonte ou sumidouro

$\Omega$ é o volume de controle no qual a massa é conservada

$\partial \Omega$ é a superfície do volume de controle no qual a massa é conservada

Esta equação indica que uma mudança na massa do fluido dentro do volume de controle $\Omega$ no tempo é igual ao fluxo de massa entrando e saindo do volume de controle mais a redução ou acumulo ocasionado por um termo q de fonte ou sumidouro, respectivamente. Aplicando o Teorema da Divergência (ou de Gauss), pode-se reescrever a conservação de massa como:

$$
\frac{\partial(\varnothing \rho)}{\partial t}+\nabla \cdot(\rho \vec{v})=q
$$

Henry Darcy observou através de resultados experimentais que existe uma dependência direta entre a vazão que atravessava uma amostra porosa e a diferença de carga hidráulica associada à qual a amostra estava submetida, encontrando uma relação diretamente proporcional à permeabilidade do meio poroso $(\mathbf{K})$ e inversamente proporcional à viscosidade do fluido $(\mu)$.

Considera-se que a velocidade do escoamento de fluido no meio poroso é baixa o suficiente para que seja válida a Lei de Darcy, portanto:

$$
\vec{v}=-\frac{\boldsymbol{K}}{\mu}(\nabla p+\rho g \nabla z)
$$

A velocidade do fluido $\vec{v}$ é descrita pela permeabilidade (tensor) $\boldsymbol{K}$ do meio poroso, a diferença de pressão $\nabla p$, a constante da aceleração da gravidade $g$ e a coordenada espacial $z$, cuja direção é vertical assumindo valores positivos para baixo.

Assumindo a rocha e os fluidos incompressíveis ( $\varnothing$ e $\rho$ constantes) a equação (8) é simplificada da seguinte maneira:

$$
\nabla \cdot \vec{v}=\frac{q}{\rho}
$$

Substituindo em (10) a Lei de Darcy (11), chega-se a equação elíptica que descreve o campo de pressão de um escoamento em um meio poroso:

$$
-\nabla \cdot\left[\frac{K}{\mu}(\nabla p+\rho g \nabla z)\right]=\frac{q}{\rho}
$$

Para fechar o modelo condições de contorno e iniciais apropriadas são impostas. A condição de contorno mais simples estabelece a ausência de 
escoamento na fronteira. Isso significa que $\vec{v} \cdot \vec{n}=0$, onde $\vec{n}$ é o vetor normal apontando para fora do limite $\partial \Omega$. Com isso o reservatório é considerado um sistema isolado onde não há fluido entrando e saindo.

\section{2. \\ Modelo de Escoamento Bifásico Água Óleo}

O exemplo típico de escoamento bifásico em um meio poroso é quando um fluido é injetado (usualmente água) em um reservatório de petróleo para deslocar o óleo para os poços produtores. Para o escoamento bifásico, faz-se necessário o conceito de saturação. A saturação da fase $i$, denotado por $S_{i}$, representa a fração de volume poroso ocupada pela fase $i$.Para o escoamento bifásico, assume-se que as duas fases preenchem o volume poroso do reservatório, então $S_{1}+S_{2}=1$. Além disso, assume-se que os dois fluidos são imiscíveis, ou seja, não há transferência de massa entre as fases. Cada fase é descrita pela pressão da fase $p_{i}$, velocidade da fase $\vec{v}_{i}$, viscosidade da fase $\mu_{i} \mathrm{e}$ massa específica da fase $\rho_{i}$. O escoamento simultâneo das duas fases causa interferência de uma no escoamento da outra; mais precisamente, cada fase reduz a capacidade da outra fase de fluir. Este efeito é descrito pela permeabilidade efetiva, que usualmente é expressa como o produto da permeabilidade absoluta $\boldsymbol{K}$ e as permeabilidades relativas dependentes das saturações das fases, $k_{r i}\left(S_{i}\right)$, que varia entre 0 e 1.

A lei de Darcy estendida para duas fases relaciona a velocidade da fase $\vec{v}_{i}$ com a pressão da fase $p_{i}$ e a força gravitacional sobre a fase dado por:

$$
\vec{v}_{i}=-\frac{\boldsymbol{K} k_{r i}}{\mu_{i}}\left(\nabla p_{i}+\rho_{i} g \nabla z\right)
$$

A relação $k_{r i}\left(S_{i}\right) / \mu_{i}$ é definida como a mobilidade da fase, $\lambda_{i}$.

A conservação de massa para cada fase é escrita como:

$$
\frac{\partial\left(\emptyset \rho_{i} S_{i}\right)}{\partial t}+\nabla \cdot\left(\rho_{i} \vec{v}_{i}\right)=q_{i}
$$

Expandindo as derivadas no espaço e tempo e dividindo pela densidade da fase, obtém-se uma formulação alternativa para a equação de continuidade (15)):

$$
\frac{\partial \emptyset}{\partial t} S_{i}+\emptyset \frac{\partial S_{i}}{\partial t}+\varnothing \frac{S_{i}}{\rho_{i}} \frac{\partial \rho_{i}}{\partial t}+\nabla \cdot \vec{v}_{i}+\frac{\vec{v}_{i} \cdot \nabla \rho_{i}}{\rho_{i}}=\frac{q_{i}}{\rho_{i}}
$$


Para derivar a equação de pressão, utilizando o conceito de mobilidade de uma fase $i: \lambda_{i}=k_{r i} / \mu_{i}$, e para o sistema água-óleo $(i=0, w)$ somando as equações de continuidade das fases (16) óleo e água e adotando que $q=\frac{q_{w}}{\rho_{w}}+\frac{q_{o}}{\rho_{o}}$, e usando o fato de que $s_{w}+s_{o}=1$, pode-se deduzir que:

$\nabla .\left(\vec{v}_{w}+\vec{v}_{o}\right)+\frac{\partial \emptyset}{\partial t}+\emptyset \frac{S_{w}}{\rho_{w}} \frac{\partial \rho_{w}}{\partial t}+\emptyset \frac{S_{o}}{\rho_{o}} \frac{\partial \rho_{o}}{\partial t}+\frac{\vec{v}_{w} \cdot \nabla \rho_{w}}{\rho_{w}}+\frac{\vec{v}_{o} . \nabla \rho_{o}}{\rho_{o}}=q$

Definido o conceito de compressibilidade da rocha como:

$$
c_{r}=\frac{1}{\emptyset} \frac{d \emptyset}{d p}
$$

E compressibilidade das fases como:

$$
c_{i}=\frac{1}{\rho_{i}} \frac{d \rho_{i}}{d p_{i}}
$$

Utilizando os conceitos acima de compressibilidade da rocha (18) e compressibilidade dos fluidos (19) e inserindo a expressão de velocidade de Darcy (14), obtém-se:

$$
\begin{aligned}
-\nabla \cdot\left[\boldsymbol { K } \lambda _ { w } \left(\nabla p_{w}\right.\right. & \left.\left.+\rho_{w} g \nabla z\right)+\boldsymbol{K} \lambda_{o}\left(\nabla p_{o}+\rho_{o} g \nabla z\right)\right]+c_{r} \emptyset \frac{\partial p}{\partial t} \\
& -c_{w}\left[\nabla p_{w} \cdot \boldsymbol{K} \lambda_{w}\left(\nabla p_{w}+\rho_{w} g \nabla z\right)-\emptyset S_{w} \frac{\partial \rho_{w}}{\partial t}\right] \\
& -c_{o}\left[\nabla p_{o} \cdot \boldsymbol{K} \lambda_{o}\left(\nabla p_{o}+\rho_{o} g \nabla z\right)-\emptyset S_{o} \frac{\partial \rho_{o}}{\partial t}\right]=q
\end{aligned}
$$

$\mathrm{Na}$ equação acima aparecem três pressões: a pressão no óleo $\left(p_{o}\right)$, a pressão na água $\left(p_{w}\right)$ e a pressão total $p$. Pode-se relacionar estas pressões através do conceito de pressão capilar.

Quando duas ou mais fases imiscíveis estão presentes no reservatório, uma fase molha o meio poroso mais do que a outra e esta é referida como a fase molhante (índice $m$ ). A fase molhante significa que esta tem a capacidade para manter o contato com a superfície sólida no meio poroso. A outra fase é a fase não-molhante (índice $n$ ). Dentro de um sistema óleo-água, a água é, na maioria das vezes, a fase de molhante.

Existe uma diferença entre as pressões dos fluidos em cada fase, devido à presença de interfaces curvas entre elas. A diferença de pressão é denominada de pressão capilar $\left(p_{c n m}\right)$ e definida como: 


$$
p_{c n m}=p_{n}-p_{m}
$$

No sistema água-óleo é comum que a água seja a fase molhante, neste caso a equação (21) é reescrita como:

$$
p_{\text {cow }}=p_{o}-p_{w}
$$

Assumindo que a rocha e as fases são incompressíveis, $c_{r}=c_{w}=c_{o}=0$. A Equação (20) pode ser reduzida para:

$$
v=-\left[K \lambda_{w}\left(\nabla p_{w}+\rho_{w} g \nabla z\right)+\boldsymbol{K} \lambda_{o}\left(\nabla p_{o}+\rho_{o} g \nabla z\right)\right], \quad \nabla . v=q,
$$

Nesta equação existem duas incógnitas, $p_{o}$ e $p_{w}$. Para eliminar uma delas é comum utilizar o conceito de pressão capilar (equação (22)) que é função da saturação de água $S_{w}$, o que traz um alto grau de acoplamento entre a equação de pressão e a equação de saturação. Para minimizar o acoplamento define-se uma pressão global $p=p_{o}-p_{c}$ que é função de uma pressão complementar $p_{c}$ dependente da saturação de água:

$$
p_{c}\left(S_{w}\right)=\int_{1}^{S_{w}} f_{w}(\xi) \frac{\partial p_{\operatorname{cow}(\xi)}}{\partial S_{w}} d \xi
$$

Sendo o fluxo fracional $f_{w}=\frac{\lambda_{w}}{\lambda_{w}+\lambda_{o}}=\frac{\lambda_{w}}{\lambda}$ que descreve a fração entre o fluxo de água e o fluxo total. Utilizando o conceito de pressão global e sabendose que $\nabla p_{c}=f_{w} \nabla p_{\text {cow }}$, pode-se expressar a velocidade total $v=v_{w}+v_{o}$ como função da pressão global $p$ :

$$
v=-\boldsymbol{K}\left(\lambda_{w}+\lambda_{o}\right) \nabla p-\boldsymbol{K}\left(\lambda_{w} \rho_{w}+\lambda_{o} \rho_{o}\right) g \nabla z
$$

Finalmente, substituindo a mobilidade total $\left(\lambda=\lambda_{w}+\lambda_{o}\right)$ obtemos a equação de pressão:.

$$
-\nabla \cdot\left[K \lambda \nabla p+\boldsymbol{K}\left(\lambda_{w} \rho_{w}+\lambda_{o} \rho_{o}\right) g \nabla z\right]=q
$$

A equação da pressão fornece uma equação para a solução da primeira incóntita $p$. Para derivar um modelo completo, deve-se obter também as equações para as saturações de fases usando as equações de continuidade de cada fase. 
Como $S_{o}+S_{w}=1$, tem-se apenas uma equação de saturação e, é prática comum, escolher $S_{w}$ como a segunda incógnita.

Para combinar a equação de continuidade da fase água com a equação de pressão (26), precisa-se derivar uma expressão para a velocidade da fase água $\vec{v}_{w}$ em termos da pressão global. Para isso, utiliza-se a formulação total de velocidade expressando $\vec{v}_{w}$ em termos da velocidade total $\vec{v}$ e os termos adicionais que dependem da saturação $S_{w}$. Da lei de Darcy (14) segue-se que

$$
\boldsymbol{K} \lambda_{o} \lambda_{w} \nabla p_{\text {cow }}=\lambda_{o} v_{w}-\lambda_{w} v_{o}-\boldsymbol{K} \lambda_{o} \lambda_{w}\left(\rho_{o}-\rho_{w}\right) g \nabla z
$$

Considerando que $v_{o}=v-v_{w}$ e dividindo a equação por $\lambda$, obtém-se:

$$
v_{w}=f_{w}\left[v+K \lambda_{o} \nabla p_{c o w}-K \lambda_{o}\left(\rho_{w}-\rho_{o}\right) g \nabla z\right]
$$

A equação de conservação de massa para a fase aquosa é escrita como:

$$
\frac{\partial\left(\varnothing \rho_{w} S_{w}\right)}{\partial t}+\nabla \cdot\left(\rho_{w} \vec{v}_{w}\right)=q_{w}
$$

Substituindo (28) em (29) e considerando as simplificações de fluido incompressível e pressão capilar desprezível temos a equação de transporte da fase aquosa da seguinte forma:

$$
\varnothing \frac{\partial S_{w}}{\partial t}+\nabla \cdot\left\{f_{w}\left[v-\boldsymbol{K} \lambda_{o}\left(\rho_{w}-\rho_{o}\right) g \nabla z\right]\right\}=\frac{q_{w}}{\rho_{w}}
$$

A equação (30) é chamada a equação da saturação.

\section{3. \\ Escoamento de Emulsões}

Segundo Farias (2013), a descrição do escoamento de emulsões em meios porosos pode ser feita através de modelos baseados no balanço de forças viscosas e capilares na escala dos poros. Os modelos baseados no balanço de forças viscosas e capilares buscam estabelecer uma relação entre o fluxo das gotas através das gargantas de poros e a redução da permeabilidade ao fluxo.

A abordagem é feita a partir da definição de uma lei de formação que estabelece a relação entre o número de capilaridade local e um fator de redução de permeabilidade local (ou fator de bloqueio).

Para uma dada distribuição de garganta de poros e tamanho de gotas dispersas, existirá uma faixa de número de capilaridade (número de capilaridade crítico) abaixo do qual as gotas são capturadas pelo meio e a permeabilidade local 
é reduzida. Para números de capilaridade mais altos, o fluxo ocorre com algum aumento no diferencial de pressão, mas o bloqueio é muito pequeno ou inexistente.

O escoamento de uma emulsão diluída (concentração menor do que 10\% $(\mathrm{v} / \mathrm{v})$ ) e estável (não muda a distribuição de tamanho de gota com o tempo) em um meio poroso, depende de suas características, como tamanho de gota da fase dispersa, concentração da fase dispersa, concentração e tipo de surfactantes, viscosidade dos fluidos. Neste trabalho, o efeito das gotas da fase dispersa no escoamento é descrito através de modificações nas curvas de permeabilidades relativas das fases aquosas e oleicas.

No modelo elaborado Ponce et al. (2014), a parametrização das curvas de permeabilidades relativas da fase aquosa com emulsão, em cada célula do modelo discreto, é alterada como função da concentração da fase dispersa da emulsão. Posteriormente modificado por Ponce et al. (2016), a parametrização das curvas de permeabilidades relativas da fase aquosa com emulsão é modificada como função de dois parâmetros: o Número de Capilaridade e a concentração da fase dispersa da emulsão. Esta alteração é realizada em duas etapas de interpolação.

Na primeira etapa a interpolação é realizada entre as curvas dos sistemas óleo-água e óleo-emulsão em função do Número de Capilaridade local para o cálculo da saturação de óleo residual, os exponentes do modelo de Corey e o ponto terminal da fase aquosa.

Já na segunda etapa esses valores são recalculados em função da concentração da emulsão mediante a interpolação entre os parâmetros calculados na primeira etapa e os da fase aquosa.

Ou seja, o efeito da injeção de emulsões foi avaliado através da parametrização das curvas de permeabilidade relativa como função da concentração da fase dispersa da emulsão e do Número de Capilaridade local conforme a equação abaixo.

$$
K_{r i}=K_{r}\left(S_{o r}, C_{e}, N C_{a}\right)
$$

onde:

$C_{e}$ é a concentração da fase dispersa (gotas)

$N C_{a}$ é o Número de Capilaridade 
Ponce et al. (2016) modificaram o modelo black-oil programado no código aberto MRST do SINTEF incluindo a modelagem do transporte da fase dispersa da emulsão transportada pela fase aquosa.

A equação de conservação de massa de gotas de emulsão que descreve o transporte da fase dispersa da emulsão no meio poroso é dada por:

$$
\varnothing \frac{\partial\left(C_{e} S_{w}\right)}{\partial t}+\nabla .\left\{C_{e} f_{w}\left[v-K \lambda_{o}\left(\rho_{w}-\rho_{o}\right) g \nabla z\right]\right\}=C_{e 0}\left(\frac{q_{w}}{\rho_{w}}\right)+C_{e} f_{w} q
$$

Já o número de capilaridade ( $\mathrm{NCa}$ ) associado ao deslocamento da fase aquosa é calculado célula a célula conforme a equação a seguir:

$$
N C_{a}=\frac{\mu_{w} \cdot v_{w}}{\sigma}
$$

Para as simulações com o modelo descrito foram estabelecidos pontos extremos (Swi, Sor, krowi, krwor) das curvas de permeabilidade relativa do óleo e da agua e com os parâmetros de Corey (nw, no) foram calculadas as curvas de permeabilidades relativas do sistema água-óleo ( $\mathrm{krw}$, krow).

Posteriormente alguns desses parâmetros foram modificados para construir as curvas de permeabilidade relativa do sistema emulsão-óleo (kre e kroe) conforme os efeitos observados experimentalmente por Guillen et al. (2012a,b) e Engelke et al.(2013).

As curvas de kre geradas a partir das mudanças na curva de permeabilidade da água tem o intuito de simular tanto o mecanismo de controle de mobilidade (efeito macroscópico) quanto o mecanismo de eficiência de deslocamento (efeito microscópico).

O mecanismo de controle de mobilidade foi modelado reduzindo a permeabilidade relativa da emulsão injetada no meio poroso quando comparado com a água, gerando uma razão de mobilidades mais favorável e possibilitando uma frente de avanço mais uniforme (retardamento da formação dos caminhos preferenciais de escoamento).

Para reproduzir o efeito da emulsão no mecanismo de eficiência de deslocamento diminui-se o valor da saturação de óleo residual nas curvas de permeabilidade relativa do sistema água-óleo, retratando uma melhora na eficiência de deslocamento na escala de poro. O mecanismo de eficiência de deslocamento pode ser associado a modificação dos caminhos da fase aquosa a nível de poros e consequente mobilização de óleo residual. 


\section{4. \\ Solução do Sistema de Equações Diferenciais}

O sistema de equações diferenciais é dado pelas equações de pressão, saturação e transporte da emulsão, que estão apresentadas novamente a seguir:

$$
\begin{gathered}
-\nabla \cdot\left[\boldsymbol{K} \lambda \nabla p+\boldsymbol{K}\left(\lambda_{w} \rho_{w}+\lambda_{o} \rho_{o}\right) g \nabla z\right]=q \\
\varnothing \frac{\partial S_{w}}{\partial t}+\nabla \cdot\left\{f_{w}\left[v-\boldsymbol{K} \lambda_{o}\left(\rho_{w}-\rho_{o}\right) g \nabla z\right]\right\}=\frac{q_{w}}{\rho_{w}} \\
\varnothing \frac{\partial\left(C_{e} S_{w}\right)}{\partial t}+\nabla .\left\{C_{e} f_{w}\left[v-\boldsymbol{K} \lambda_{o}\left(\rho_{w}-\rho_{o}\right) g \nabla z\right]\right\}=C_{e 0}\left(\frac{q_{w}}{\rho_{w}}\right)+C_{e} f_{w} q
\end{gathered}
$$

Para fazer uma descrição completa do escoamento, além das equação acima, devem ser definidas as condições de contorno e condições iniciais. Considerando um reservatório definido de domínio $\partial \Omega$ e fronteira $\Omega$ com poços injetores e produtores na fronteira $\partial \Omega_{i}$ e $\partial \Omega_{p}$ respectivamente, assume-se as condições de não deslizamento, vazão de injeção e produção prescrita e saturação de água inicial conhecida:

$$
\begin{gathered}
\boldsymbol{K} \lambda \nabla p(\partial \Omega, \tau) \cdot \vec{n}=0 \\
p\left(\partial \Omega_{p}, \tau\right)=0 \\
\frac{q_{w}}{\rho_{w}}\left(\partial \Omega_{i}, \tau\right)=c t e \\
S_{w}(\Omega, \tau=0)=c t e
\end{gathered}
$$

Esse sistema é discretizado usando método de volumes finitos através da aproximação de derivadas pelo método TPFA (Two-point flux approximation). código resolve 0 acoplamento dos sistemas de equações resolvendo implicitamente a equação de pressão e de forma explicita a equação de saturação (IMPES - implicit method pressure explicit saturation).

A solução desacoplada das equações de pressão e saturação é realizada de forma iterativa para cada passo de tempo. Com valores iniciais de distribuição de saturação calcula-se primeiramente as mobilidades das fases para resolver a equação de pressão (34). Obtida a pressão global, computa-se o campo de velocidade total. Em seguida mantendo a velocidade total $v t$ constante resolve-se iterativamente a equação de saturação (35) e de transporte de emulsão (36) 
sequencialmente de forma explícita dividindo-se o passo de tempo ( $\Delta \tau \mathrm{global})$ em frações menores ( $\Delta t$ local) para satisfazer a condição CFL de estabilidade para $S_{w}$. (Aarnes et al., 2007)

Posteriormente, com os novos valores de saturação, concentração de emulsão e número de capilaridade resolve-se novamente a equação de pressão repetindo-se o mesmo processo para cada passo de tempo até o final do processo de injeção.

No capítulo seguinte são apresentados os resultados obtidos. O primeiro item do capítulo seguinte é a descrição do modelo de reservatórios. Neste as curvas de permeabilidade relativas utilizadas são ilustradas e os respectivos valores dos parâmetros são definidos. A seguir apresenta-se também a validação do modelo tridimensional desenvolvido com o simulador comercial (CMGIMEX $\left.{ }^{\mathrm{TM}}\right)$. 


\section{4 \\ Resultados}

Nesse capítulo serão apresentados e discutidos os resultados das simulações de reservatórios de injeção de água e injeção WAE com modelos com duas e três dimensões.

\section{1.}

\section{Modelo de Reservatório}

O modelo de reservatório utilizado foi o segundo modelo do $10^{\circ}$ Projeto comparativo do SPE (Society of Petroleum Engineers - SPE 10 - www.spe.org). O modelo geológico completo tem dimensões 365,76 x 670,56 x 51,82 $\mathrm{m}^{3}$ descrito com uma malha cartesiana retangular contendo $60 \times 220 \times 85$ células. Foi escolhido este modelo por conta de sua heterogeneidade tendo sido utilizado um recorte do modelo completo em cada uma das simulações com algumas modificações em relação a posição dos poços, vazões consideradas e características de rocha e fluido.

O modelo consiste em uma parte da sequência Brent. A parte superior do modelo (35 primeiras camadas) consiste na formação Tarbert que representa progradações próximas a linha da costa, enquanto que a parte inferior (50 camadas restantes) trata-se da formação Upper Ness que é um ambiente fluvial. Apresenta-se na Figura 4-1 a distribuição da porosidade de todo modelo e na figura abaixo a direita apresenta-se a parte inferior onde são evidenciados os canais fluviais. 

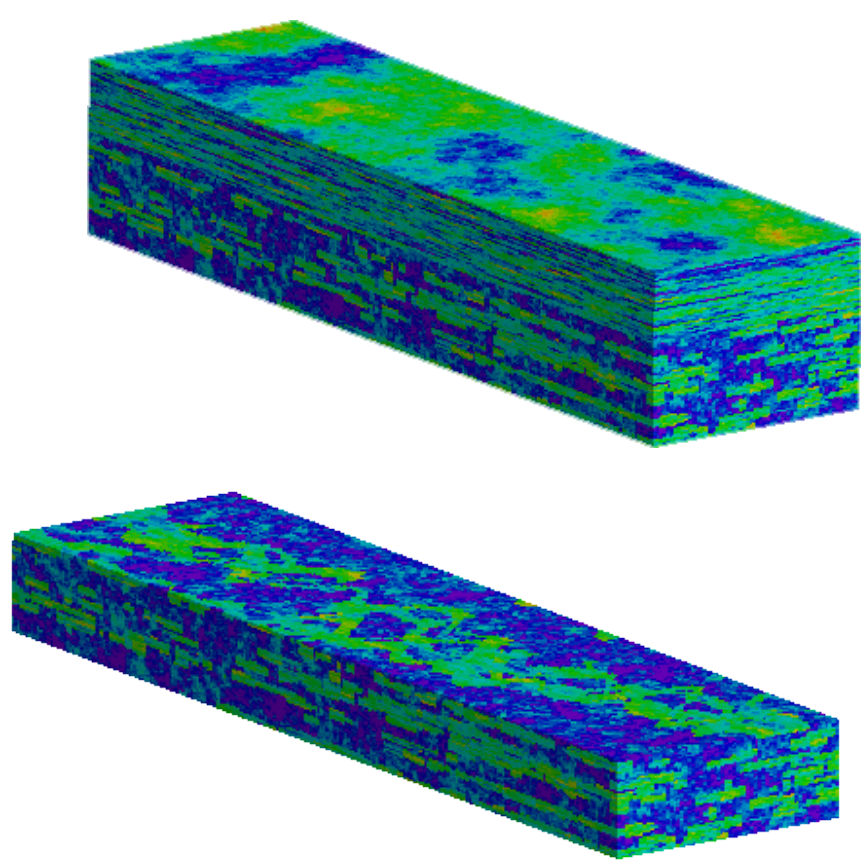

Figura 4-1 - Distribuição da porosidade do modelo na figura superior e na parte inferior são evidenciados os canais fluviais (http://www.spe.org/web/csp/datasets/set02.htm)

Em todas as simulações foi considerado que a compressibilidade do sistema era pequena o suficiente que poderia ser desprezada. Foram impostas vazões de produção e injeção iguais e constantes e o controle foi feito por pressão fixa no poço produtor.

O poço produtor foi posicionado em uma das extremidades do domínio enquanto o injetor foi posicionado na extremidade oposta, ambos completados em todas as camadas. As vazões de produção foram mantidas constantes para cada uma das simulações: 2D e 3D, sendo esta calculada ponderando a vazão total do caso SPE 10 pelo volume do recorte selecionado em cada uma das simulações.

A saturação de água conata foi definida com $S w c=0,15$, a saturação de óleo residual a injeção de água Sorw=0,4 e a saturação de óleo residual na injeção de emulsão Sore=0,2. Os expoentes de Corey utilizados foram no=2,0 e nw=ne=4,0. E finalmente, o valor de permeabilidade relativa ao óleo na saturação de água inicial $k r o=1,0$ a permeabilidade relativa a água na saturação de óleo residual krw=0,6 e permeabilidade relativa a emulsão na saturação de óleo residual $k r e=0,2$, conforme ilustrado na Figura 4-2. 


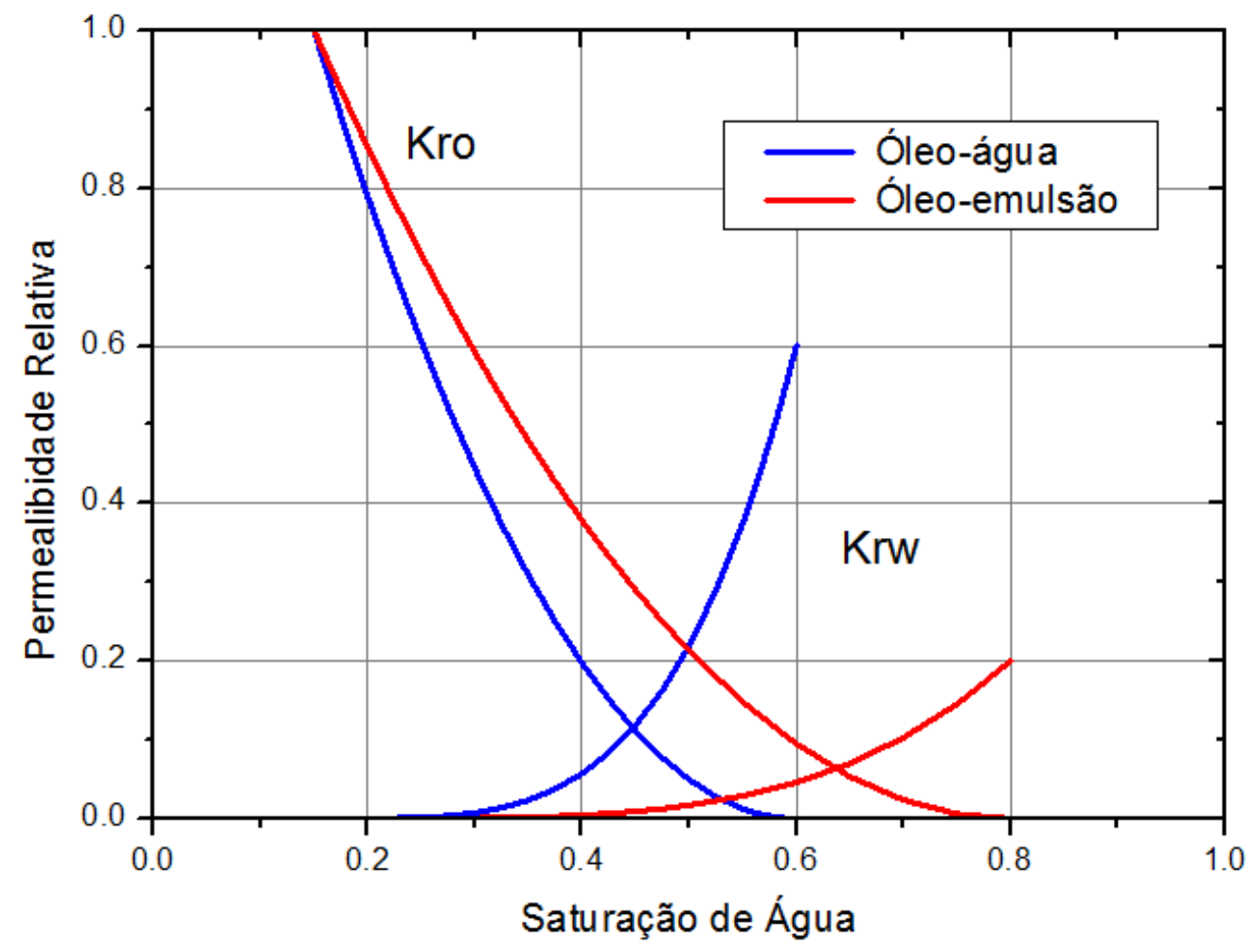

Figura 4-2 - Permeabilidades relativas dos sistemas óleo-água e óleo-emulsão utilizadas nas simulações dos casos

Destaca-se que a emulsão (fase água contendo gotas de óleo) modelada no sistema óleo-emulsão, contem gotas de óleo em uma concentração diluída o suficiente para não modificar a viscosidade da fase aquosa (concentração da fase dispersa < 10\%). Desta maneira as viscosidades da água e da emulsão são as mesmas ( $\mu \mathrm{w}=\mu \mathrm{e}=0,001 \mathrm{~Pa} . \mathrm{s})$ e para se considerar a modelagem de um óleo leve a razão de viscosidade óleo/água foi definida como sendo $\mu \mathrm{o} / \mu \mathrm{w}=10$.

\section{2.}

\section{Simulações 2D}

Para as simulações em duas dimensões foi selecionada a primeira camada do modelo ( $K=1$ - Formação Tarbert). Nesta foi posicionado um poço produtor na primeira célula e um poço injetor na última célula, ambos controlados por vazão de líquido. A vazão de produção utilizada em todas as simulações 2D foi mantida constante. 
Inicialmente (Caso 1) foi feita a simulação de injeção de água (IA) totalizando a injeção de dois volumes porosos (VP). A simulação base de referência foi de injeção de água. Com a simulação da injeção de água pode-se avaliar os mapas de saturação de água e Número de Capilaridade ( $\mathrm{NCa}$ ) e com isso selecionar faixas de atuação da emulsão no meio poroso.

Em seguida foram feitas as simulações WAE para a mesma injeção total de 2 VP. A primeira análise foi feita variando a faixa de NCa onde atua a emulsão com agente de bloqueio (Casos 2, 3 e 4). Foram selecionadas três faixas de $\mathrm{NCa}$ de forma a representar a ocorrência maior ou menor das regiões de menor velocidade onde os efeitos capilares seriam efetivos o suficiente para que a emulsão atuasse bloqueando os poros. Para a faixa mais ampla, onde a emulsão atuava em quase todo o meio poroso, os valores de $\mathrm{NCa}$ adotados foram a partir de $10^{-7}$, para uma faixa média NCa a partir de $10^{-8}$ e onde a atuação da emulsão era muito restrita $\mathrm{NCa}$ a partir de $10^{-9}$.

Depois, mantendo os demais parâmetros constantes foi feita uma avaliação do momento mais efetivo para o início da injeção do banco de emulsão, variando o volume de água injetada antes do banco (Casos 4, 5 e 6). E finalmente, foi feita uma análise quanto ao impacto do tamanho do banco de emulsão na recuperação de óleo (Casos 6, 7 e 8).

Os casos simulados foram resumidos na Tabela 4-1 a seguir.

Tabela 4-1 - Quadro comparativo das simulações 2D (camada k=1)

\begin{tabular}{|c|c|c|c|c|}
\hline Caso & $\begin{array}{l}\text { Tipo de } \\
\text { Injeção }\end{array}$ & $\begin{array}{c}\text { Volume de água } \\
\text { injetada antes da } \\
\text { emulsão } \\
\text { (VPs) }\end{array}$ & $\begin{array}{l}\text { Volume } \\
\text { banco } \\
\text { emulsão } \\
\text { (VPs) }\end{array}$ & $\begin{array}{l}\text { NCa para o qual } \\
\text { emulsão atua }\end{array}$ \\
\hline 1 & IA & - & - & - \\
\hline 2 & WAE & \multirow{3}{*}{0,3} & \multirow{5}{*}{0,2} & ampla $(\wedge 10-7)$ \\
\hline 3 & WAE & & & restrita $(\wedge 10-9)$ \\
\hline 4 & WAE & & & \multirow{5}{*}{ media $(\wedge 10-8)$} \\
\hline 5 & WAE & 0,1 & & \\
\hline 6 & WAE & \multirow{3}{*}{0,2} & & \\
\hline 7 & WAE & & 0,1 & \\
\hline 8 & WAE & & 0,05 & \\
\hline
\end{tabular}

Os resultados do efeito de variação do NCa são apresentados nas Figura 4-3 e Figura 4-4, ilustrando a evolução do fator de recuperação (FR), corte de água (WCUT), pressão de injeção (IBP) e concentração de emulsão (Ce) versus volume poroso (VP) injetado de água para os casos 1, 2, 3 e 4. Para o Caso 3, 
onde a emulsão atua em uma região muito restrita, o resultado é muito similar a injeção de água (Caso 1). Nos casos 2 e 4 destaca-se a antecipação e o incremento na produção de óleo, função da atuação da emulsão mais ampla, nestes casos pode-se observar a modificação no perfil de produção de água, com redução significativa no WCUT no poço produtor com a chegada da frente de óleo remobilizada pela emulsão.

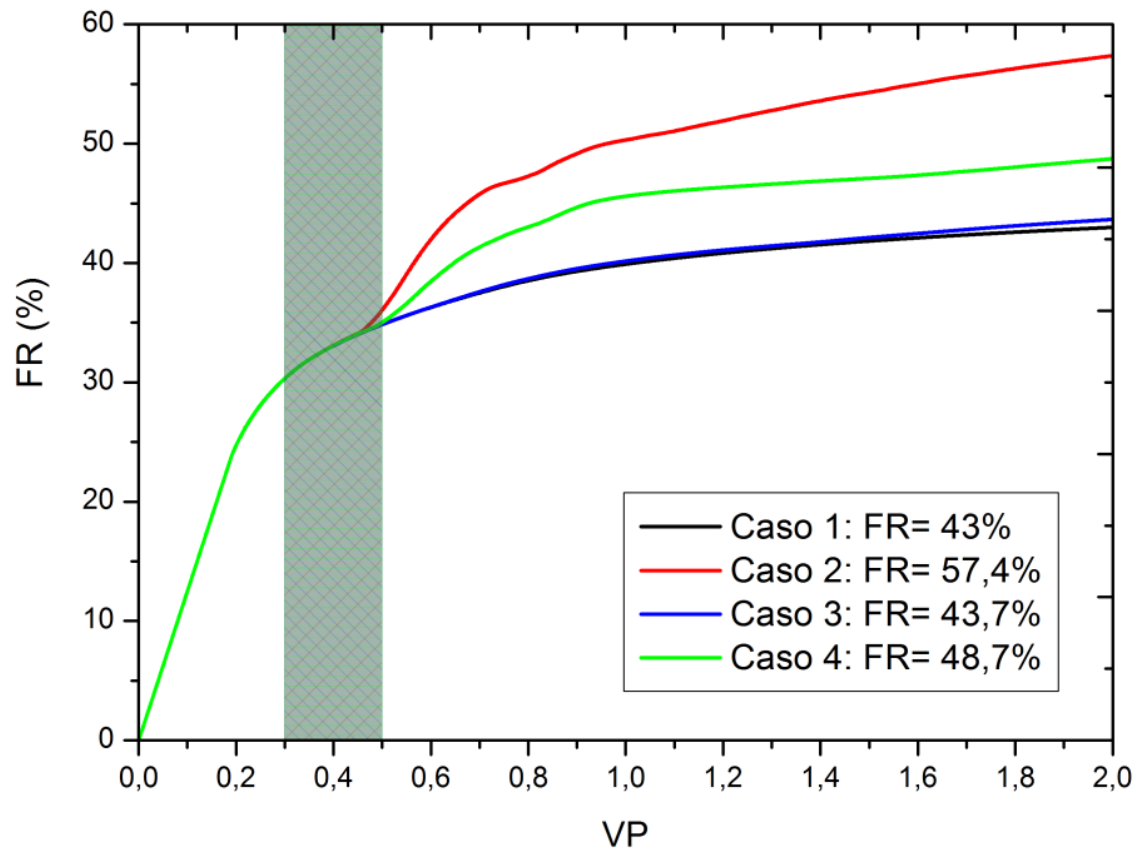

Figura 4-3 - Curvas de evolução do fator de recuperação de óleo (FR); com o período da injeção de emulsão sinalizada versus volume poroso (VP) injetado para os Casos 1 (IA), 2 (WAE - faixa ampla), 3 (WAE - faixa restrita) e 4 (WAE - faixa média). 


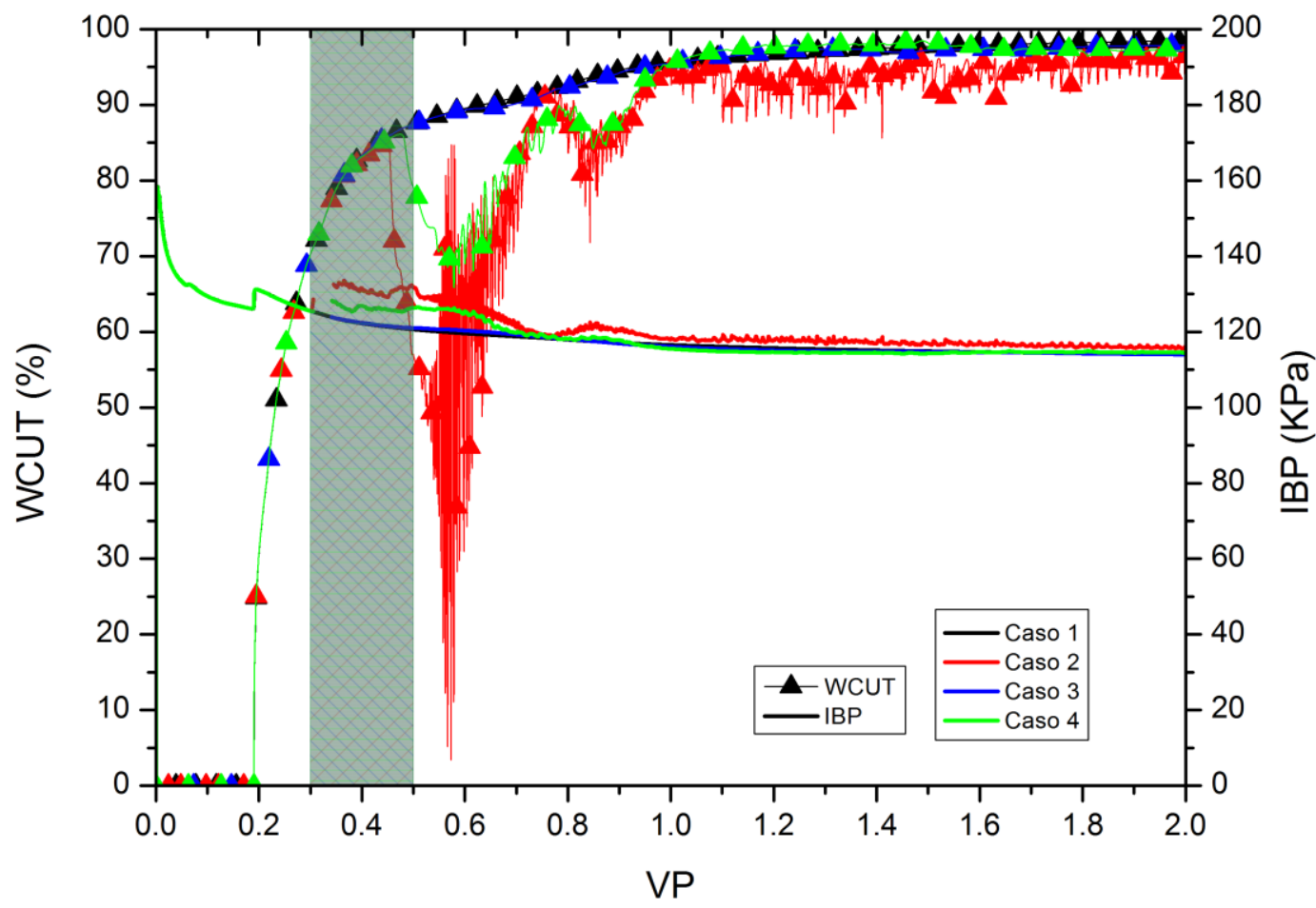

Figura 4-4 - Curvas de corte de água (WCUT) e a pressão de fundo no injetor (IBP), com o período da injeção de emulsão sinalizada versus volume poroso (VP) injetado para os Casos 1 (IA), 2 (WAE - faixa ampla), 3 (WAE - faixa restrita) e 4 (WAE - faixa média).

Em seguida foi feita a análise em relação ao momento de iniciar a injeção de emulsão. No caso 4, foi realizada a injeção da emulsão após a injeção 0,3 VP de água, posteriormente foi feita uma análise com 0,2VP de injeção de água (Caso 6) e ainda antes, com injeção de 0,1 VP (Caso5). Em todos estes casos mantevese o tamanho do banco de emulsão igual a 0,2VP.

Apresenta-se nas Figura 4-5 e Figura 4-6 a evolução do fator de recuperação de óleo (FR), o corte de água (WCUT), a pressão de fundo no injetor (IBP) e a concentração da emulsão (Ce) injetada versus volume poroso injetado para os casos 1, 4, 5 e 6. Modificando o momento do início da injeção da emulsão há mudança relevante no perfil de produção de água com consequente efeito na antecipação da produção adicional de óleo. Porém não foi observado variação significativa na fração de óleo adicional recuperado ao final da simulação, indicando que a variação do momento de injeção do banco não altera a recuperação final (dado que o volume de emulsão é o mesmo), mas causa a antecipação da produção do volume de óleo adicional. 


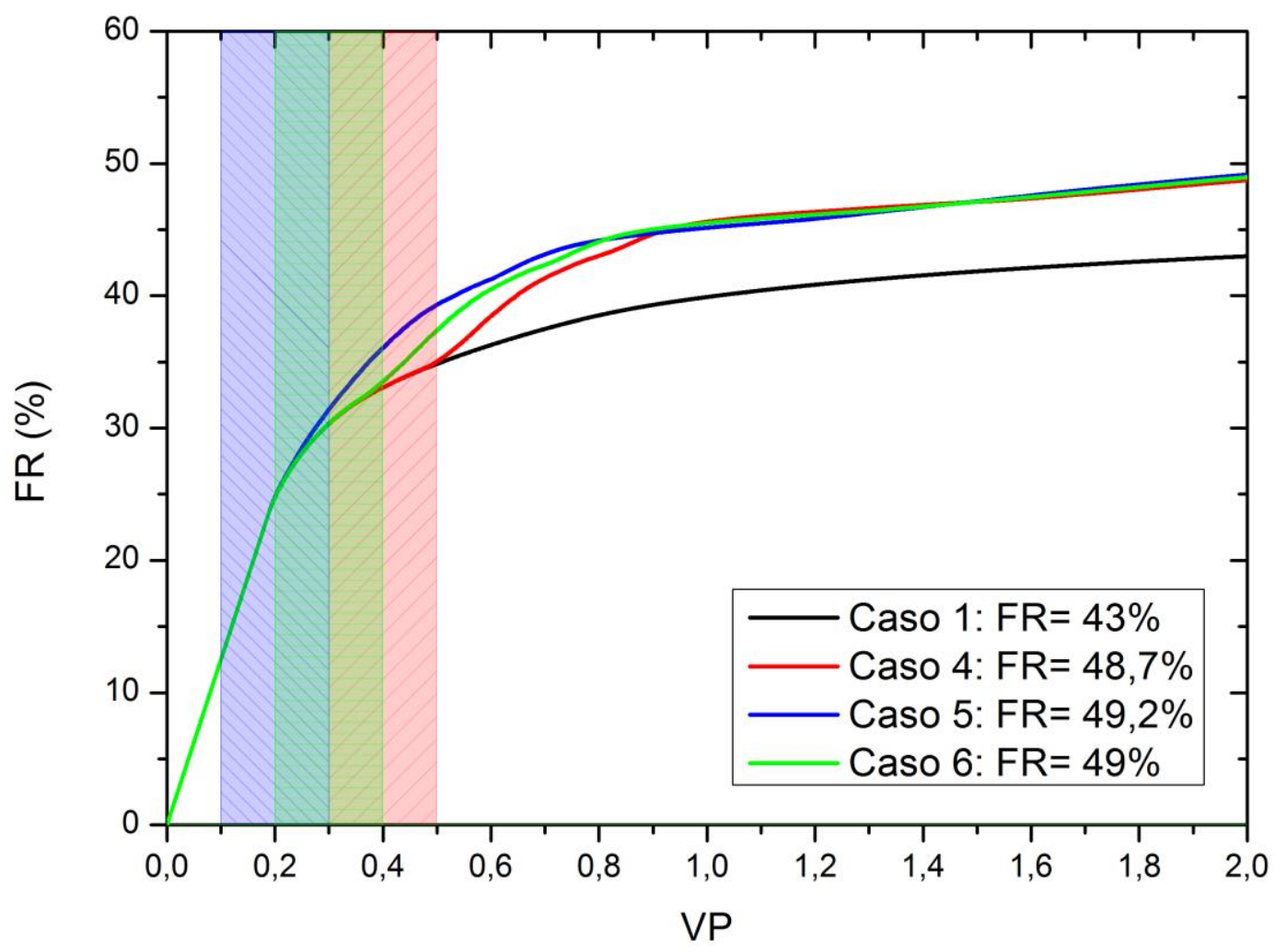

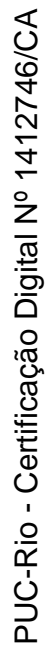

Figura 4-5 -Curvas de evolução do fator de recuperação de óleo; com o período da injeção de emulsão sinalizada versus volume poroso injetado para os Casos 1 (IA), 4 (WAE 0,3/0,2/1,5), 5 (WAE 0,1/0,2/1,7) e 6 (WAE 0,2/0,2/1,6).

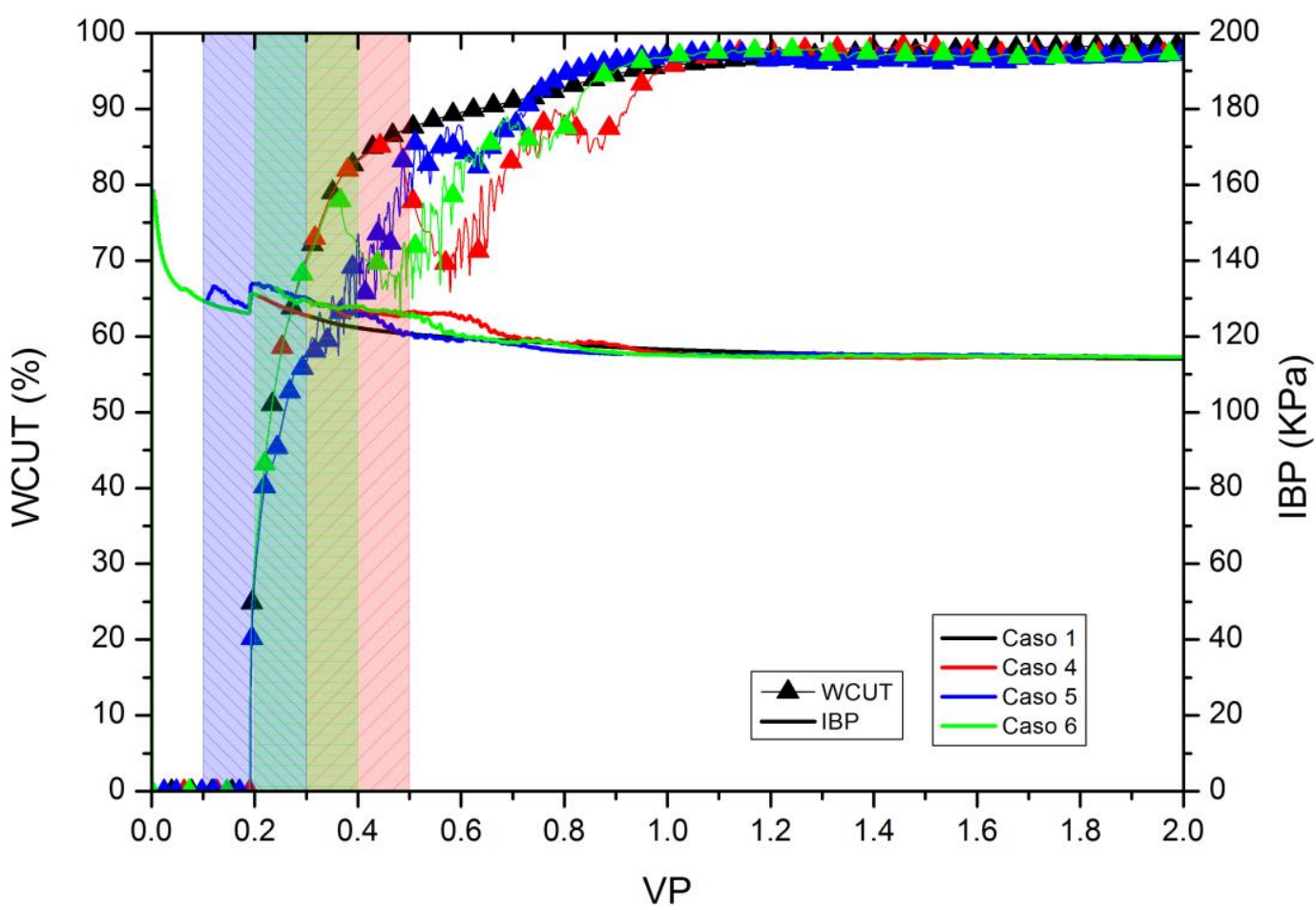

Figura 4-6 -Curvas de corte de água e a pressão de fundo no injetor, com o período da injeção de emulsão sinalizada versus volume poroso injetado para os Casos 1 (IA), 4 (WAE 0,3/0,2/1,5), 5 (WAE 0,1/0,2/1,7) e 6 (WAE 0,2/0,2/1,6). 
Finalmente foi realizada uma análise do efeito do tamanho do banco de emulsão injetado. Para o caso WAE com injeção de emulsão iniciando após 0,2 VP injetados de água foi feito um estudo com banco de emulsão com 0,2, 0,1 e 0,05 VP, casos 6, 7 e 8 respectivamente. Os resultados são apresentados nas Figura 4-7 e Figura 4-8. A redução do volume do banco de emulsão diminui a recuperação de óleo mas ainda são atingidos valores significativos de acréscimo de 4 a 6\% no fator de recuperação em relação à injeção de água. Mesmo com banco de emulsão reduzido, há mobilização de óleo adicional e alteração na evolução da produção de água.

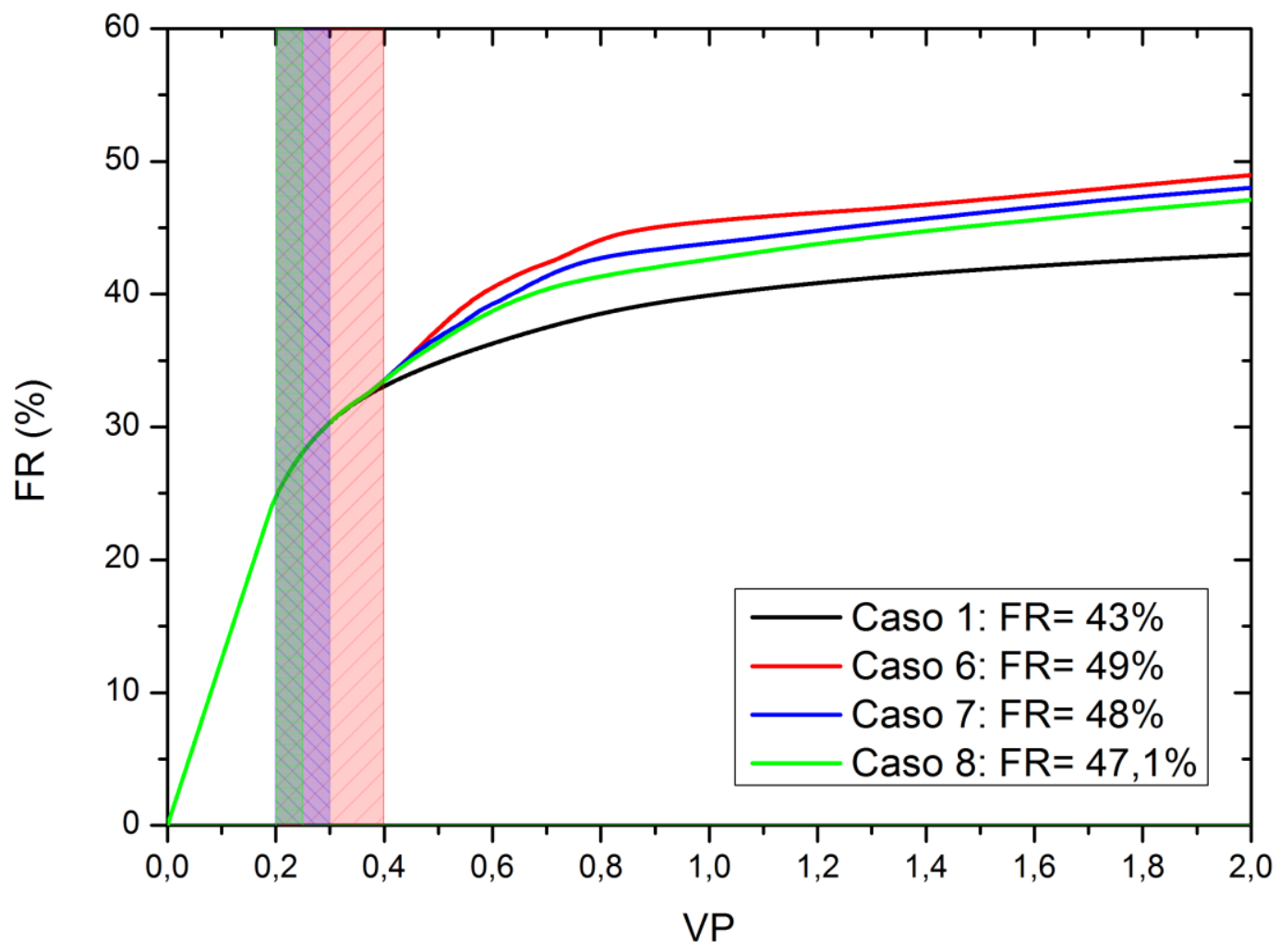

Figura 4-7 - Curvas de evolução do fator de recuperação de óleo contra o volume poroso injetado para os Casos 1 (IA), 6 (WAE 0,2/0,2/1,6), 7 (WAE 0,2/0,1/1,7) e 8 (WAE $0,2 / 0,05 / 1,75)$. 


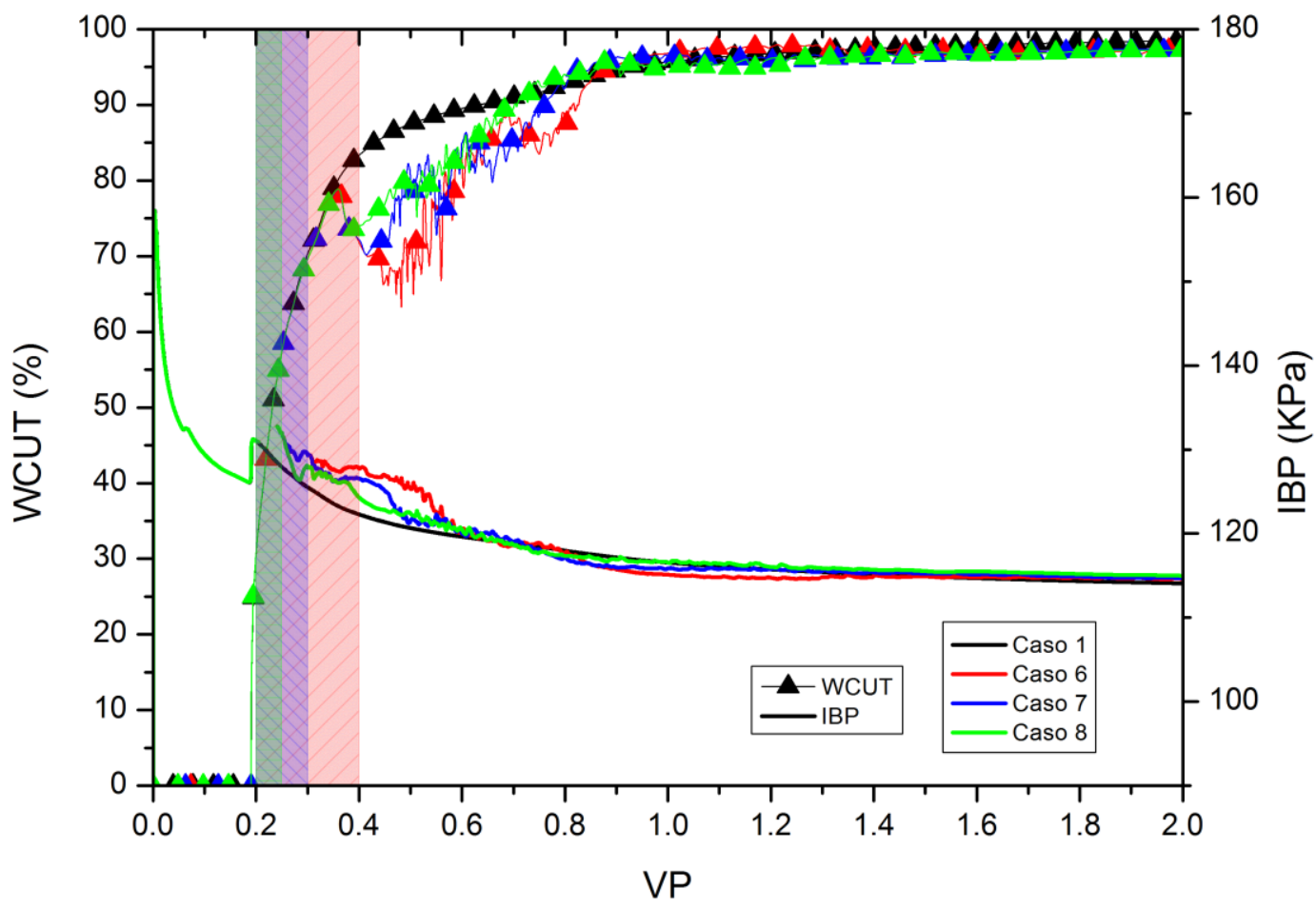

Figura 4-8 - Curvas do corte de água e a pressão de fundo no injetor contra o volume poroso injetado para os Casos 1 (IA), 6 (WAE 0,2/0,2/1,6), 7 (WAE 0,2/0,1/1,7) e 8 (WAE $0,2 / 0,05 / 1,75)$.

Para ilustrar o efeito da injeção de água e emulsão são apresentados na Figura 4-9 os mapas de saturação de água, concentração de emulsão e Número de Capilaridade do caso 4 (WAE 0,3/0,2/1,5). São mostrados os resultados para 3 tempos de simulação selecionados. Os primeiros mapas apresentados são para o tempo de simulação equivalente a injeção de 0,5VP (Figura 4-9a), ou seja, após início da injeção de emulsão, já após a irrupção de água. A distribuição da saturação de água entre injetor e produtor mostra o grau de heterogeneidade do modelo. E na Figura 4-9b, com a injeção de 0,9VP é possível verificar a variação da saturação na região varrida pela emulsão. Ao final da simulação com 2 VP, Figura 4-9c, quando praticamente só restou emulsão nas regiões de baixa permeabilidade e o perfil de saturação de água foi bem alterado mostrando o efeito da injeção WAE na distribuição de saturação no meio poroso. 


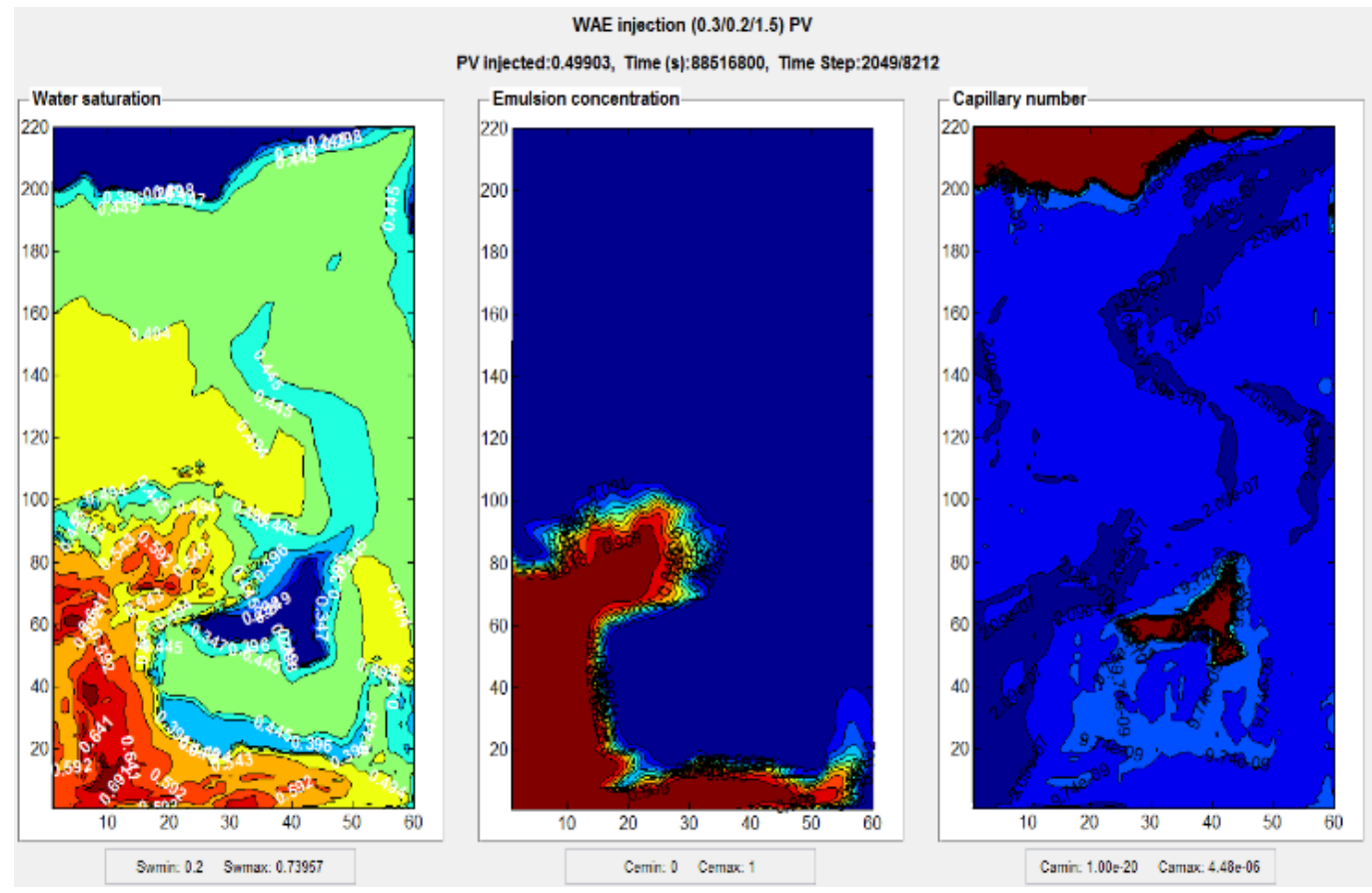

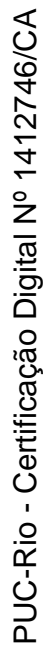

(b)

WAE injection $(0.3 / 0.211 .5)$ PV

PV injected:0.89846, Time (8):159364800, Time Step:3689/8212
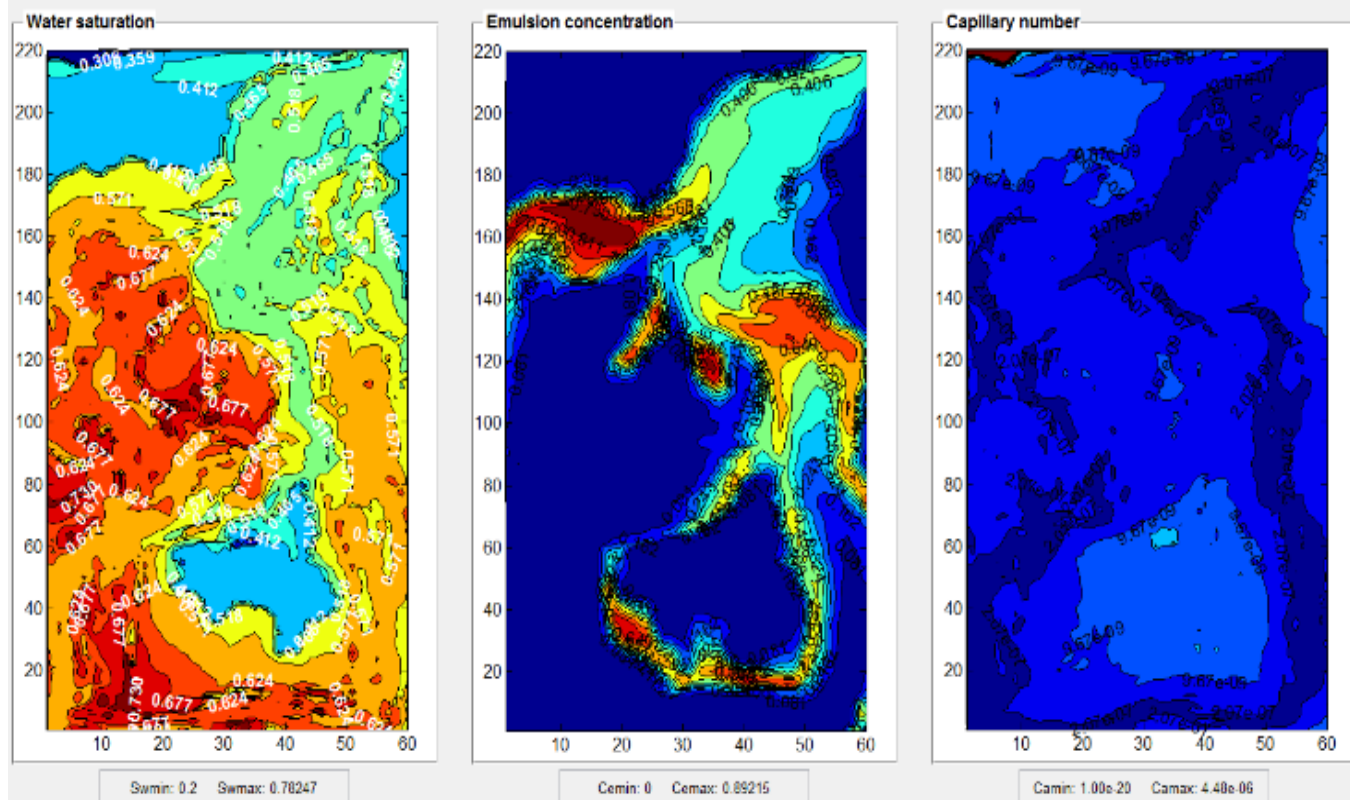
(c)

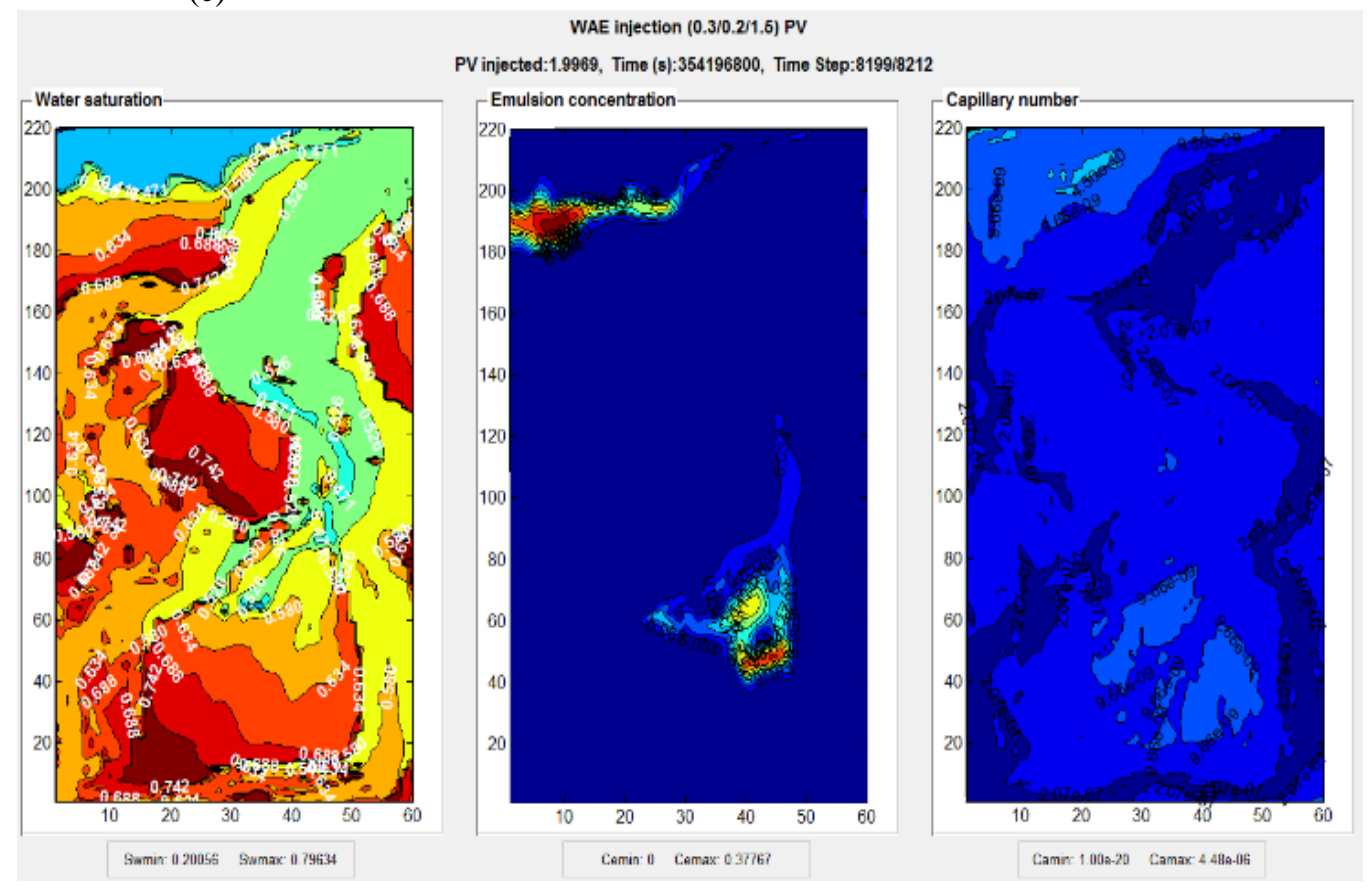

Figura 4-9 - Mapas de saturação de água, concentração de emulsão e Número de

Capilaridade do Caso 4 (WAE 0,3/0,2/1,5) para a injeção de 0,5VP (a) 0,7VP (b) e 2,0VP

(c)

\section{3. \\ Simulações 3D com 4 camadas}

Para as simulações 3D foram selecionadas as 4 camadas do segundo modelo do caso 10 do SPE. Por conta do considerável acréscimo de tempo e custo computacional para a inclusão da terceira dimensão nas simulações foi feita uma análise reduzindo o tamanho do domínio para um quarto e um oitavo do domínio original e verificou-se que os fatores de recuperação obtidos eram similares, indicando que os modelos com tamanho reduzido ainda conservam a alta heterogeneidade característica do modelo original. No presente trabalho foi escolhido um oitavo do domínio original para as simulações em três dimensões.

No recorte de um oitavo do domínio original foram feitas as simulações 3D com 4 camadas, separadas em dois tipos de agrupamentos. O primeiro agrupamento com 4 camadas da formação superior do modelo SPE10, a formação Tarbert, tendo sido selecionadas as camadas ( $k=3,4,5$ e 6). O segundo agrupamento foi feito selecionando as camadas adjacente a interface de duas 
formações. Foram selecionadas as 2 últimas camadas da formação superior (Tarbert) e as duas camadas superiores da formação inferior (Upper Ness), ou seja, as camadas $(K=34,35,36$ e 37$)$

Em ambos os agrupamentos, o poço produtor foi completado nas quatro camadas em uma das extremidades do grid enquanto o injetor foi completado nas quatro camadas na extremidade oposta.

\subsection{1.}

\section{Simulações 3D com 4 camadas na mesma formação reservatório}

A vazão de produção utilizada em todas as simulações 3D com 4 camadas na mesma formação foi mantida constante. Esta vazão foi calculada utilizando como referência a vazão utilizada no segundo modelo do caso SPE10, ponderando pelo volume do recorte em relação ao volume total.

Para esta configuração de reservatório foi feita uma análise quanto ao momento da injeção de emulsão, bem como o tamanho do banco. Os casos são apresentados na Tabela 4-2.

Tabela 4-2 - Quadro comparativo das simulações 3D (4 camadas k=3, 4, 5 e 6)

\begin{tabular}{|c|c|c|c|c|}
\hline \multicolumn{2}{|c}{ Caso } & Formação & \multicolumn{3}{c}{$\begin{array}{c}\text { Volume de água } \\
\text { injetado antes da } \\
\text { emulsão } \\
\text { (VPs) }\end{array}$} & $\begin{array}{c}\text { Volume do } \\
\text { banco de } \\
\text { emulsão } \\
\text { (VPs) }\end{array}$ \\
\hline A & única (topo) & IA & - & - \\
\hline B & única (topo) & WAE & & 1,2 \\
\hline C & única (topo) & WAE & \multirow{2}{*}{0,4} & 0,2 \\
\hline D & única (topo) & WAE & & \multirow{2}{*}{0,4} \\
\hline E & única (topo) & WAE & 0,2 & \\
\hline F & única (topo) & WAE & 2,0 & \\
\hline
\end{tabular}




\subsubsection{1.}

\section{Validação do código tridimensional}

Antes de iniciar as simulações em três dimensões foi feita a validação das alterações realizadas no código para implementar o termo gravitacional. Para validação das alterações no modelo black-oil programado com o simulador de código aberto MRST do SINTEF foi feita a comparação com o simulador comercial (CMG-IMEXTM).

Para tanto foi realizada a simulação do caso de injeção de água no modelo descrito acima, com os poços produtor e injetor em cada extremidade do modelo e com reposição de massa de forma a manter a pressão do sistema constante. $O$ modelo de fluido no (CMG-IMEX ${ }^{\mathrm{TM}}$ ) foi definido para que a compressiblidade do óleo fosse bem reduzida e foram utilizadas as curvas de permeabilidade relativa do sistema óleo-água descritas acima.

Na Figura 4-10 a seguir são apresentados os resultados de evolução do fator de recuperação e d corte de água para o Caso $A$, injeção de água, com a validação do modelo desenvolvido com o simulador comercial.

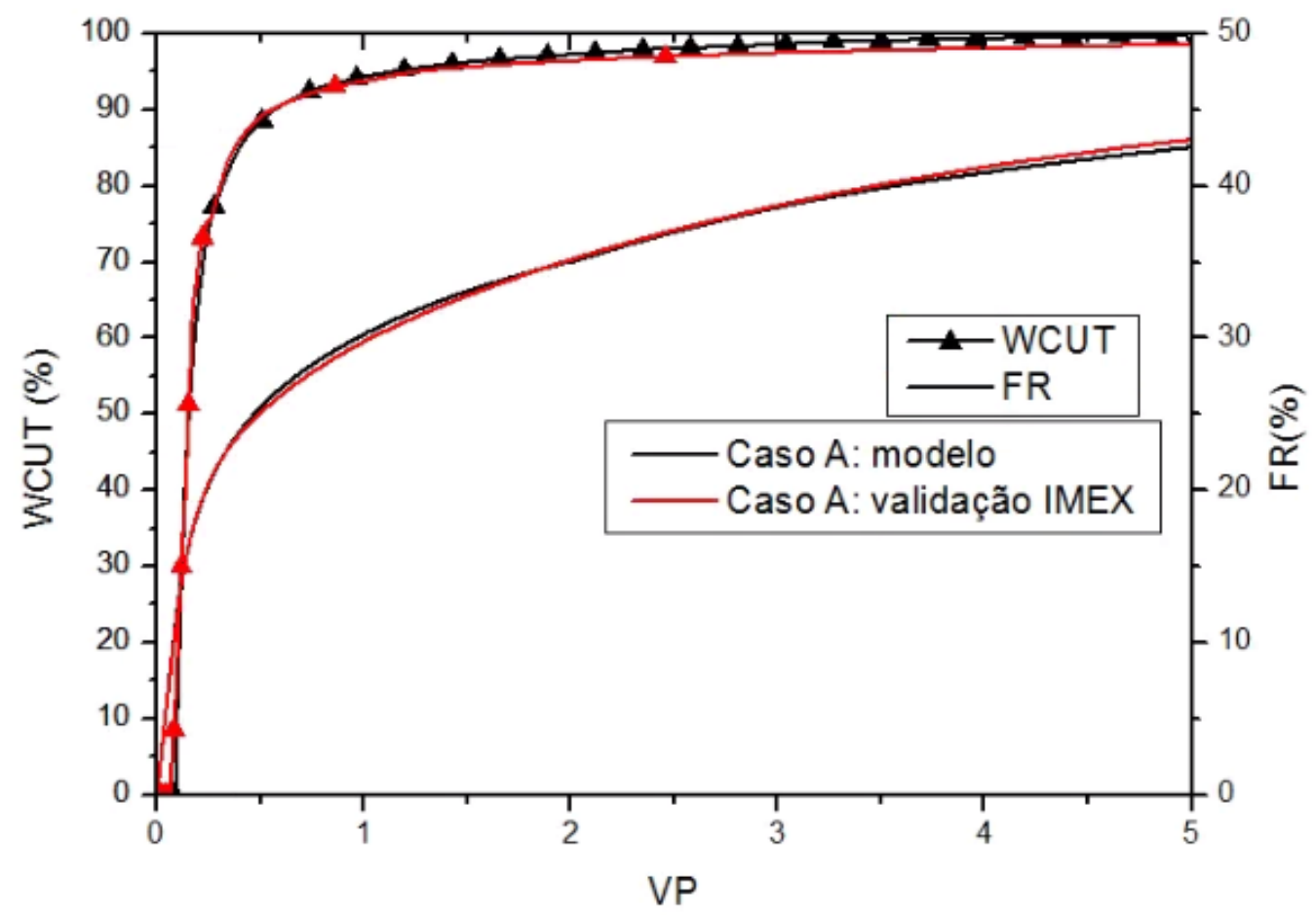

Figura 4-10 - Validação do código tridimensional implementado no modelo black-oil programado no simulador de código aberto MRST do SINTEF com simulador comercial. 
Uma vez realizada a validação do modelo 3D foram simulados os casos de estudo apresentados na tabela 4-2. No caso de injeção de água (Caso A) foram injetados continuamente 5 VP e o resultado é apresentado na Figura 4-11. Para o caso WAE, foi realizada uma análise quanto ao tamanho do banco de emulsão com injeção de emulsão iniciando após 0,4 VP injetados de água. Foram considerados bancos de emulsão com 1,2, 0,2 e 0,4 VP, casos B, C e D respectivamente. Os resultados são apresentados nas Figura 4-11 e Figura 4-12, os bancos de emulsão estão sombreados conforme o caso.

O banco de emulsão com 0,2 VP já é suficiente para afetar a produção de água e o varrido no reservatório de forma a aumentar o fator de recuperação de cerca de $42,54 \%$ para o caso de injeção de água para cerca de $46,57 \%$. Aumentando o tamanho do banco para 0,4 e 1,2 VP, observa-se um acréscimo de recuperação atingindo um $\mathrm{FR}$ de até $47,25 \%$, embora os resultados indiquem que existe alguma diferença no resultado final, o efeito do tamanho do banco de emulsão é bem pequeno na recuperação final. Ou seja, mesmo um banco de emulsão de tamanho reduzido foi suficiente para mudar o varrido e reduzir a saturações residuais de óleo afetando a recuperação.

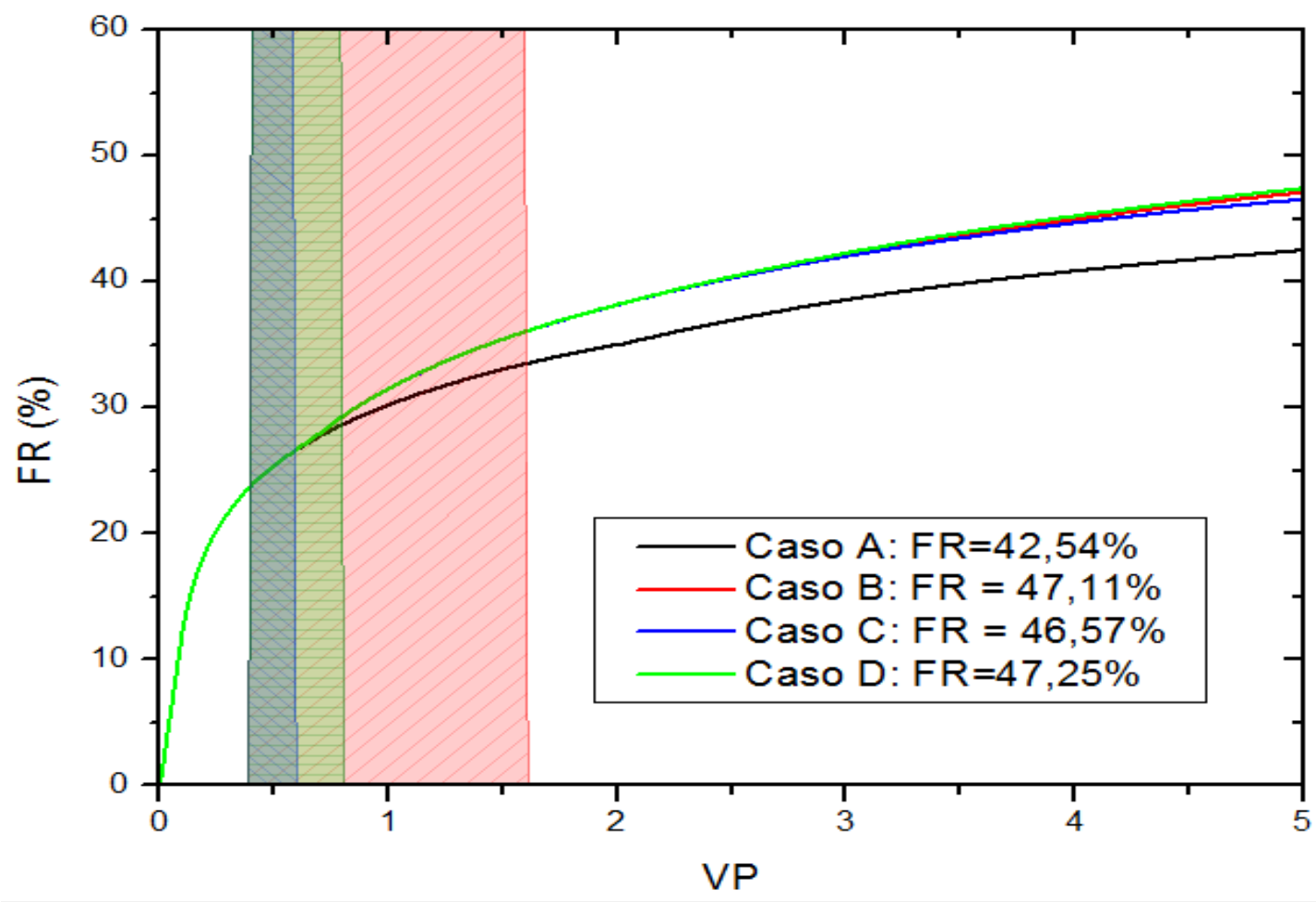

Figura 4-11 - Curvas de evolução do fator de recuperação de óleo para os Casos $A(I A)$, B (WAE 0,4/1,2/3,4), C (WAE 0,4/0,2/4,4) e D (WAE 0,4/0,4/4,2). 


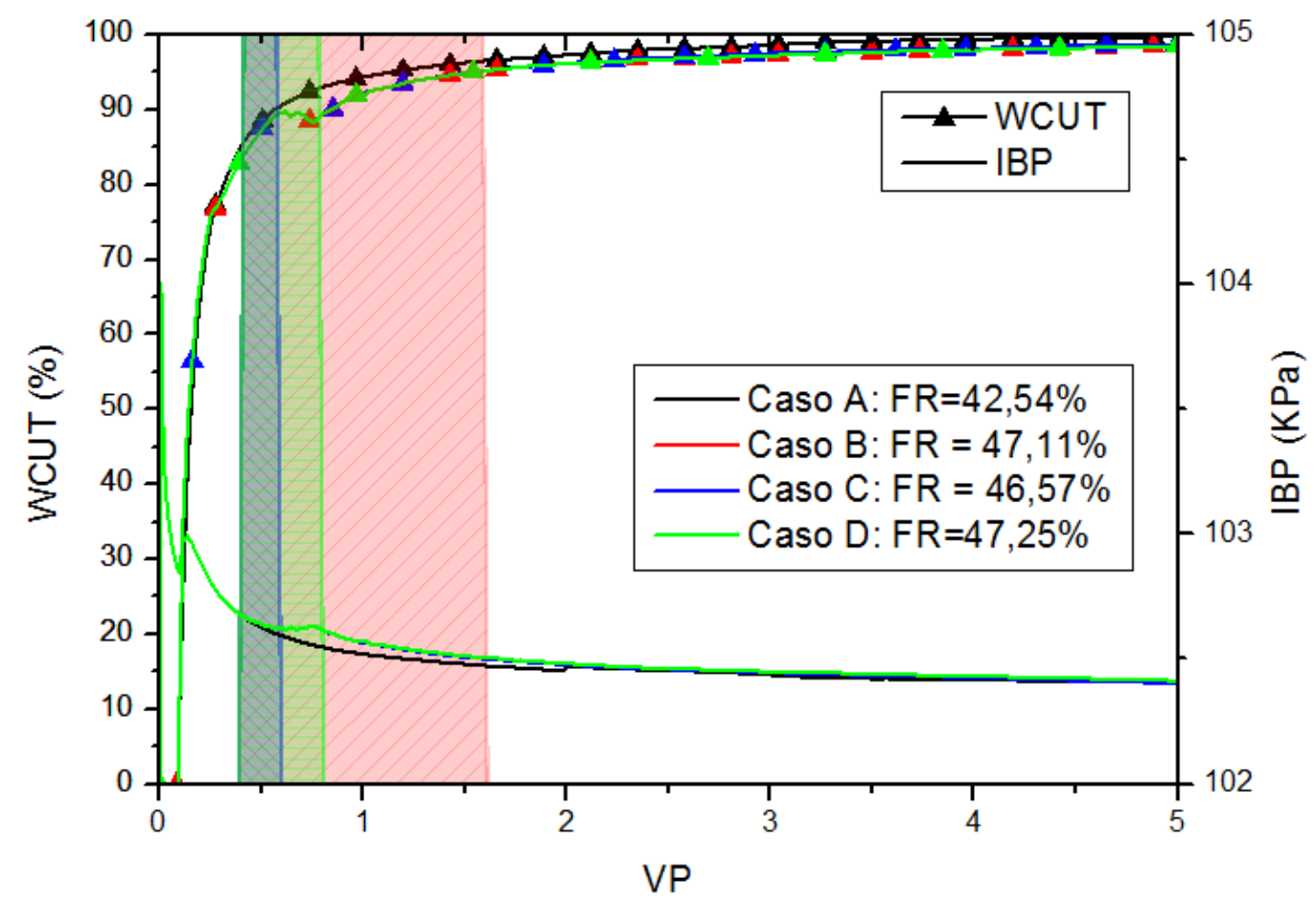

Figura 4-12 - Curvas de evolução do corte de água e da pressão de fundo no poço injetor para os Casos A (IA), B (WAE 0,4/1,2/3,4), C (WAE 0,4/0,2/4,4) e D (WAE $0,4 / 0,4 / 4,2)$.

A seguir são apresentados os mapas das quatro camadas ( $k=3$ a 6$)$ de porosidade e de saturação de óleo para o Caso A (injeção de água) e o Caso $D$ (injeção WAE). Eles ilustram a mudança na saturação em três momentos: após a injeção do banco de emulsão (1,0 VP), após a injeção total de 2,0VP e ao final da simulação com injeção de 5 VP.

Os mapas de saturação de óleo apresentados na Figura 4-13 mostram a redução da saturação de óleo (cores mais frias) no caso $D$ após a injeção da emulsão. Nesses mapas é possível comparar em cada um dos três tempos selecionados a distribuição de saturação de óleo em cada camada para a injeção de água (Caso A) e a injeção WAE (Caso D). Só foi apresentado o caso D, pois como verifica-se nos gráficos, as diferenças entre os Casos $B, C$ e $D$, variando o tamanho do banco de emulsão são pequenas.

Na figura é possível observar como é o padrão da injeção de água, do injetor (esquerda inferior) ao produtor (direita superior) em cada quadro. Comparando os resultados da injeção de água entre as camadas verifica-se que a primeira camada apresenta um pior varrido. Já com a injeção de emulsão, verifica-se que é possível atingir menores saturações de óleo. O banco de emulsão com 0,2 VP já é suficiente para afetar a produção de água e o varrido no reservatório de forma a aumentar o fator de recuperação. 


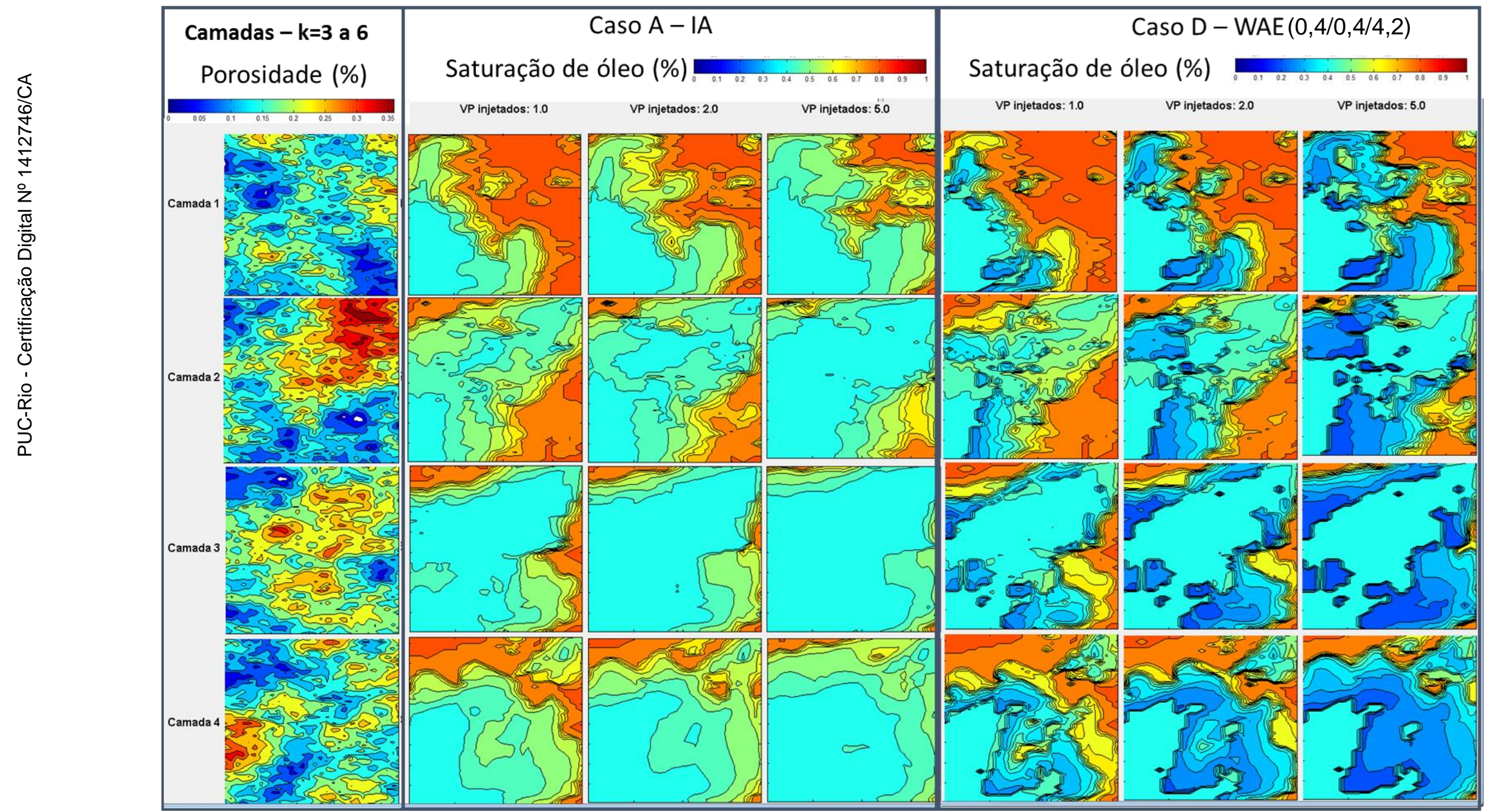

Figura 4-13 - Mapas de porosidade e saturação de óleo das camadas k=3 a 6 dos Casos A (injeção de água) e D (WAE 0,4/0,4/4,2) durante a injeção de 1, 2 e 5 VP de fluidos. 
Além da visualização das camadas, para avaliar o resultado em um reservatório estratificado é importante visualizar seções em cortes verticais do reservatório. Na Figura 4-14 a seguir, apresenta-se para o Caso A (injeção de água) o mapa de saturação da última camada $(k=4)$ e seções em $\mathrm{i}=15$ e j=23 (meio do domínio), o injetor está na extremidade esquerda inferior e o produtor na extremidade direita para injeção de 1,0 VP.
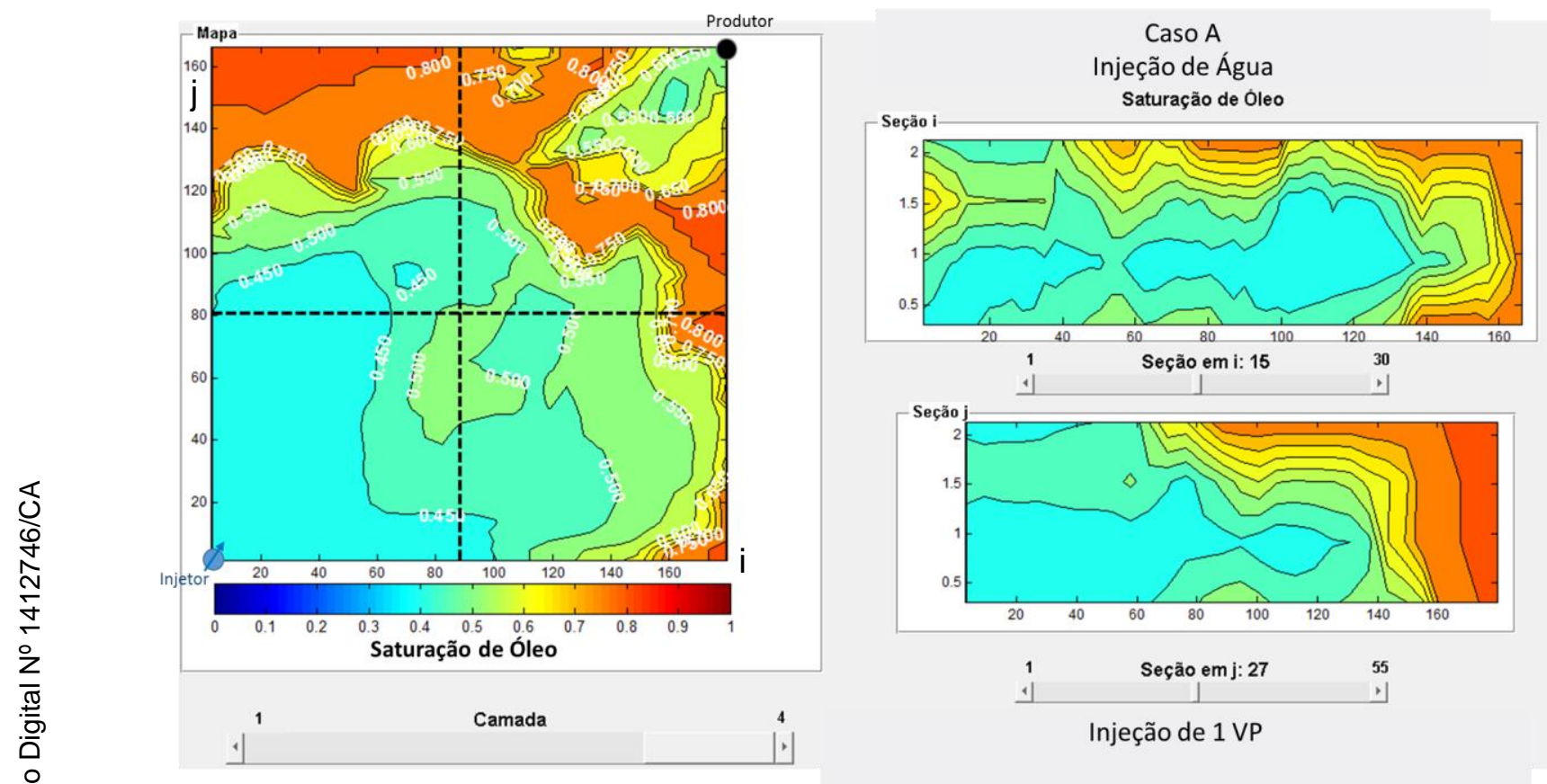

Figura 4-14 Mapa de saturação de óleo da quarta camada do modelo e seções do mesmo no meio do grid para o Caso A (injeção de água) durante a injeção de 1 VP.

No lado esquerdo da figura está o mapa de saturação óleo da quarta camada onde estão marcadas as linhas indicando a posição das seções no domínio e no lado esquerdo da figura, as seções para i e j constantes correspondentes com o perfil de saturação de óleo.

Na Figura 4-15 são apresentados os mesmos resultados para o Caso D (WAE 0,4/0,4/4,2), em mapa e seção para comparação com o Caso $A$ (injeção de água). Comparando os mapas de saturação em seções i e j constantes é possível avaliar a diferença no varrido vertical. 

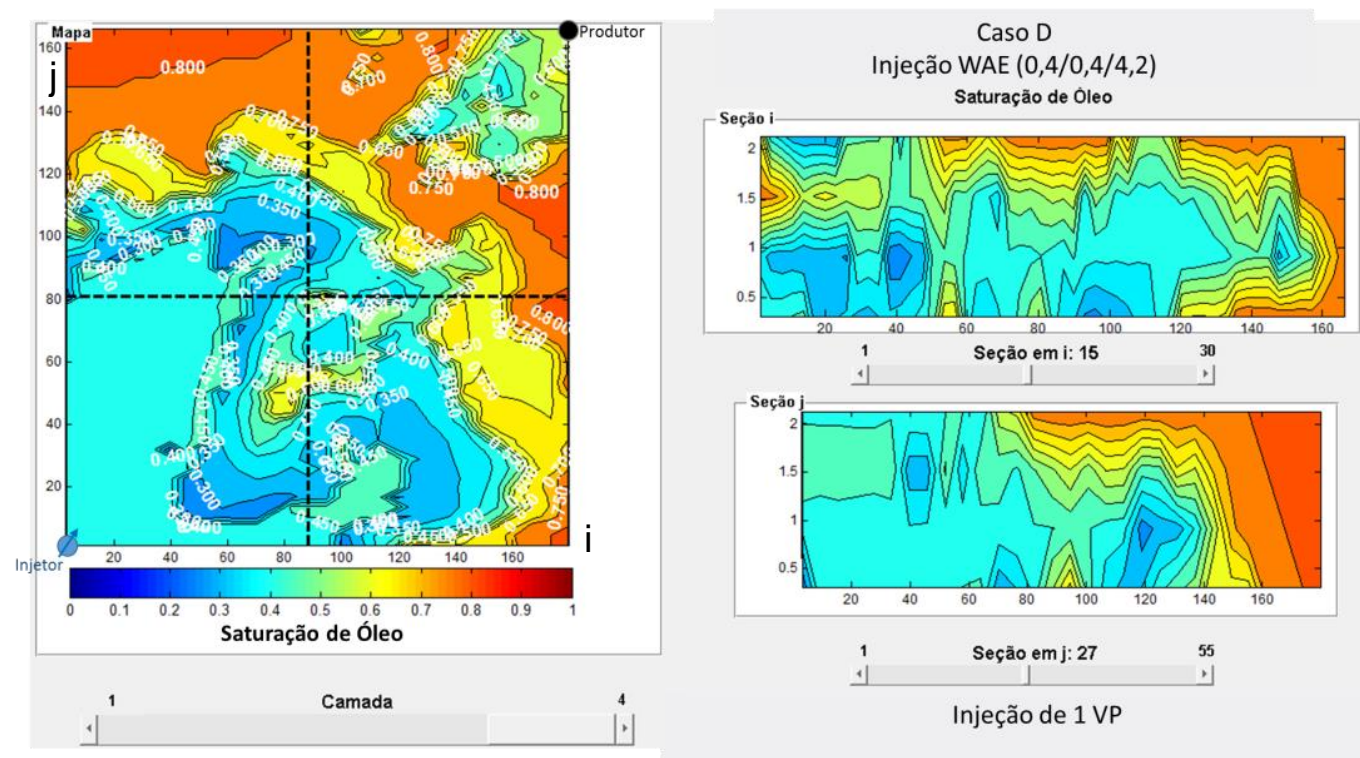

Figura 4-15 Mapa de saturação de óleo da quarta camada do modelo e seções do mesmo no meio do grid para o Caso D (WAE 0,4/0,4/4,2) durante a injeção de 1 VP.

Para avaliar ao longo do tempo e em diferentes posições do domínio, apresenta-se na Figura 4-16 seções, para i e j constantes, de saturação de óleo para o Caso A (injeção de água) e o Caso D (injeção WAE $(0,4 / 0,4 / 4,2))$. Os mapas ilustram a mudança na saturação em três momentos: após a injeção do banco de emulsão (1,0 VP), após a injeção total de 2,0VP e ao final da simulação com injeção de 5 VP.

As seções i e j constante na figura abaixo também evidenciam as regiões onde a saturação de óleo atingiu menores valores (cores mais frias) no caso $D$ após a injeção da emulsão. Nessas seções pode-se observar que a eficiência da injeção de emulsão é diferente em diferentes porções do domínio e entre camadas, indicando melhora no varrido vertical e há recuperação adicional nas regiões varridas. 


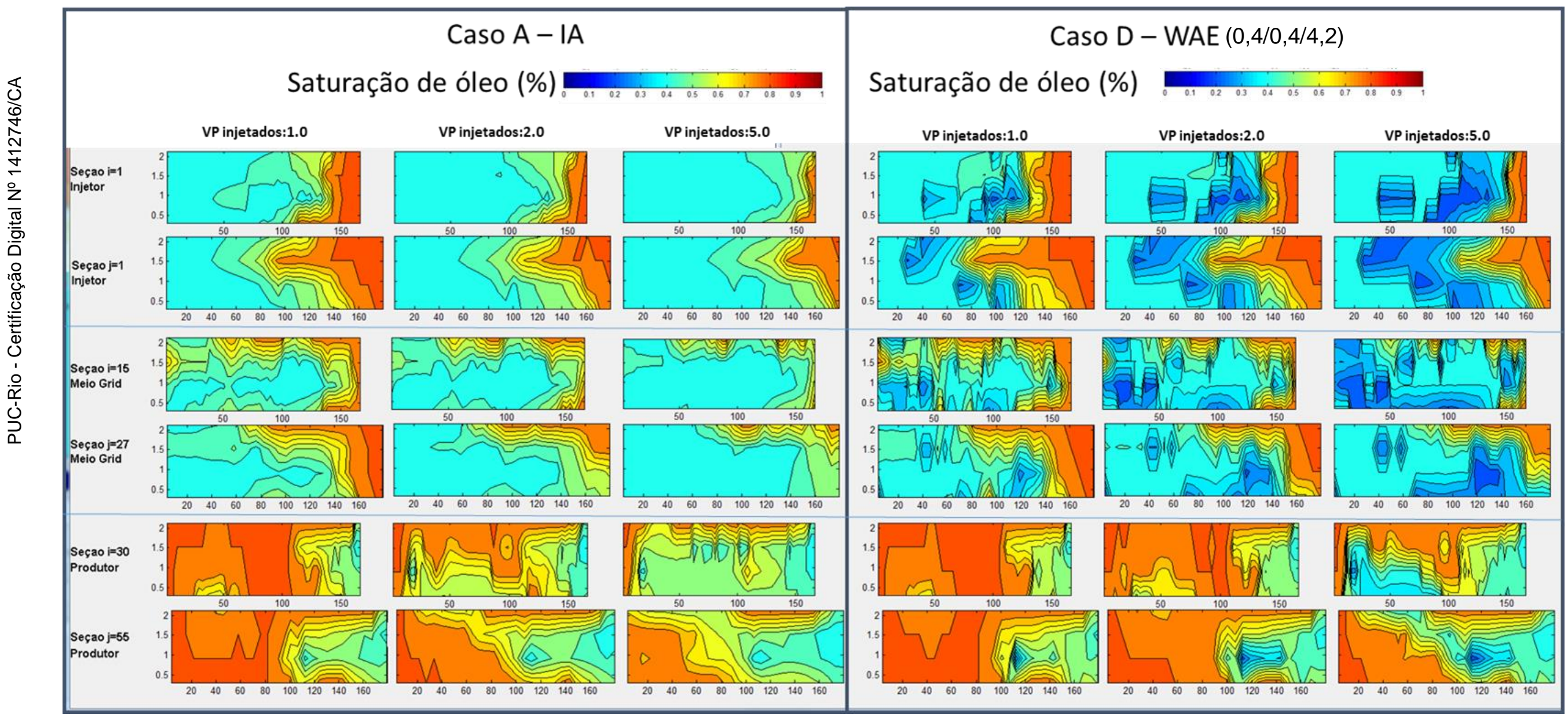

Figura 4-16 - Mapas de saturação de óleo para seções (i,j) localizadas no poço injetor, no meio do domínio e no poço produtor - Caso A (injeção de água) e Caso D (WAE 0,4/0,4/4,2) durante a injeção de 1, 2 e 5 VP de fluidos. 
Continuando com a análise paramétrica para a injeção WAE no modelo 3D com quatro camadas da mesma formação, manteve-se o banco de emulsão de 0,4 VP, e foi realizada a análise em relação ao tempo de início da injeção de emulsão. Foram avaliados os casos com injeção de emulsão iniciando após a injeção de 0,4 VP de água, após 0,2 VP de água e após 2,0 VP de água, casos D, E e F, respectivamente. Os resultados apresentados nas Figura 4-17 e Figura 4-18, mostram os bancos de emulsão com linhas verticais, sempre em comparação com o caso da injeção de água.

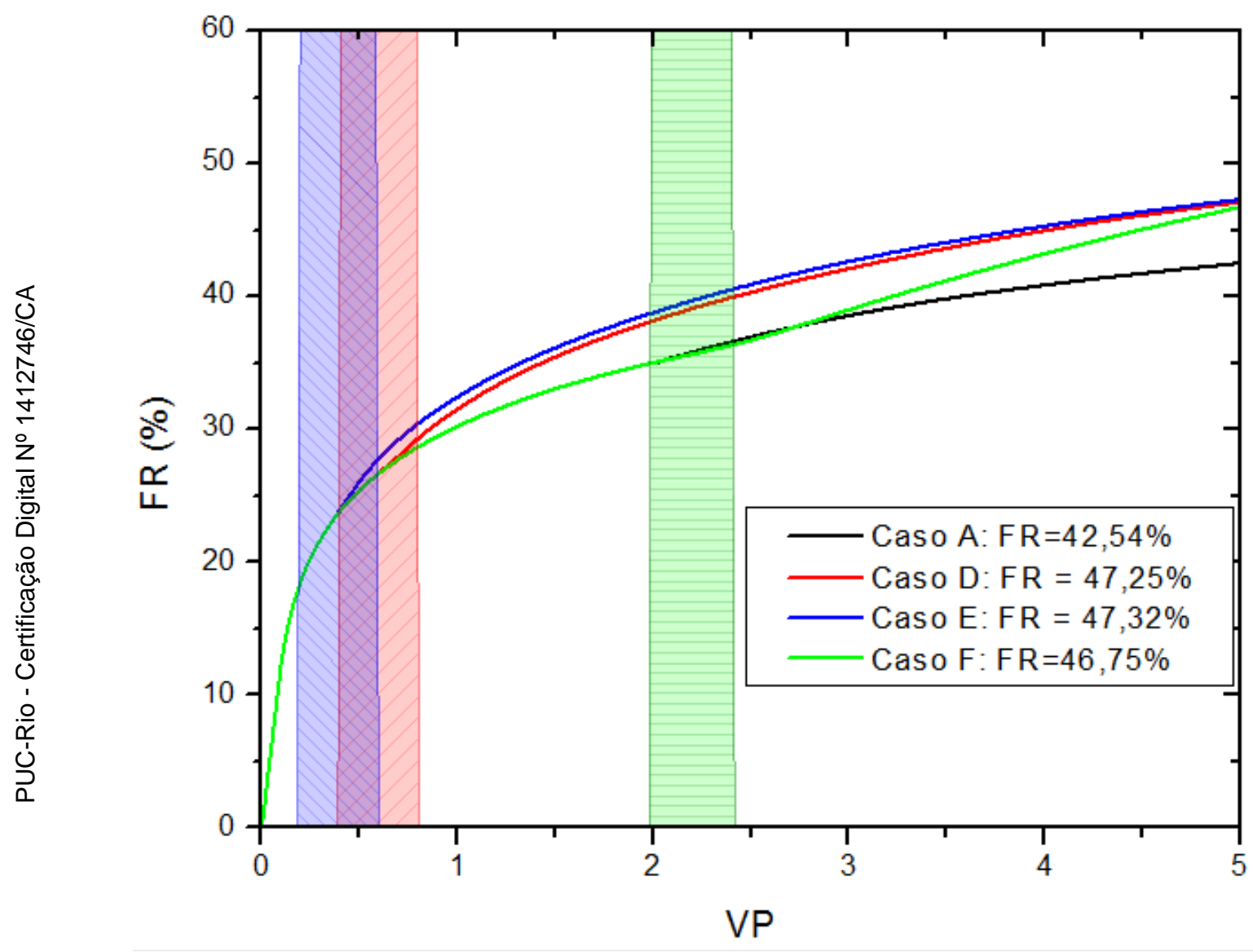

Figura 4-17 - Curvas de evolução do fator de recuperação de óleo para os Casos $A(I A)$, D (WAE 0,4/0,4/4,2), E (WAE 0,2/0,4/4,4), e F (WAE 2,0/0,4/2,6). 


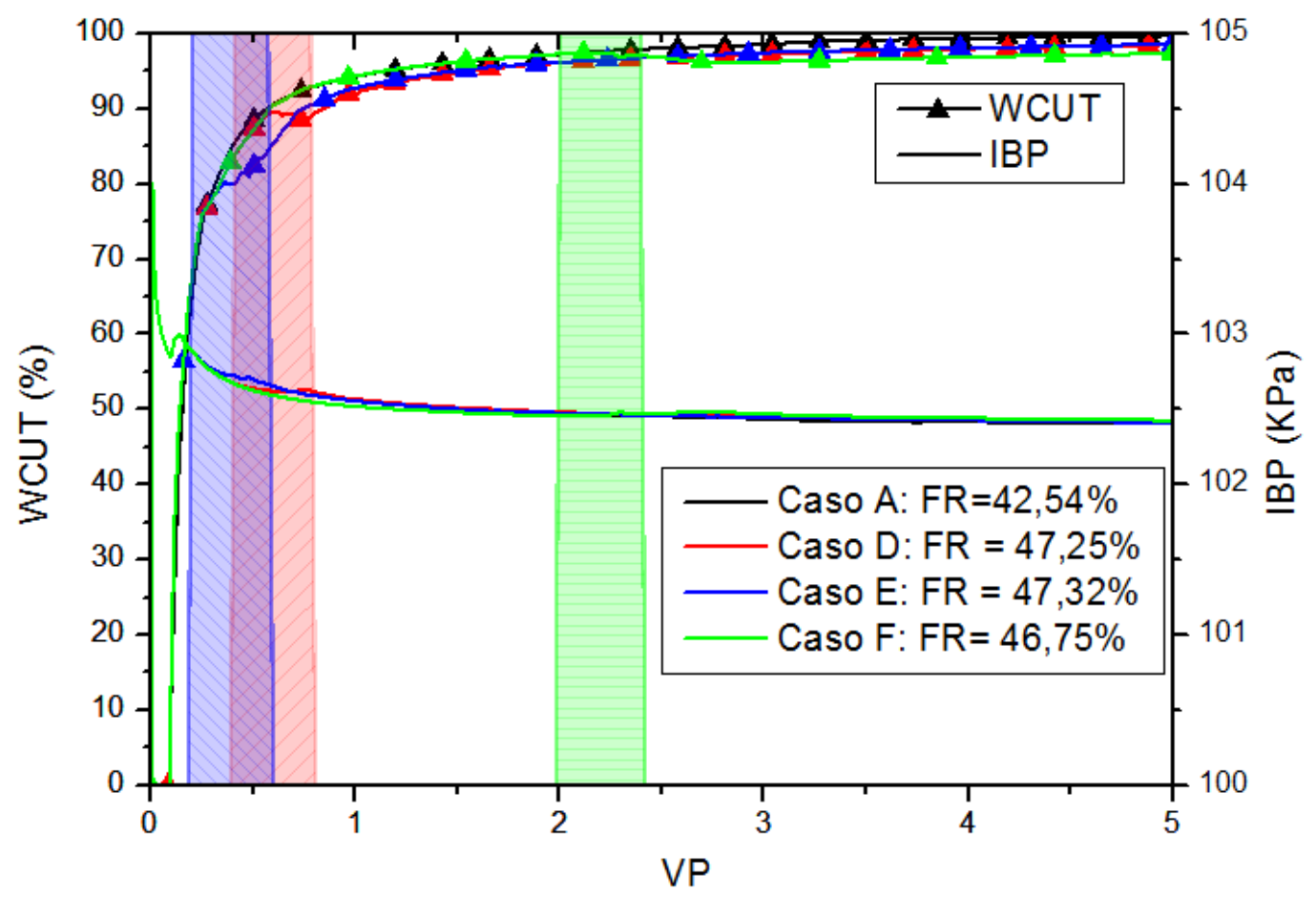

Figura 4-18 - Curvas de evolução do corte de água da pressão de injeção no poço injetor para os Casos A (IA), D (WAE 0,4/0,4/4,2), E (WAE 0,2/0,4/4,4), e F (WAE $2,0 / 0,4 / 2,6)$.

Os resultados indicam que quanto antes é injetado o banco de emulsão maior é a antecipação obtida no acréscimo de óleo agregado com o método WAE. Esta diferença é evidenciada na curva de Corte de água pois no Caso $\mathrm{E}$ (injeção mais cedo), a redução no corte de água é antecipado.

Quando a injeção do banco de emulsão é realizada no momento da irrupção de água ou logo após esta (Casos E e D, respectivamente), o efeito no corte de água é maior e a recuperação de óleo é acelerada. Quando a injeção do banco de emulsão é tardia (Caso F) estes efeitos são postergados e de menor impacto pois o corte de água já está bastante elevado.

A Figura 4-19 apresenta os mapas de porosidade e de saturação de óleo nas quatro camadas ( $\mathrm{k}=3$ a 6) para o Caso $\mathrm{A}$ (injeção de água) e o Caso $\mathrm{E}$ (injeção $\operatorname{WAE}(0,2 / 0,4 / 4,4))$ durante a injeção de 1,2 e 5 VP de fluidos. Os mapas das seções verticais, para i e j constantes, localizadas no poço injetor, meio do grid e no poço produtor desses casos são apresentadas na Figura 4-20.

Na Figura 4-21, são apresentados os mapas comparando o Caso A com o Caso F (WAE $(2,0 / 0,4 / 2,6))$ cuja injeção do banco de emulsões é mais tarde, após a injeção de 2,5, 4 e 5 VP de fluido. E na Figura 4-22 são apresentadas para os mesmos momentos de injeção os mapas das seções verticais. 
Nos mapas e seções a seguir observa-se que com a injeção do banco de emulsão antecipada as regiões com saturação de óleo mais baixas (cores azuis mais frias) são maiores e ocorrem com volumes injetado de fluido menores.

Quando a injeção do banco de emulsão é feita num estágio mais maduro da explotação, as áreas afetadas pela emulsão, com remoção adicional de óleo, são menores embora o ganho final seja significativo.

Em todos os casos de injeção WAE, o acréscimo de volume adicional recuperado foi significativo, agregando até $5 \%$ ao fator de recuperação ao obtido com injeção de água. 


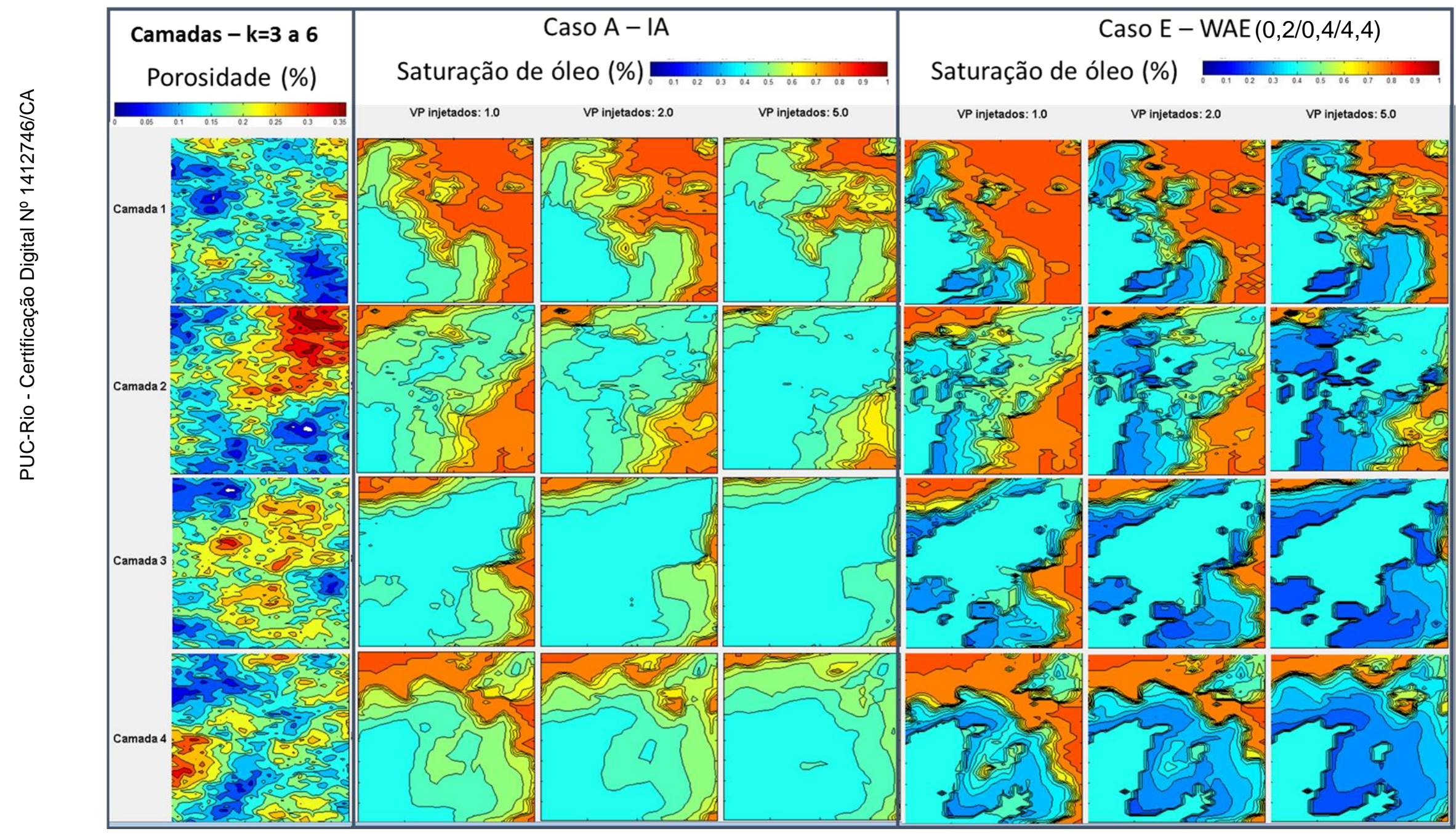

Figura 4-19 - Mapas de porosidade e de saturação de óleo das camadas k=3 a 6 dos Casos A (injeção de água) e E (WAE 0,2/0,4/4,4) durante a injeção de 1,2 e 5 VP de fluidos. 


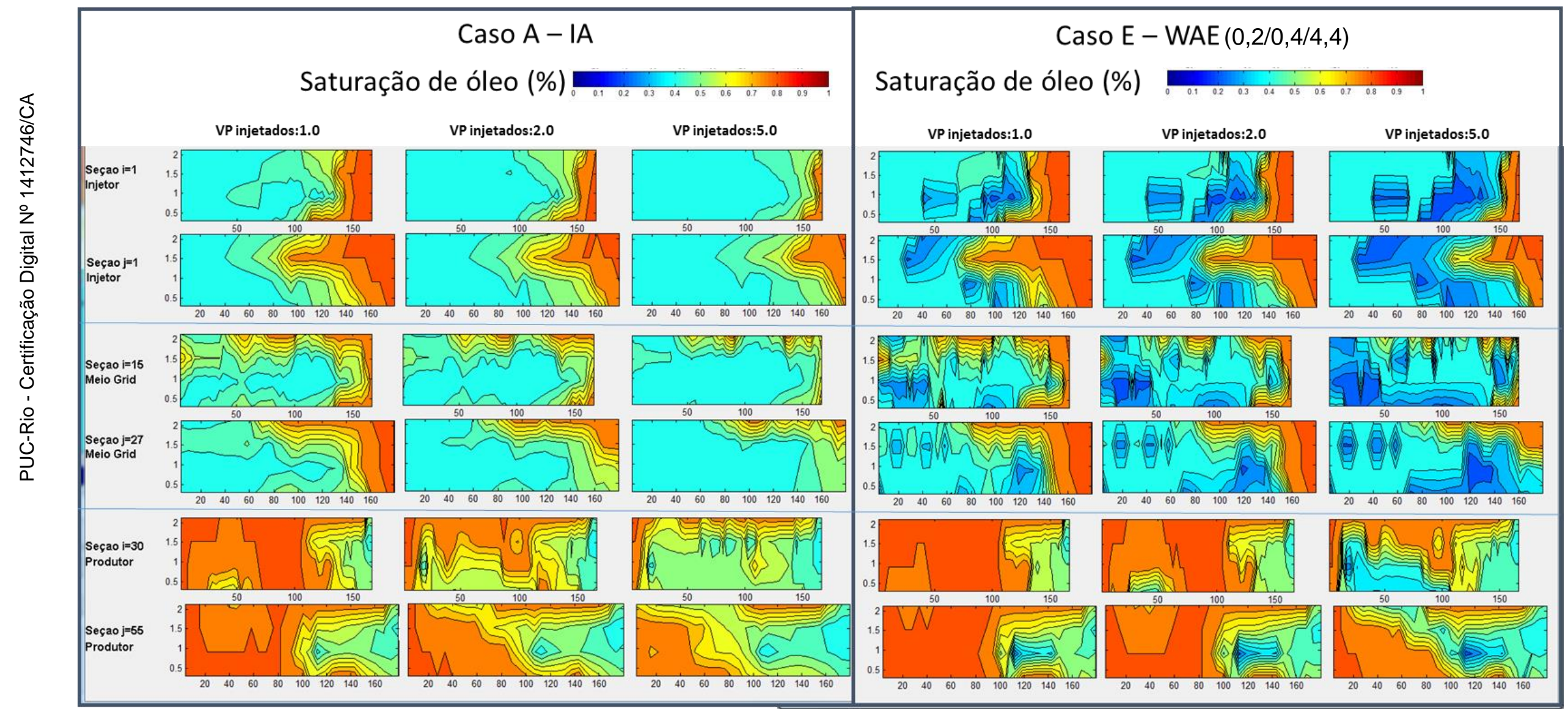

Figura 4-20 - Mapas de saturação de óleo para seções (i,j) localizadas no poço injetor, no meio do domínio e no poço produtor - Caso A (injeção de água) e E (WAE 0,2/0,4/4,4) durante a injeção de 1,2 e 5 VP de fluidos. 


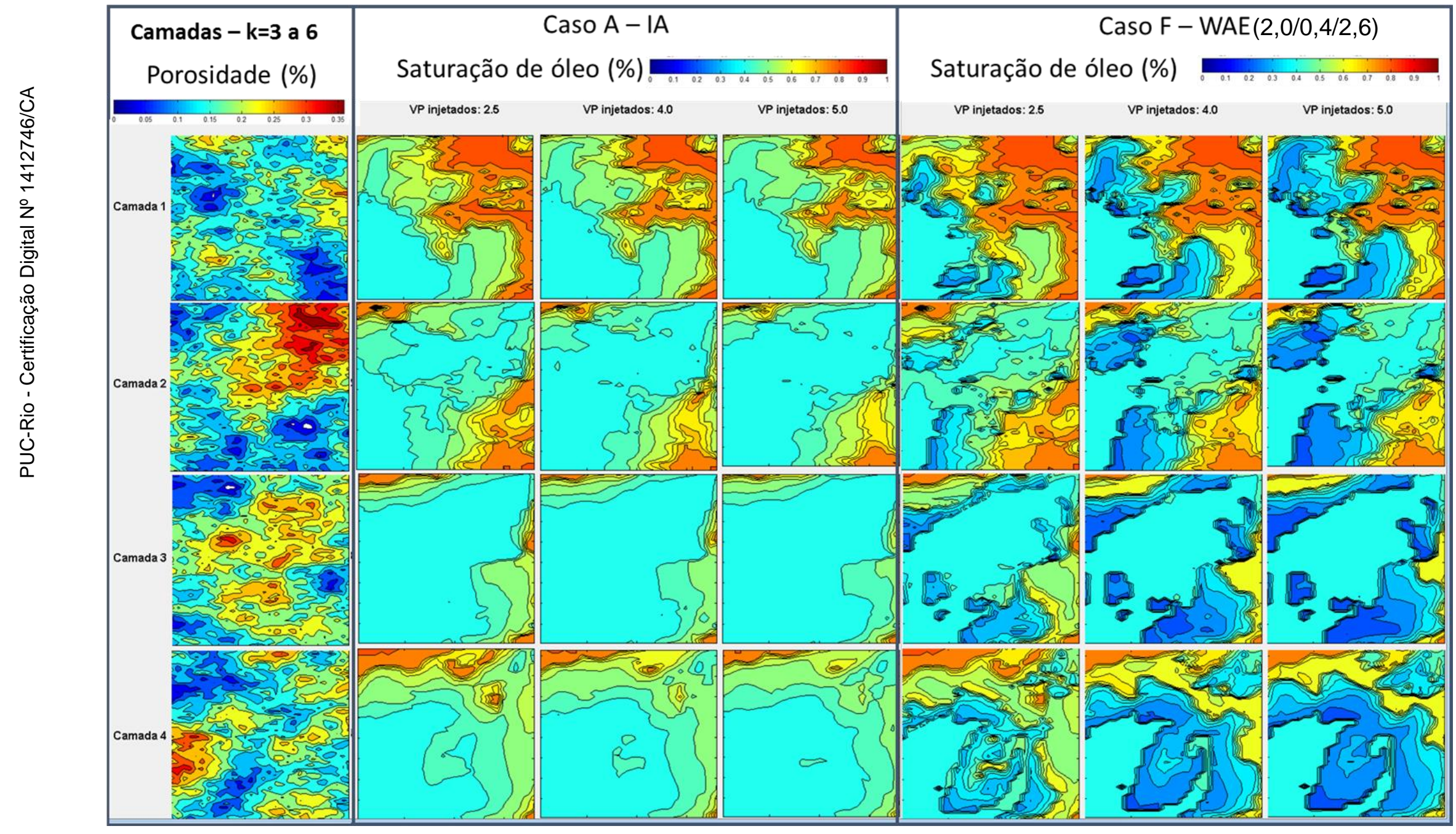

Figura 4-21 - Mapas de porosidade e de saturação de óleo das camadas k=3 a 6 dos Casos A (injeção de água) e F (WAE 2,0/0,4/2,6) durante a injeção de 2,5, 4 e 5 VP de fluidos. 


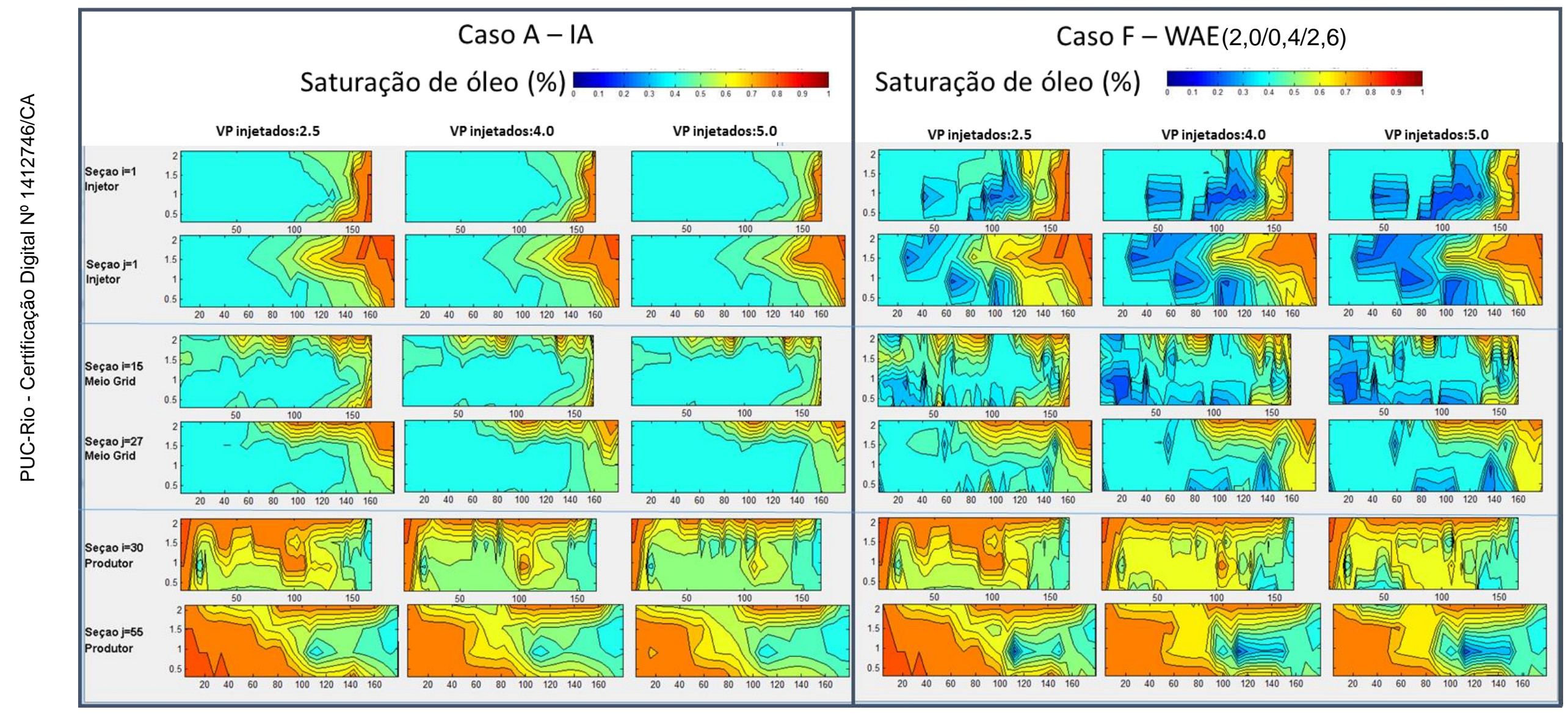

Figura 4-22 - Mapas de saturação de óleo para seções (i,j) localizadas no poço injetor, no meio do domínio e no poço produtor - Caso A (injeção de água) e Caso F (WAE 2,0/0,4/2,6) durante a injeção de 2,5 4 e 5 VP de fluidos. 


\subsection{2.}

\section{Simulações 3D com 4 camadas na interface entre duas formações reservatório}

Neste segundo agrupamento de 4 camadas, foram selecionadas as camadas adjacentes à interface das duas formações. Foram selecionadas as 2 últimas camadas da formação superior (Tarbert) e as duas camadas superiores da formação inferior (Upper Ness), ou seja, as camadas ( $K=34,35,36$ e 37)

Para esta configuração de reservatório foi feita uma análise do efeito do momento da injeção de emulsão, bem como o tamanho do banco. A vazão de produção utilizada para estas simulações 3D com 4 camadas foi mantida constante. Os casos são apresentados na Tabela 4-3.

Tabela 4-3 - Quadro comparativo das simulações 3D (4 camadas k=34, 35, 36 e 37) com vazão constante

\begin{tabular}{|c|c|c|c|c|}
\hline Caso & Formação & Tipo de Injeção & $\begin{array}{c}\text { Volume de água } \\
\text { injetado antes da } \\
\text { emulsão } \\
\text { (VPs) }\end{array}$ & $\begin{array}{l}\text { Volume do } \\
\text { banco de } \\
\text { emulsão } \\
\text { (VPs) }\end{array}$ \\
\hline G & duas (interface) & IA & - & - \\
\hline $\mathrm{H}$ & duas (interface) & WAE & \multirow{3}{*}{0,4} & 1,2 \\
\hline 1 & duas (interface) & WAE & & 0,2 \\
\hline $\mathrm{J}$ & duas (interface) & WAE & & \multirow{3}{*}{0,4} \\
\hline$K$ & duas (interface) & WAE & 0,2 & \\
\hline $\mathrm{L}$ & duas (interface) & WAE & 2,0 & \\
\hline
\end{tabular}

Além disso, foi feita uma análise do efeito da vazão dada a dependência da atuação da emulsão ao Número de Capilaridade. Para esta análise foram simulados os casos apresentados na Tabela 4-4. 
Tabela 4-4 - Quadro comparativo das simulações 3D (4 camadas k=34, 35, 36 e 37) com sensibilidade a vazão

\begin{tabular}{|c|c|c|c|c|c|}
\hline Caso & Formação & Tipo de Injeção & $\begin{array}{c}\text { Volume de água } \\
\text { injetado antes da } \\
\text { emulsão } \\
\text { (VPs) }\end{array}$ & $\begin{array}{l}\text { Volume do } \\
\text { banco de } \\
\text { emulsão } \\
\text { (VPs) }\end{array}$ & $\begin{array}{c}\text { Relação com a } \\
\text { vazão de } \\
\text { referência }\end{array}$ \\
\hline G & duas (interface) & $\mathrm{IA}$ & - & - & \multirow{2}{*}{ Qref } \\
\hline $\mathrm{J}$ & duas (interface) & WAE & 0.4 & 0.4 & \\
\hline $\mathrm{M}$ & duas (interface) & WAE & 0.4 & 0.4 & Qref / 5 \\
\hline $\mathrm{N}$ & duas (interface) & WAE & 0.4 & 0.4 & Qref*5 \\
\hline
\end{tabular}

No caso de injeção de água (Caso G) foram injetados continuamente 5 VP. Para a injeção WAE, foi realizada uma análise do tamanho do banco de emulsão com injeção de emulsão iniciando após 0,4 VP injetados de água. Foram considerados bancos de emulsão com 1,2, 0,2 e 0,4 VP, casos $\mathrm{H}$, I e J respectivamente. Os resultados são apresentados nas Figura 4-23 e Figura 4-24 e em todas os bancos de emulsão estão sombreados conforme o caso.

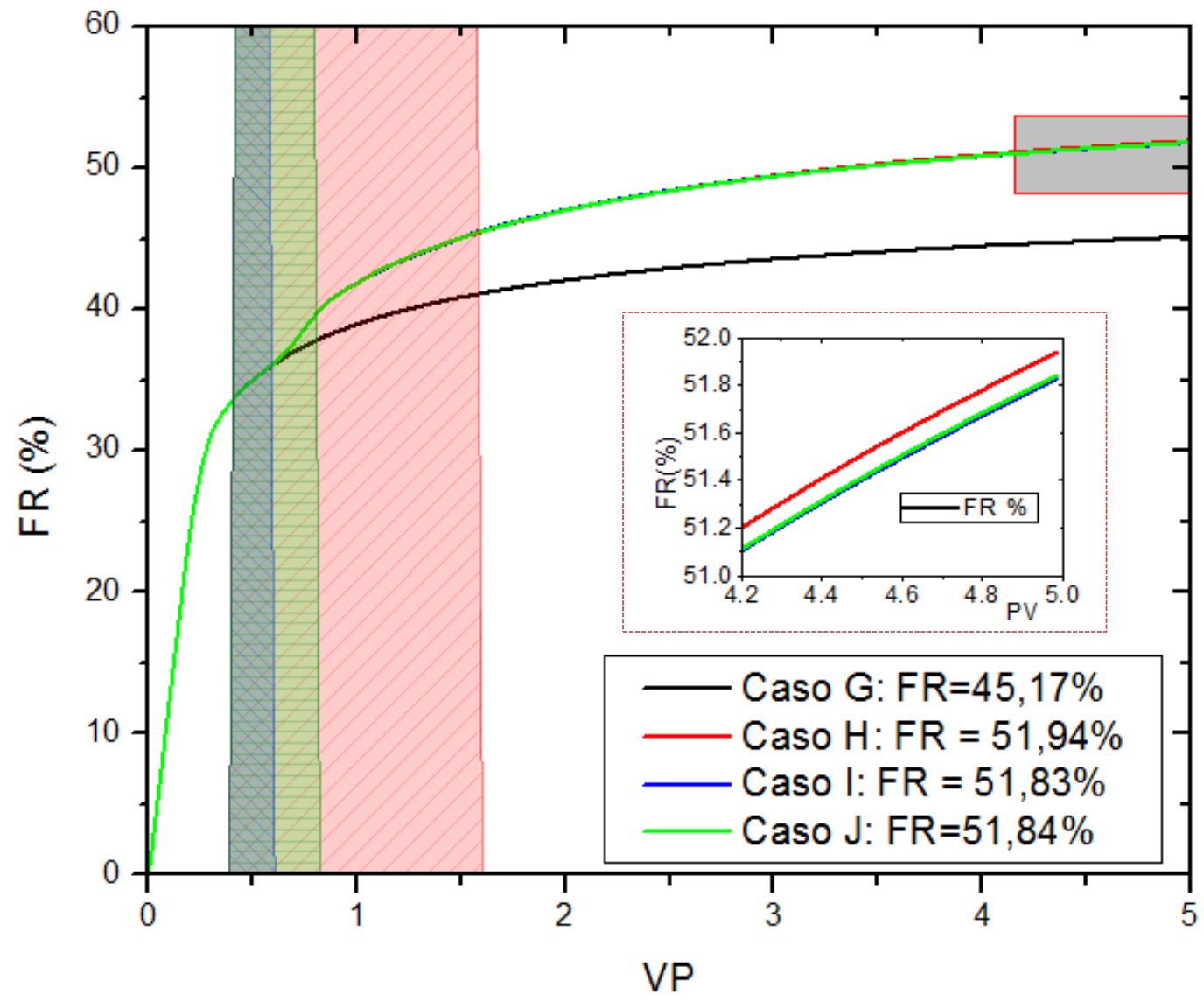

Figura 4-23 - Curvas de evolução do fator de recuperação de óleo para os Casos $G(I A)$, H (WAE 0,4/1,2/3,4), I (WAE 0,4/0,2/4,4) e J (WAE 0,4/0,4/4,2). 
Para esta análise na parte intermediária do reservatório a diferença entre os resultados de tamanho do banco de emulsão é tão pequena que foi destacado na figura acima o quadro vermelho com o trecho final das curvas de FR para que fosse possível observar a diferença.

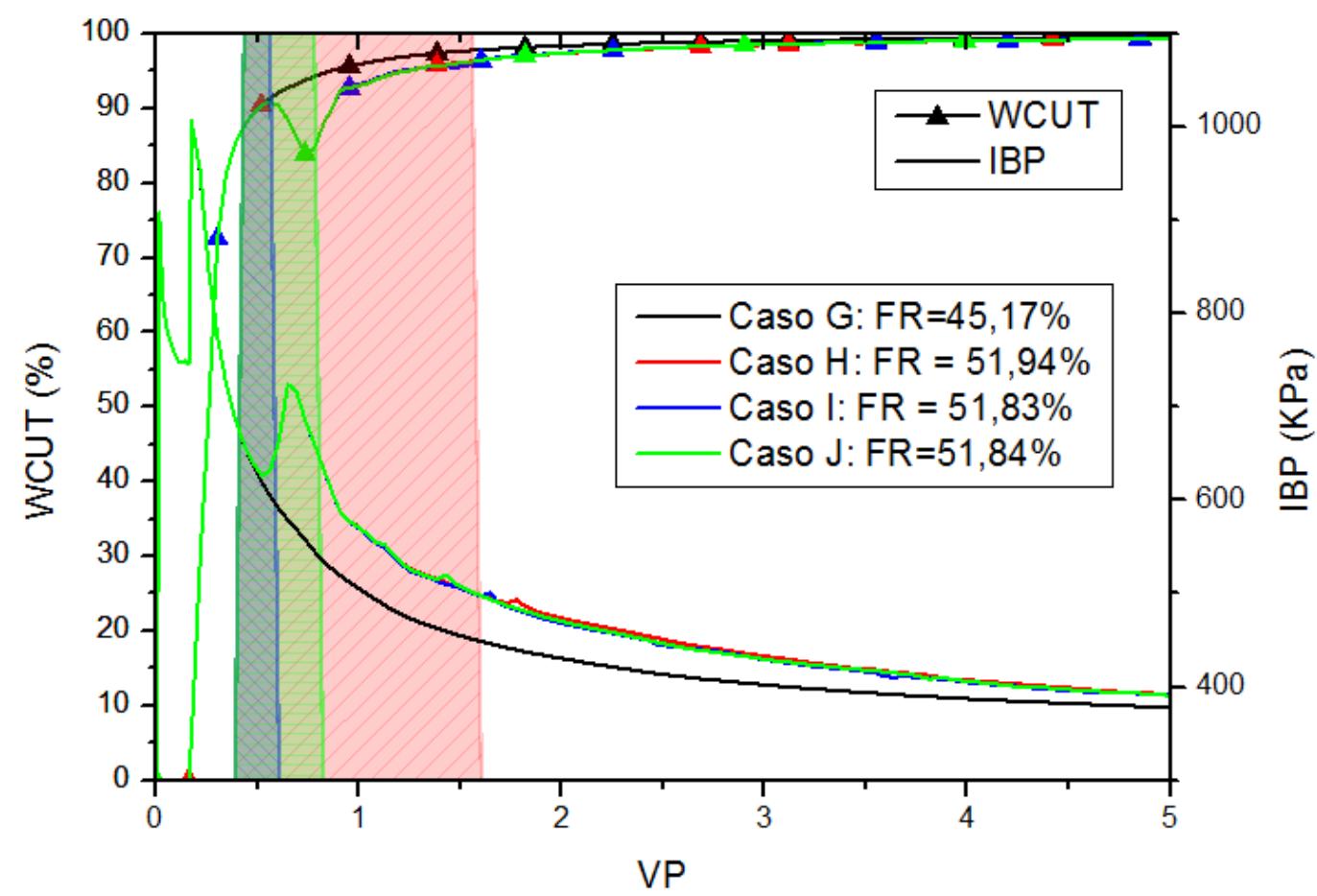

Figura 4-24 - Curvas de evolução do corte de água e pressão de injeção no poço injetor para os Casos G (IA), H (WAE 0,4/1,2/3,4), I (WAE 0,4/0,2/4,4) e J (WAE 0,4/0,4/4,2).

As diferenças são mínimas também nos gráficos de corte de água e pressão de injeção, indicando que o banco de emulsão reduzido (0,2 VP) já foi suficiente para obter os benefícios da injeção de emulsão no meio poroso e o aumento do banco de emulsão não trouxe maiores benefícios.

No Caso H, o volume do banco de emulsão é o mais elevado, 1,2VP. Então foi feita uma variação deste caso (Caso $\mathrm{H}$ _ciclo) injetando os mesmos 1,2VP de emulsão em três ciclos WAE de 0,4 VP seguidos de injeção contínua de água até completar 5 VP. Os resultados são apresentados nas Figura 4-25 e Figura 4-26 e em todas os bancos de emulsão estão sombreados conforme os casos. 


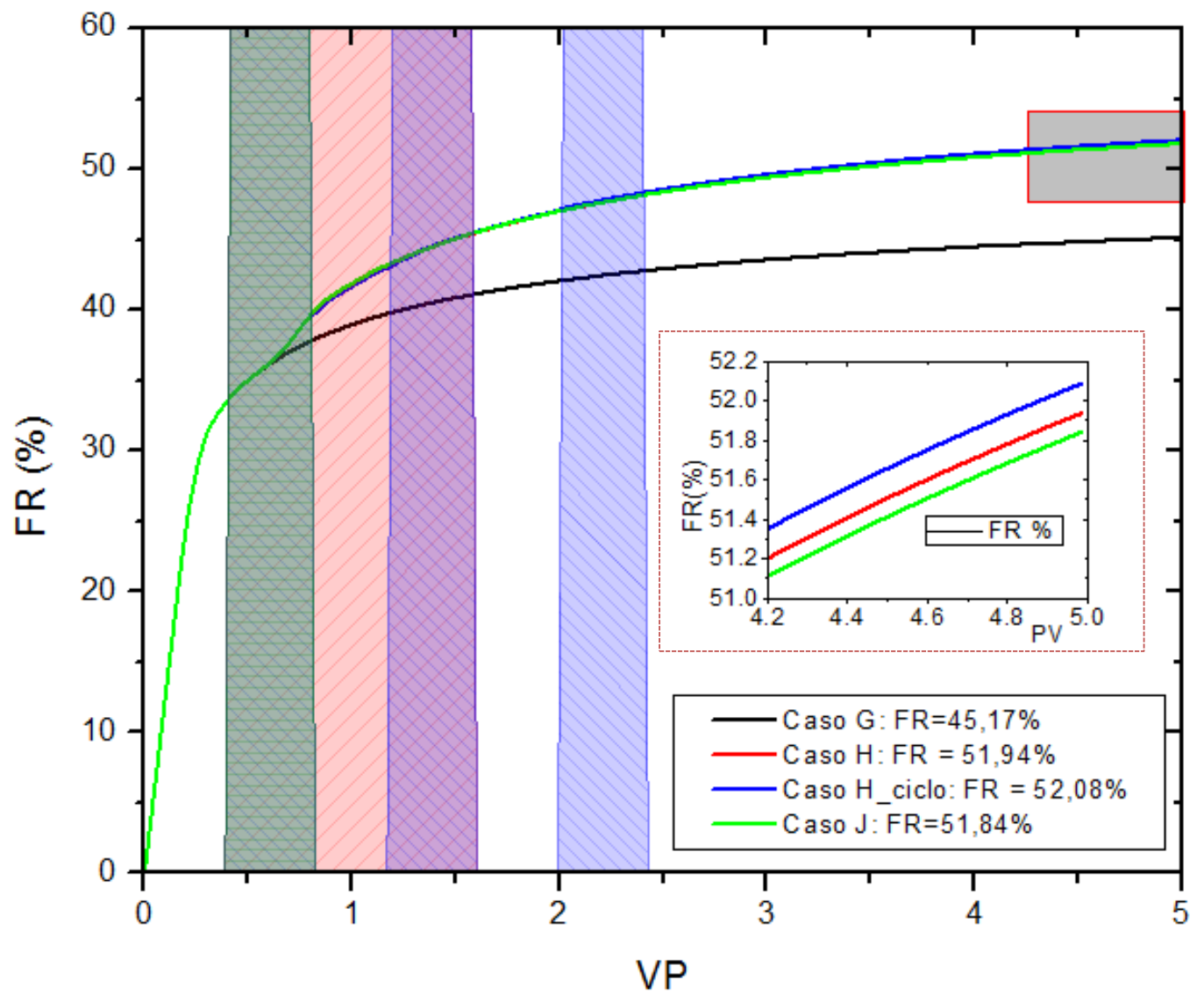

Figura 4-25 - Curvas de evolução do fator de recuperação de óleo para os Casos $G(I A)$, H (WAE 0,4/1,2/3,4), H_ciclo e J (WAE 0,4/0,4/4,2).

Novamente a diferença entre os resultados é tão pequena que foi destacado na figura acima o quadro vermelho com o trecho final das curvas de FR para que fosse possível observar a diferença. 


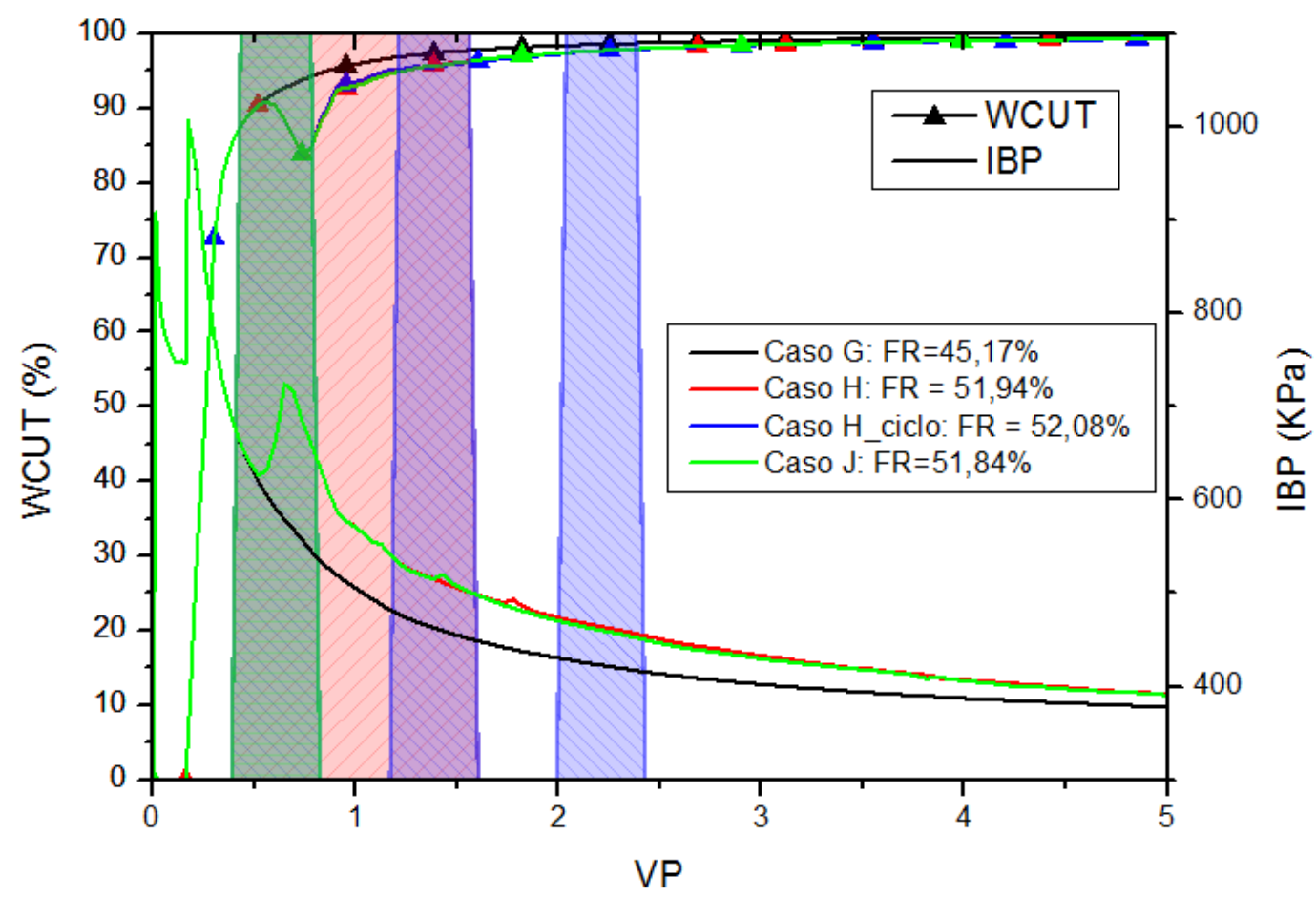

Figura 4-26 - Curvas de evolução do corte de água e da pressão de injeção no poço injetor para os Casos G (IA), H (WAE 0,4/1,2/3,4), H_ciclo e J (WAE 0,4/0,4/4,2).

Não foi possível observar diferença entre a pressão de injeção do caso $\mathrm{H}$ com o caso equivalente com injeção cíclica (H_ciclo), resultado que pode estar relacionado à alta heterogeneidade do reservatório.

A seguir são apresentados na Figura 4-27 os mapas das quatro camadas ( $\mathrm{k}=34$ a 37) de porosidade e de saturação de óleo para o Caso $\mathrm{G}$, injeção de água e o Caso J, injeção WAE. Assim, como, na Figura 4-28 são apresentados para os mesmos casos as seções verticais com saturações de óleo. Estas figuras ilustram a mudança na saturação em três momentos: após a injeção do banco de emulsão (1,0 VP), após a injeção total de 2,0 VP e ao final (5,0 VP).

Só foi apresentado o caso J, pois como verifica-se nos gráficos, a diferença entre os Casos H, H_ciclo, I e J, variando o tamanho do banco de emulsão são bem pequenas, reforçando os resultados observados nos gráficos de produção. As áreas afetadas pela injeção de emulsão são similares embora os volumes dos bancos de emulsão injetados sejam distintos, indicando que os casos com banco de emulsão com menores volumes já foram suficientes para afetar a área varrida pelo fluido injetado. 


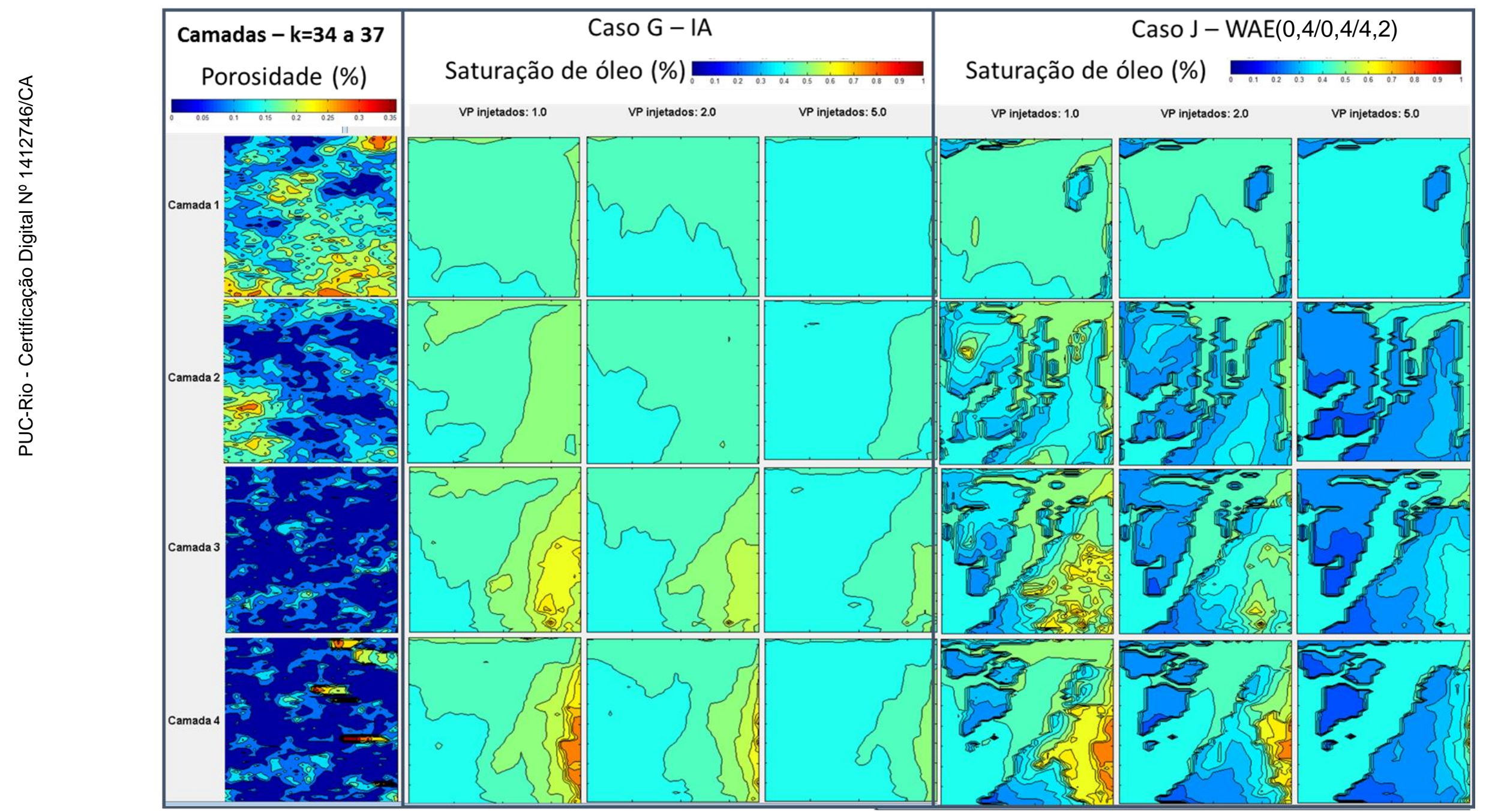

Figura 4-27 - Mapas de porosidade e de saturação de óleo das camadas k=34 a 37 dos Casos G (injeção de água) e J (WAE 0,4/0,4/4,2) durante a injeção de 1,2 e 5 VP de fluidos. 


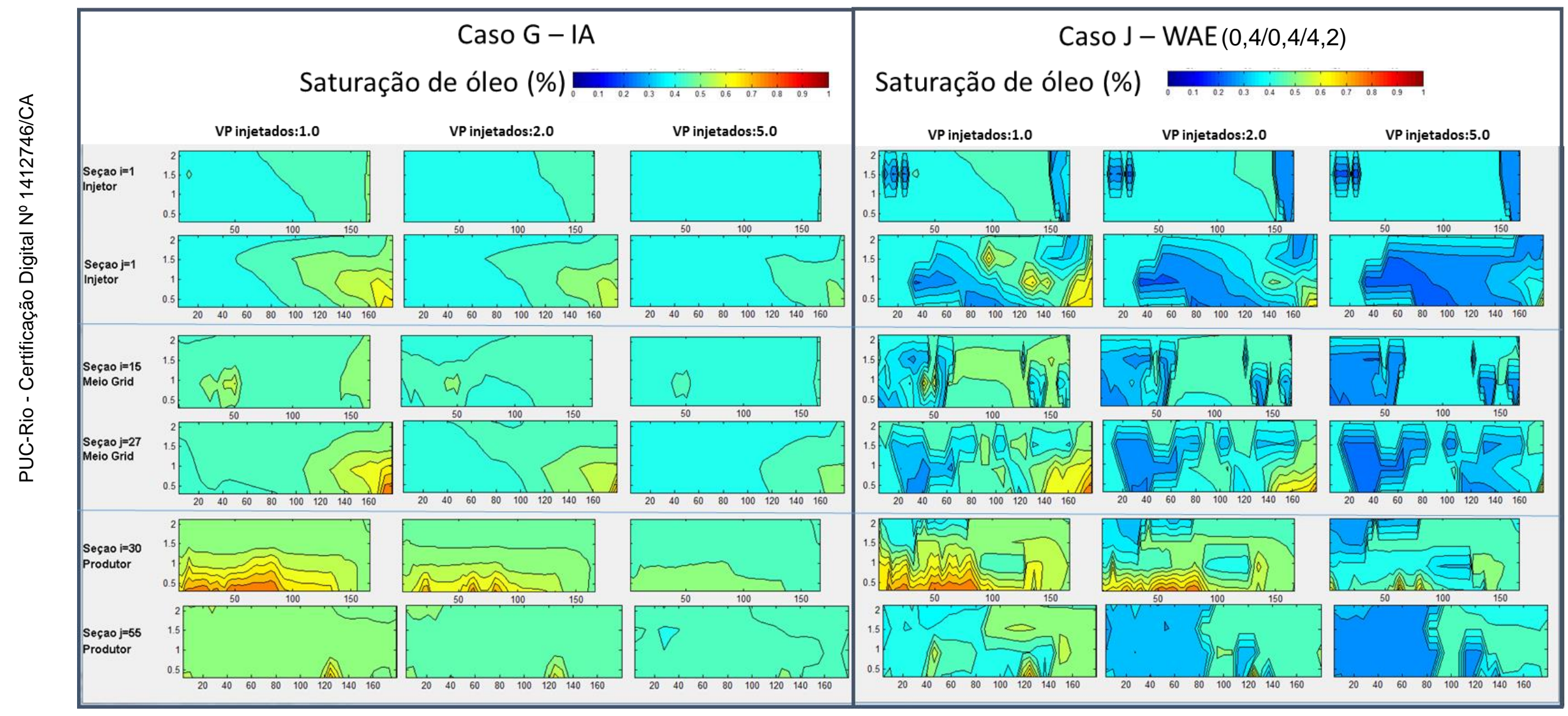

Figura 4-28 - Mapas de saturação de óleo para seções (i,j) localizadas no poço injetor, no meio do domínio e no poço produtor - Caso G (injeção de água) e Caso J (WAE 0,4/0,4/4,2) durante a injeção de 1, 2 e 5 VP de fluidos. 
Assim como verificado para as simulações com 4 camadas no topo, a diferença entre os casos variando o tamanho do banco é bem pequena, o que indica que mesmo o banco de emulsão com 0,2 VP já é suficiente para afetar a produção de água e o varrido no reservatório, e assim aumentar o fator de recuperação de cerca de $45,17 \%$ para o caso de injeção de água para cerca de $51,83 \%$. Aumentando o tamanho do banco para 0,4 e 1,2 VP observa-se um acréscimo de recuperação de óleo atingindo um FR de até $51,94 \%$. Os resultados indicam que existe alguma diferença, porém o efeito do tamanho do banco de emulsão é bem pequeno na recuperação final.

Ou seja, mesmo um banco de emulsão de tamanho reduzido foi suficiente para mudar o varrido vertical e reduzir as saturações residuais de óleo, o que é ilustrado nos mapas e seções acima, afetando a recuperação. Esta redução adicional de saturação residual de óleo é ainda mais evidente nas camadas inferiores, que possuem características permoporosas piores. Os resultados são similares aos verificados por Guillen (2012a), onde verificou-se que além do efeito microscópico há mudança no varrido macroscópico também.

Continuando com a análise paramétrica para a injeção WAE no modelo 3D com quatro camadas na interface entre as duas formações, manteve-se o banco de emulsão de 0,4 VP, e foi feita a análise em relação ao momento de iniciar a injeção de emulsão. Foram avaliados os casos com injeção de emulsão iniciando após a injeção de 0,4 VP de água, após 0,2 VP de água e após 2,0 VP de água, Casos J, K e L. Os resultados são apresentados nas Figura 4-29 e Figura 4-30, em todas as figuras os bancos de emulsão estão sombreados conforme os casos. 


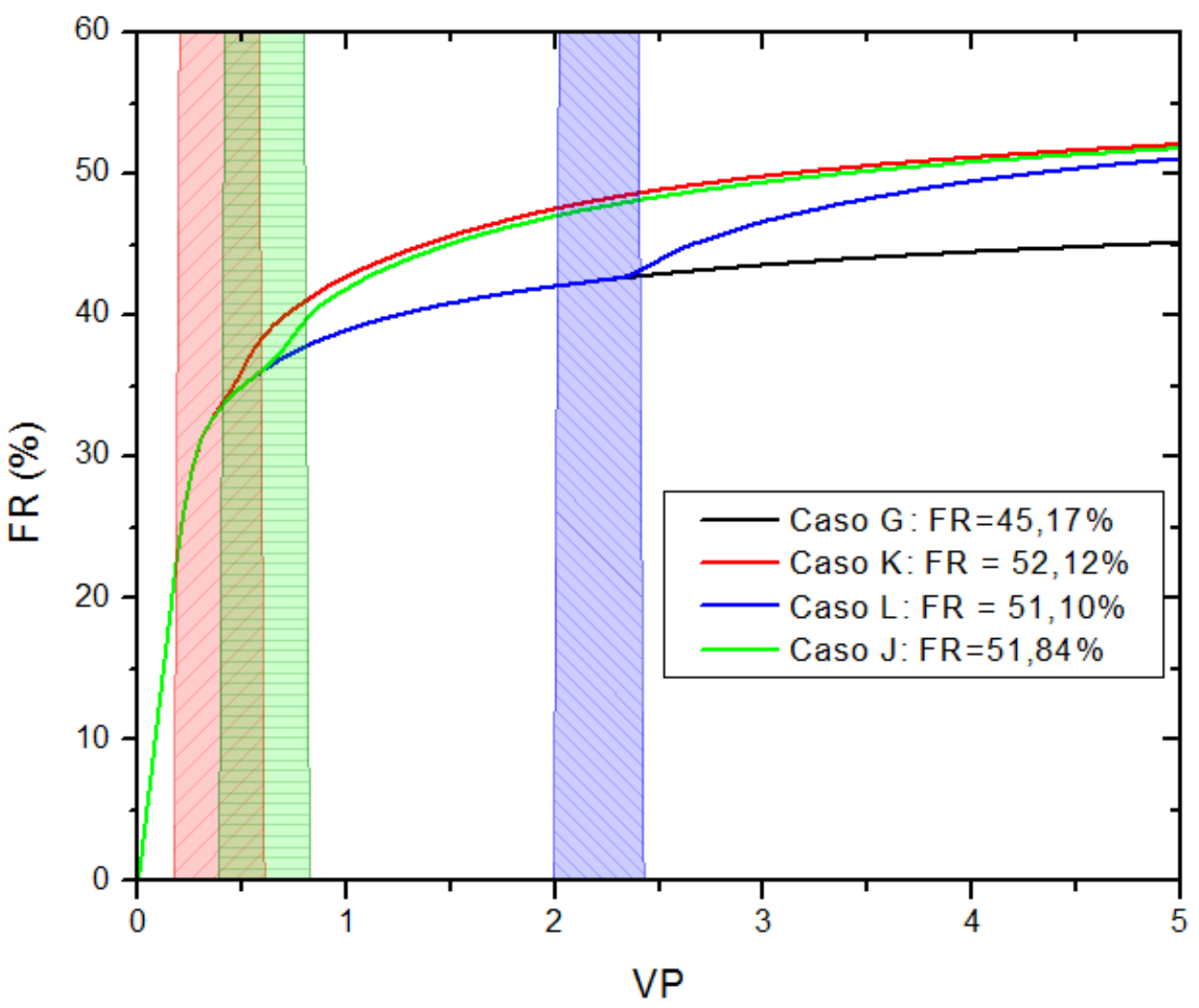

Figura 4-29 - Curvas de evolução do fator de recuperação de óleo para os Casos $G(I A)$, J (WAE 0,4/0,4/4,2), K (WAE 0,2/0,4/4,4) e L (WAE 2,0/0,4/2,6).

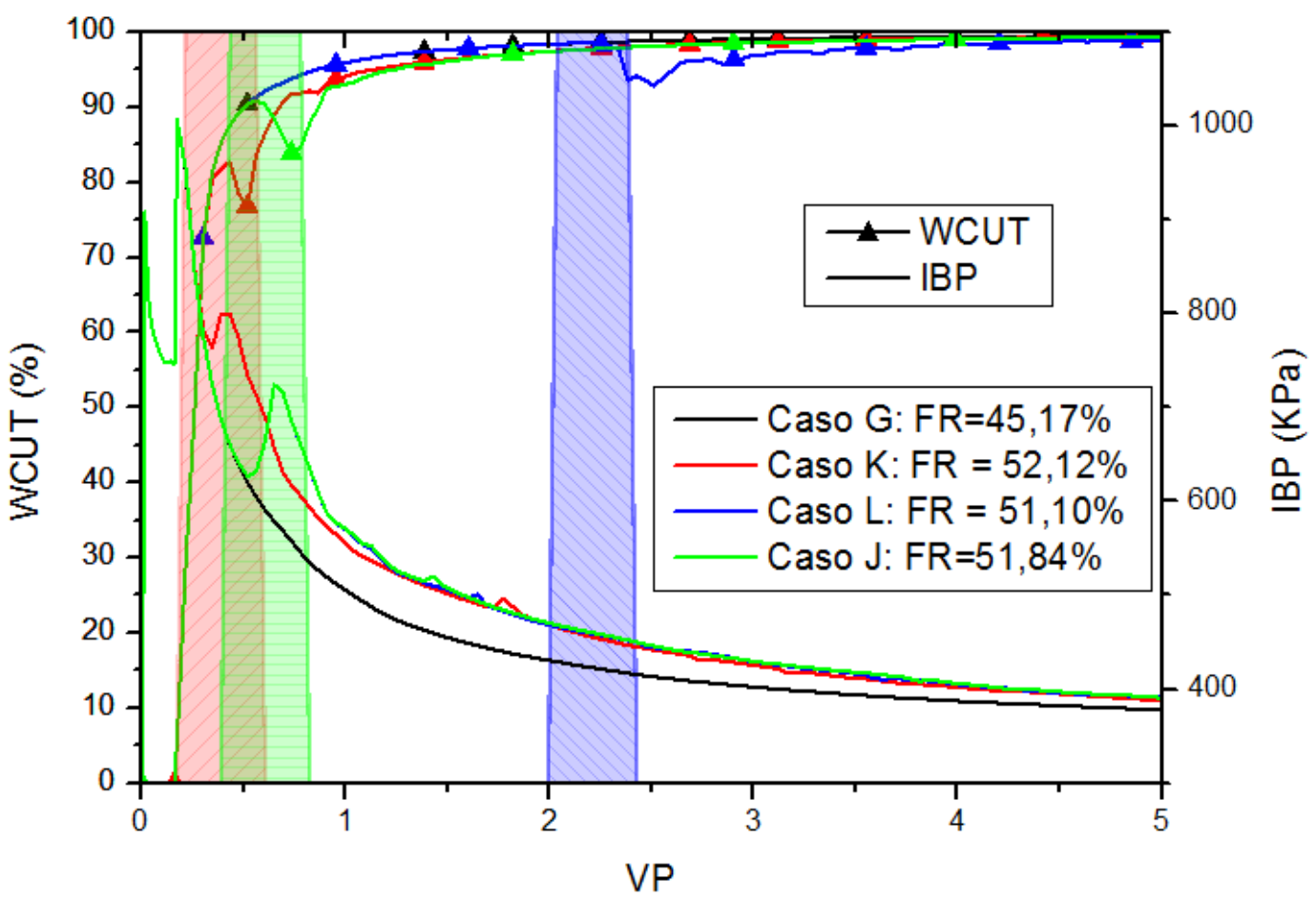

Figura 4-30 - Curvas de evolução do corte de água e da pressão de injeção no poço injetor para os Casos G (IA), J (WAE 0,4/0,4/4,2), K (WAE 0,2/0,4/4,4) e L (WAE $2,0 / 0,4 / 2,6)$. 
Os resultados apresentados nos gráficos de produção acima mostram que quanto antes for injetado o banco de emulsão melhor é o resultado na recuperação e antecipação da produção de óleo. Nos Casos K e J, quando o banco de emulsão é injetado no momento e logo após a irrupção de água de poço produtor, as reduções de corte água são mais significativas e maiores o efeito na recuperação antecipada de óleo. No Caso L, onde o banco de emulsão é injetado quando o corte de água já está bastante elevado, a emulsão também provoca redução no corte de água mas esta é menor. Com isso, o efeito na recuperação existe mas é retardado e mais lento em relação aos casos anteriores.

Na Figura 4-31 são apresentados os mapas das quatro camadas ( $\mathrm{k}=34$ a 37) de porosidade e de saturação de óleo para o Caso G, injeção de água, e o Caso K, injeção WAE.

Em seguida, na Figura 4-32 são apresentadas as respectivas seções verticais, para i e j constantes, de saturação de óleo para o Caso G (injeção de água) e o Caso K (injeção WAE). Todos os mapas mostram a mudança na saturação em três momentos: após a injeção do banco de emulsão (1,0 VP), após a injeção total de 2,0 VP e ao final da simulação (5 VP).

Na Figura 4-33 são apresentados os mesmos mapas comparando o Caso G com o Caso L cuja a injeção do banco é mais tarde, após a injeção de 2,5, 4 e 5 VP. Na Figura 4-34 são apresentadas para os mesmos momentos de injeção seções verticais, para i e j constantes, de saturação de óleo para o Caso G (injeção de água) e o Caso L (injeção WAE).

Analisando os mapas de saturação dos dois casos: K (WAE com injeção do banco de emulsão com 0,5 VP de fluido injetado) e Caso L (WAE com injeção do banco de emulsão com 2,0 VP de fluido injetado), verificamos a razão dos resultados evidenciados nas curvas de produção. Enquanto no primeiro caso (Caso K-WAE 0,2/0,4/4,4) é possível verificar os efeitos da injeção de emulsão com redução significativa de saturação de óleo residual com menores volumes injetados de fluido (cores mais frias), como 1 e 2 VP, no segundo caso (Caso LWAE 2,0/0,4/2,6) só com maiores volumes de fluido injetado (4VP) que resultados mais significativos da injeção WAE podem ser evidenciados nos mapas de saturação de óleo. 


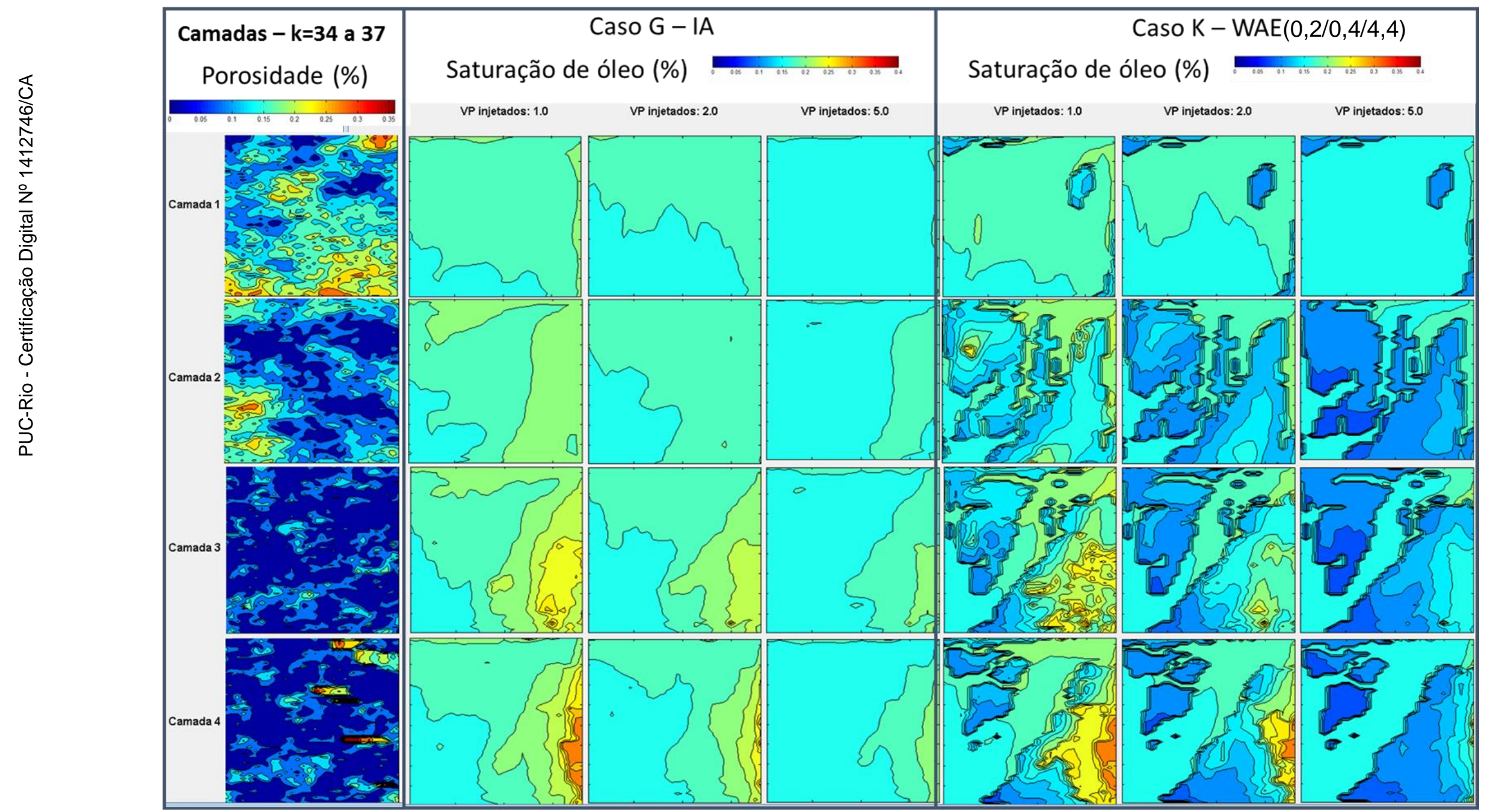

Figura 4-31 - Mapas de porosidade e de saturação de óleo das camadas k=34 a 37 dos Casos G (injeção de água) e K (WAE 0,2/0,4/4,4) durante a injeção de 1, 2 e 5 VP de fluidos. 


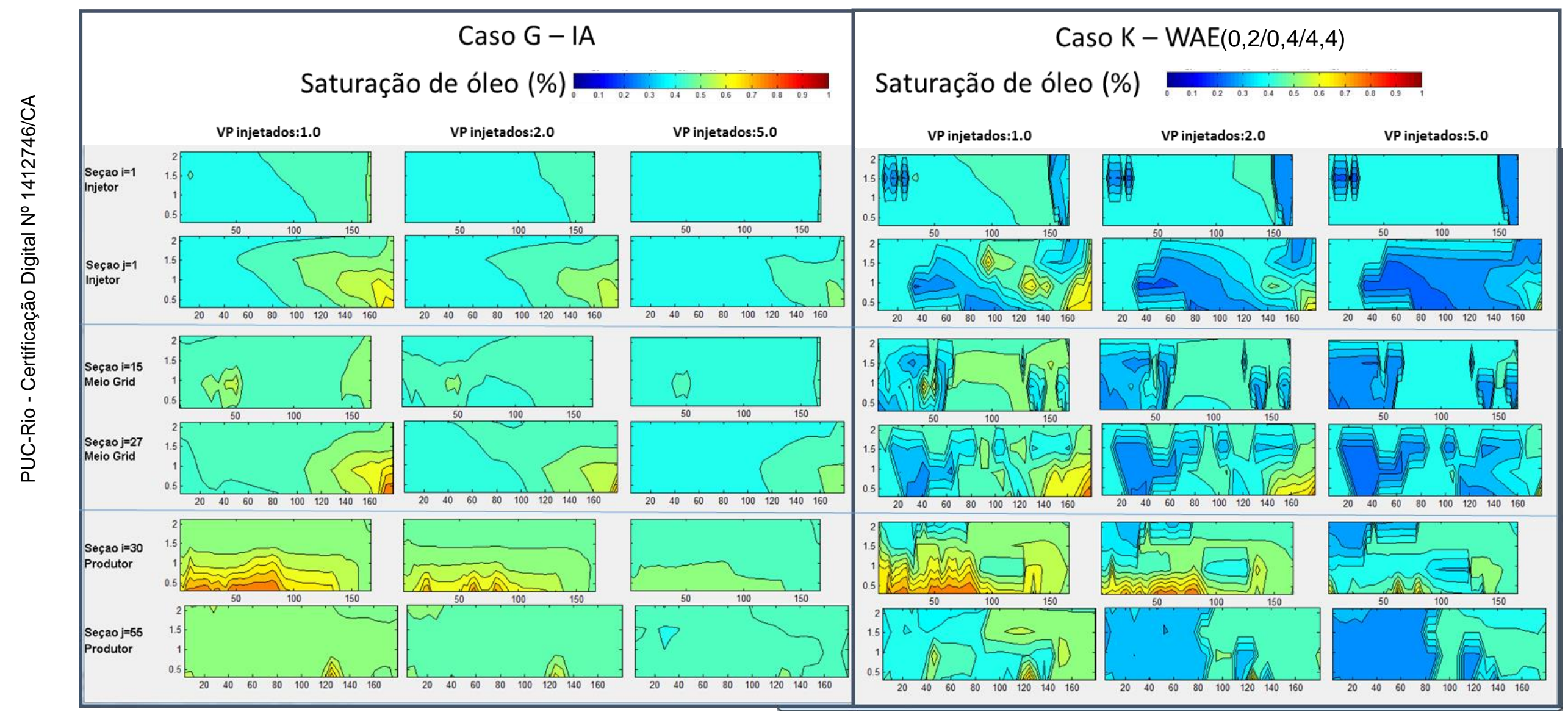

Figura 4-32 - Mapas de saturação de óleo para seções (i,j) localizadas no poço injetor, no meio do domínio e no poço produtor - Caso G (injeção de água) e Caso K (WAE 0,2/0,4/4,4) durante a injeção de 1, 2 e 5 VP de fluidos. 


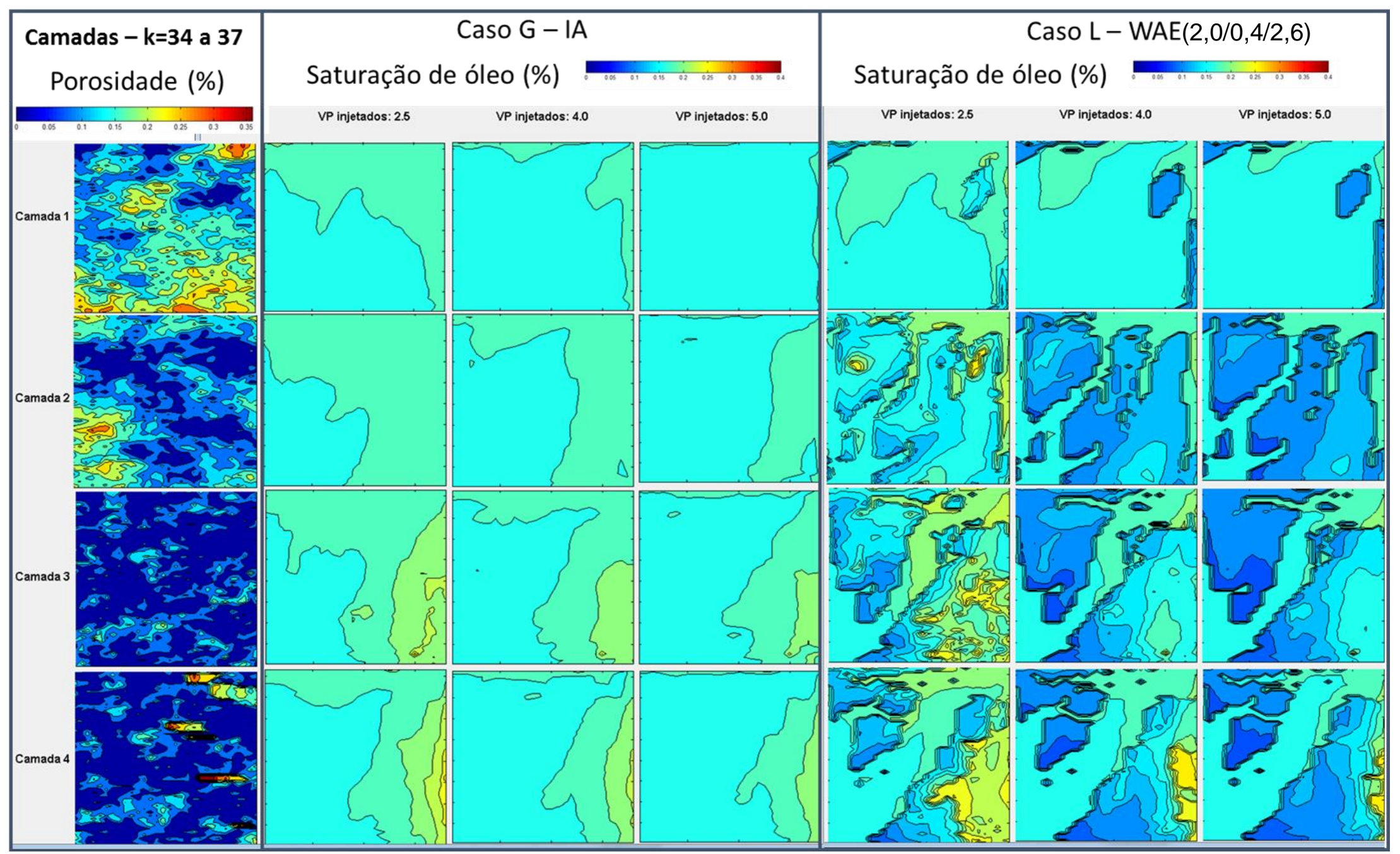

Figura 4-33 - Mapas de porosidade e de saturação de óleo das camadas k=34 a 37 dos Casos G (injeção de água) e K (WAE 2,0/0,4/2,6) durante a injeção de 2,5, 4 e 5 VP de fluidos. 


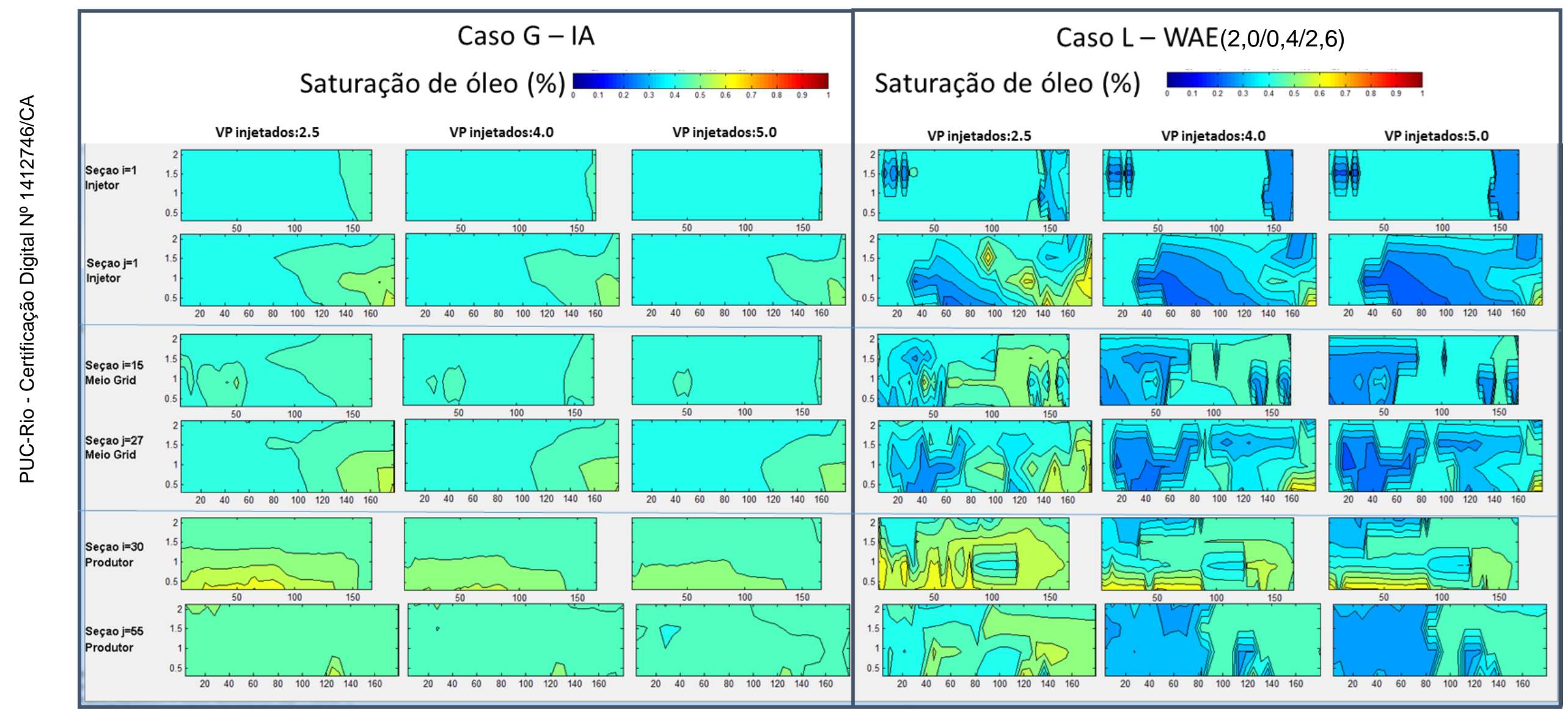

Figura 4-34 - Mapas de saturação de óleo para seções (i,j) localizadas no poço injetor, no meio do domínio e no poço produtor - Caso G (injeção de água) e Caso L (WAE 2,0/0,4/2,6) durante a injeção de 2,5, 4 e 5 VP de fluidos. 
Os resultados mostram diferenças em relação ao momento da injeção do banco de emulsão. Estas diferenças podem ser observadas também em antecipação de recuperação, redução no corte de água e impacto na pressão de injeção. A antecipação de recuperação de óleo é maior quanto antes é feita a injeção de emulsão.

Nos mapas acima verifica-se que quanto antes é feita a injeção do banco de emulsão, mais efetivo é o efeito desta na mudança do varrido no reservatório.

Em todos os casos de injeção WAE, o acréscimo de volume adicional recuperado foi significativo, agregando a injeção de água até $7 \%$ ao fator de recuperação.

Além disso, foi feita uma análise do efeito da vazão dada a dependência da atuação da emulsão ao Número de Capilaridade. Além do caso de referência de vazão (Casos G e J) foram feitas as simulações de injeção WAE $(0,4 / 0,4 / 4,2)$ com a vazão de 1/5 da vazão de referência (Caso $M$ ) bem como com a vazão 5 vezes a vazão de referência (Caso $\mathrm{N}$ ). Os gráficos com os resultados de produção são apresentados nas Figura 4-35 e Figura 4-36.

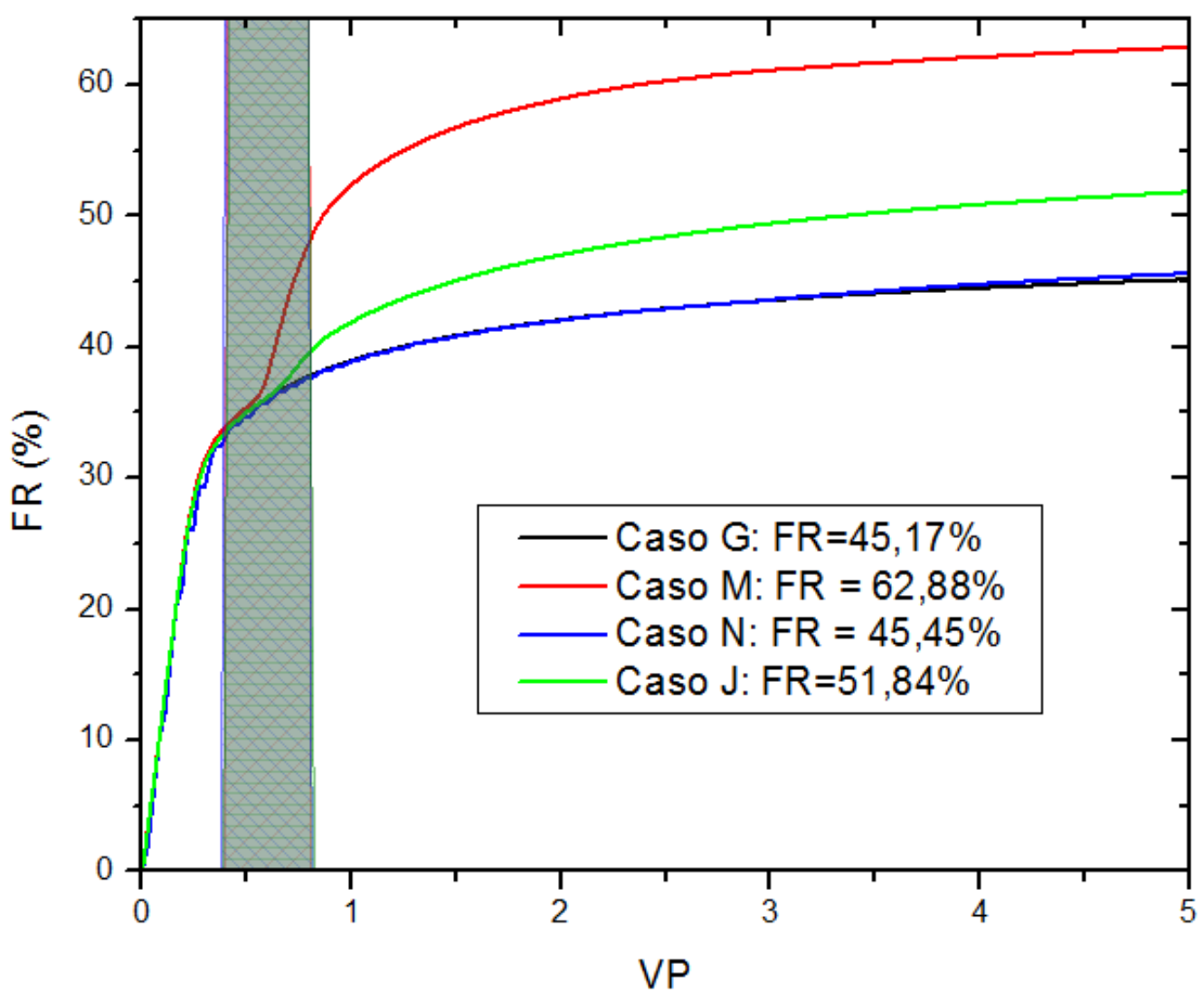

Figura 4-35 - Curvas de evolução do fator de recuperação de óleo para os Casos G (IA_Qref), J (WAE_Qref), M (WAE_Qref/5), N (WAE_5xQref) 


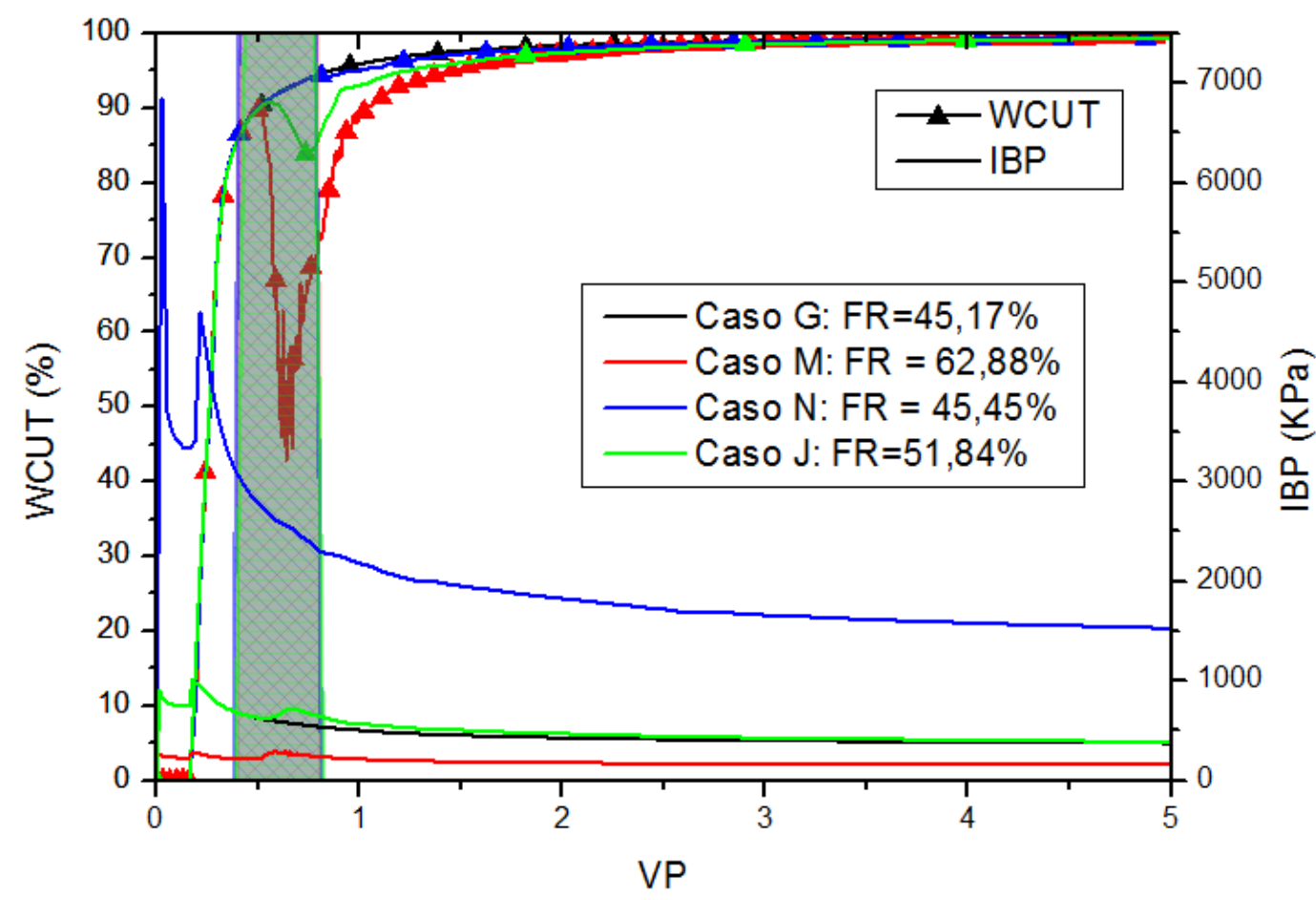

Figura 4-36 - Curvas de evolução do corte de água para os Casos G (IA_Qref), J (WAE_Qref), M (WAE_Qref/5), N (WAE_5xQref)

Os resultados de recuperação adicional da injeção WAE varia de forma bastante significativa com a mudança nas vazões, com a vazão reduzida (Caso M) a recuperação incremental é maior e com a vazão mais alta (Caso $\mathrm{N}$ ) esta recuperação incremental cai bastante em relação a vazão de referência (Caso J).

Esses resultados evidenciam a dependência do Número de Capilaridade para a atuação da emulsão, quanto menor a vazão e consequentemente o Número de Capilaridade, maior é o efeito de redução da mobilidade da fase água e da saturação de óleo residual da emulsão. O resultado obtido é bem concordante com os experimentos realizados por Engelke et al. (2012). 


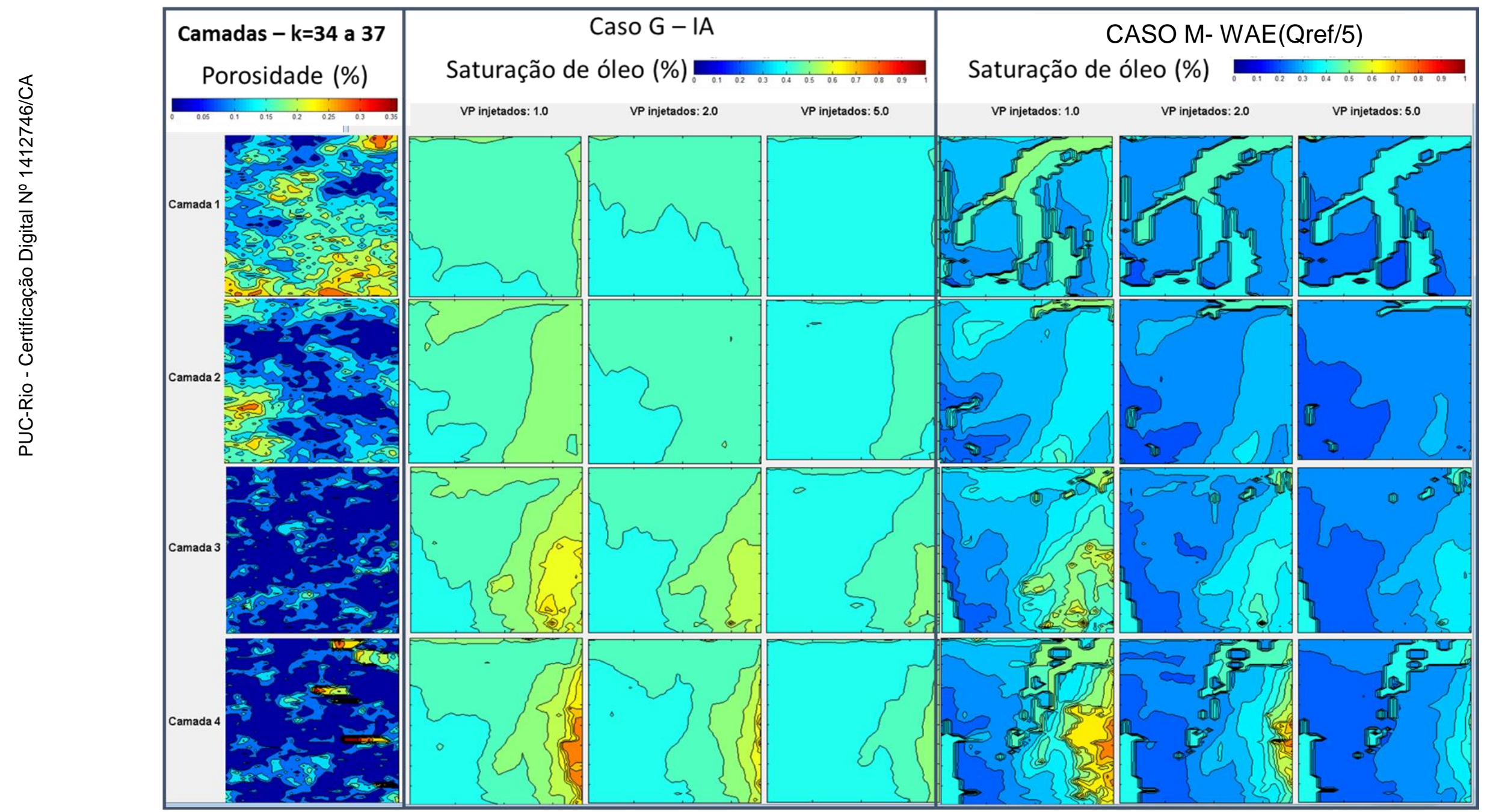

Figura 4-37 - Mapas de porosidade e de saturação de óleo das camadas k=34 a 37 dos Casos G (injeção de água) e M (WAE_Qref/5) durante a injeção de 1,2 e 5 VP de fluidos. 


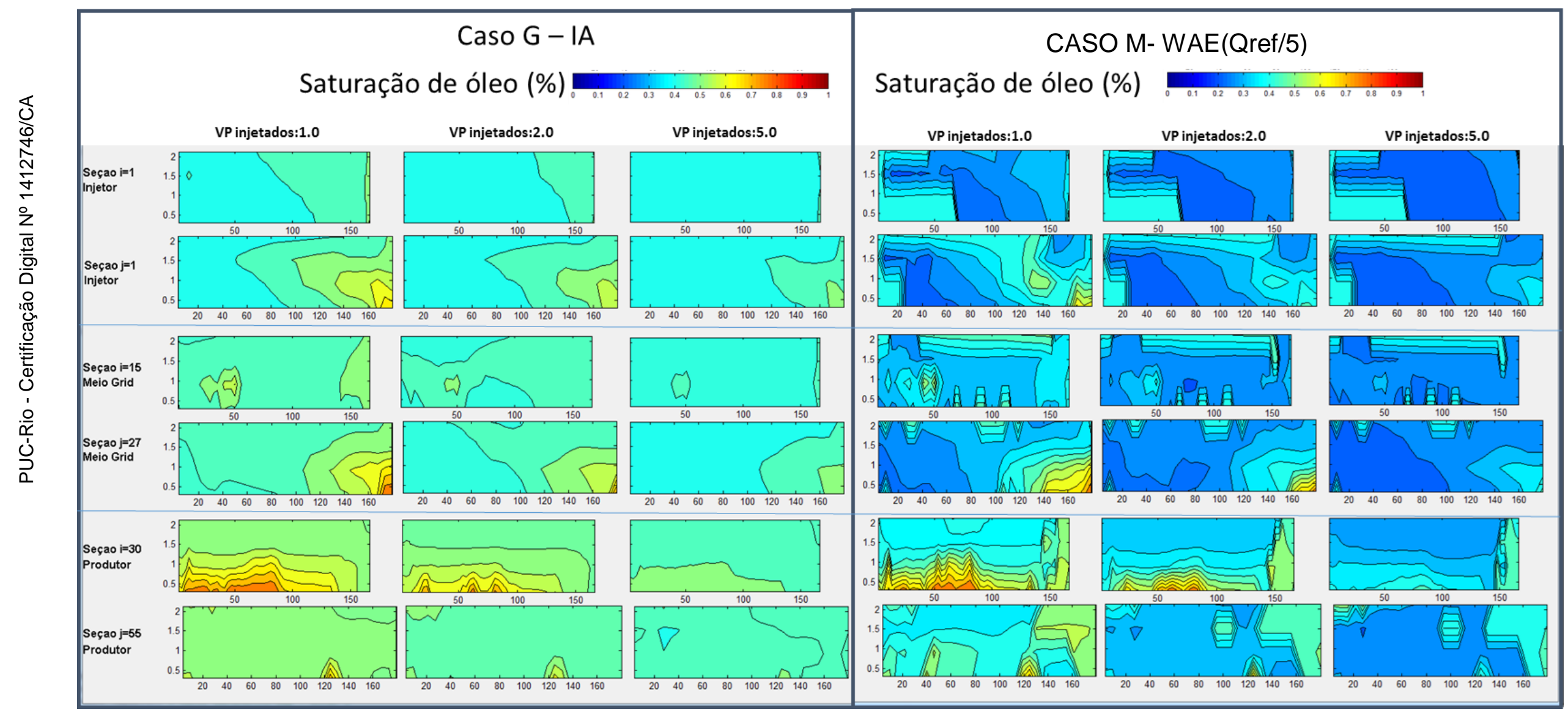

Figura 4-38 - Mapas de saturação de óleo para seções (i,j) localizadas no poço injetor, no meio do domínio e no poço produtor - Caso G (injeção de água) e Caso M (WAE_Qref/5) durante a injeção de 1, 2 e 5 VP de fluidos. 


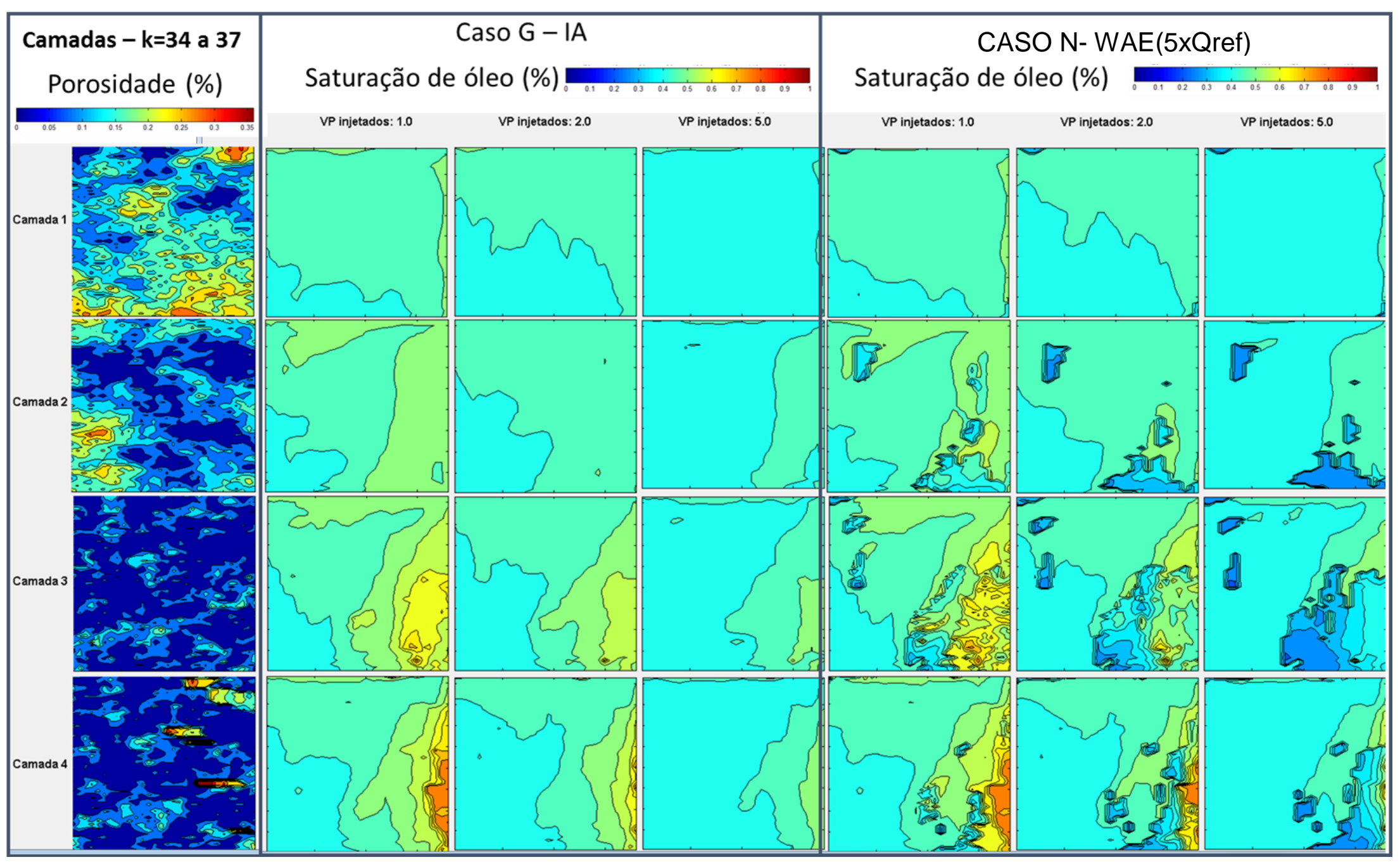

Figura 4-39 - Mapas de porosidade e de saturação de óleo das camadas k=34 a 37 dos Casos G (injeção de água) e N (WAE_5xQref) durante a injeção de 1,2 e 5 VP de fluidos. 


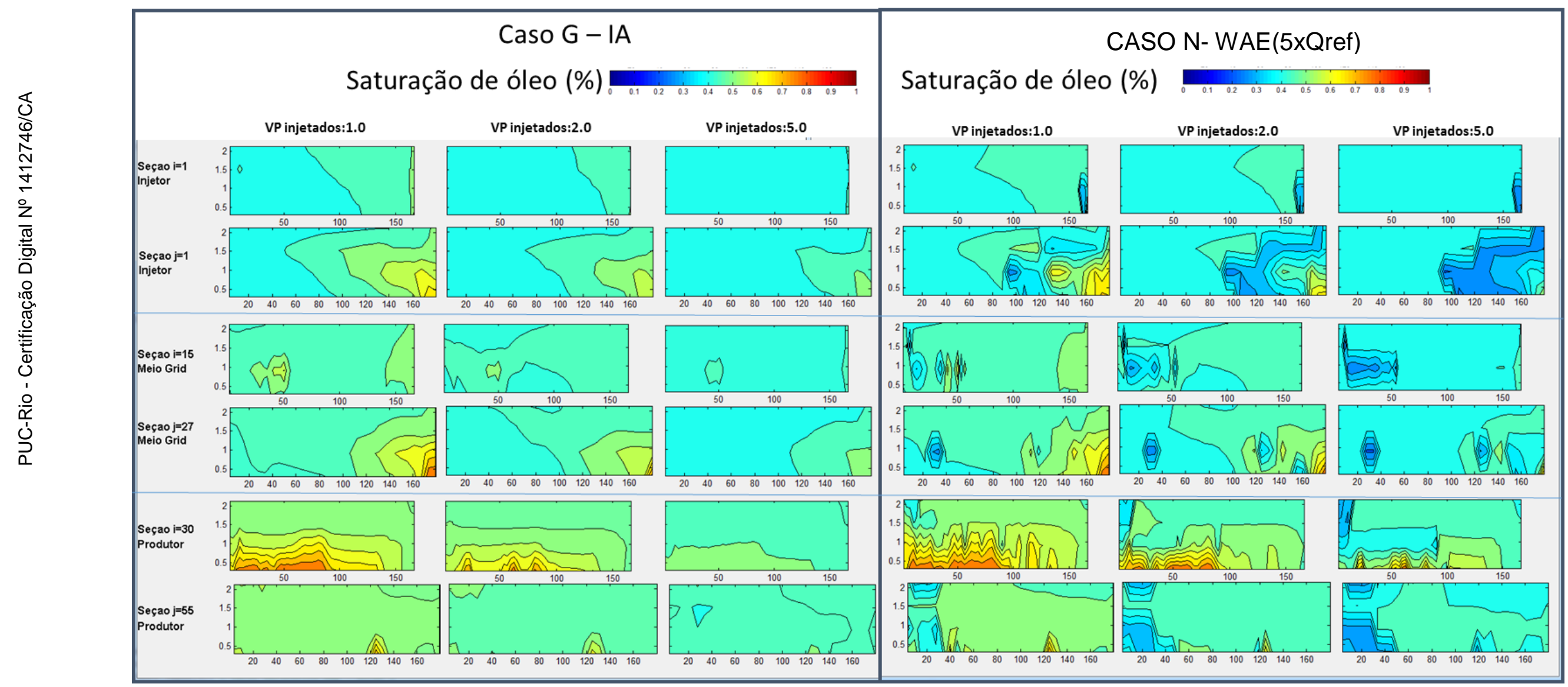

Figura 4-40 - Mapas de saturação de óleo para seções (i,j) localizadas no poço injetor, no meio do domínio e no poço produtor - Caso G (injeção de água) e Caso N (WAE_5xQref) durante a injeção de 1, 2 e 5 VP de fluidos. 
Nos mapas e seções apresentados nas Figura 4-37 e Figura 4-38, para a rodada com vazões mais baixas (Caso M) e nas Figura 4-39 e Figura 4-40 com os mapas e seções, para vazões mais altas (Caso $N$ ) fica bem claro, respectivamente, a ampliação e redução do efeito da injeção da emulsão, destaque para as regiões com cores azuis mais frias onde houve redução das saturações residuais de óleo.

É importante destacar que estes resultados estão sendo avaliados contra volume injetado. Mas se analisarmos a recuperação contra o tempo, no caso da vazão 5 vezes reduzida o tempo para atingir este volume de injeção será 5 vezes maior. Já no caso de vazões mais elevadas, o acréscimo de óleo recuperado é bem menor mas o tempo é 5 vezes menor para atingir esta recuperação. Outra questão relevante é que para vazões mais elevadas as pressões de injeção são consideravelmente maiores, o que pode vir a ser tecnicamente inviável por riscos geomecânicos ou limitações dos equipamentos de injeção. Para avaliar o caso mais otimizado faz-se necessária a avaliação do custo-benefício de cada caso. 


\section{5 \\ Comentários finais}

Neste trabalho foi realizada a modelagem do escoamento de emulsões através dos mecanismos de mobilização de óleo com redução da saturação de óleo residual e melhora do varrido macroscópico. Nesta implementação foi possível reproduzir com a simulação a dependência dos fatores mais relevantes verificados nas pesquisas experimentais, ou seja, que a eficiência da emulsão é dependente da concentração da fase dispersa da emulsão e Número de Capilaridade local.

A incorporação do termo gravitacional permitiu avaliar o processo de injeção WAE em um modelo de reservatório estratificado altamente heterogêneo. Comparando os casos com injeção de água e com injeção WAE, observam-se, de forma geral que no primeiro a água percorre caminhos preferenciais por conta das heterogeneidades do modelo e da razão desfavorável de mobilidades enquanto no segundo há incremento no varrido com alguma homogeneização da frente de água.

Com simulações de 1 camada (2D) foi possível realizar uma análise quanto ao momento da injeção de emulsão, o tamanho do banco, e as faixas de vazão (ou respectivos) Números de Capilaridade de atuação da emulsão.

O melhor resultado das simulações 2D foi obtido para injeção de emulsão junto à irrupção de água no produtor e a avaliação da redução do banco de emulsão impacta pouco o volume adicional recuperado em relação à injeção de água, mas os resultados são consistentes e significativos (recuperação adicional de até $6 \%)$.

Nas simulações em 3 dimensões com 4 camadas foi possível avaliar tanto o topo do reservatório (uma formação), quanto a interface entre duas formações com diferentes ambientes sedimentais. Os resultados obtidos permitiram fazer uma análise quanto ao momento da injeção de emulsão, o tamanho do banco, e as faixas de vazão (ou respectivos Números de Capilaridade de atuação da emulsão).

O melhor resultado das simulações 3D foi obtido para injeção de emulsão antecipada e a avaliação da redução do banco de emulsão impacta bem pouco o volume adicional recuperado em relação a injeção de água. O maior efeito pode 
ser observado com a variação nas vazões de injeção/produção, quanto mais reduzida a vazão e consequentemente o Número de Capilaridade, maior é o efeito da emulsão na recuperação de óleo.

Em todos os casos observa-se resultados consistentes e significativos de recuperação adicional entre 5 a 17\%, sendo o ganho médio de 7\%.

Observou-se ainda que na grande maioria dos casos, as pressões de injeção para injeção do banco de emulsão foram inferiores a pressão de injeção inicial, indicando que a injeção de emulsão nas condições simuladas não traria problemas de perda de injetividade.

$\mathrm{Na}$ injeção de água, esta percorre caminhos preferenciais por conta das heterogeneidades do modelo e da razão desfavorável de mobilidades enquanto na injeção WAE há incremento no varrido vertical com alguma homogeneização da frente de água. O uso da emulsão foi mais efetivo no meio mais heterogêneo, caso na interface entre duas formações.

Embora ainda existam simplificações como não considerar captura e quebra de gotas assim como distribuição do tamanho de gotas, simulação incompressível e sem presença de gás, os resultados indicam que é possível avaliar o modelo de escoamento de emulsões com efeitos capilares e de concentração da fase dispersa da emulsão em reservatórios estratificados assim como o potencial do uso de emulsões no aumento da eficiência de varrido vertical.

\section{1 . \\ Sugestões}

Os resultados mostram que foi possível estudar o processo de injeção WAE para a produção de óleo utilizando simulação de reservatórios para a realização de simulações em duas e três dimensões (2D e 3D) com geometrias mais próximas de um reservatório real.

Seria interessante ampliar o estudo apresentado para utilizando curvas de permeabilidade relativas experimentais para representar o comportamento da emulsão.

Bem como ampliar o número de camadas e geometrias avaliadas neste estudo. Para isso, outro ponto de melhoria seria promover a melhoria da eficiência computacional no cálculo das curvas de permeabilidade relativa pois esta etapa é bem custosa para o tempo de simulação. 
Além disso, seria importante incorporar a dependência de outros fatores como a distribuição do tamanho de gotas, a variação deste tamanho de gotas no meio poroso e ainda eventuais mecanismos de reação da emulsão com a rocha, como captura de gotas no meio poroso. 


\section{6 Referências bibliográficas}

ASRNES, J.E., GIMSE, T., LIE, K.A. An Introduction to the Numerics of Flow in Porous Media using Matlab. SINTEF ICT, Dept. Of Applied Mathematics, Oslo. 2007.

ARHUOMA, M., et al. Determination of water-in-oil emulsion viscosity in porous media. Ind.Eng.Chem.Res.48, 7092-7102, 2009a.

ARHUOMA, M., et al. Numerical simulation of displacement mechanisms forenhancing heavy oil recovery during alkaline flooding. Energy Fuels 23, 5995-6002, 2009b.

BECHER, P., Emulsions Theory and Practice. Oxford University Press, Inc, New York, 2001.

BERA, A., MANDAL, A., Microemulsions: a novel approach to enhanced oil recovery: a review. J Petrol Explor Prod Technol 2012-5:255-268, 2015.

COBOS, S., CARVALHO, M.S., ALVARADO, V., Flow of oil-water emulsions through a constricted capillary. Int. J. Multiphase Flow 35, 507-515, 2009.

COLLINS, R. E., Flow of fluid through porous materials, Tulsa: PennWell Books, 1976.

COREY, A. The interrelation between gas and oil relative permeabilities. Producers Monthly, p. 38 to 41, 1954.

DULLIEN, F.A.L., Porous Media:Fluid Transport and Pore Structure San Diego: Academic Press, 1994.

ENGELKE, B., CARVALHO, M.S., ALVARADO, V., Conceptual DarcyScale Modelo of Oil Displacement with Macroemulsion, Energy Fuels, 2013.

FARIAS, M. L. R. Recuperação avançada de óleos pesados por injeção em emulsões diluídas de óleo em água, Rio de Janeiro, 2013. 219p. Tese de Doutorado, Departamento de Engenharia Mecânica, Pontifícia Universidade Católica do Rio de Janeiro. 
GUILLEN, V.R., CARVALHO, M.S., ALVARADO, V., Pore Scale and Macroscopic Displacement Mechanisms in Emulsion Flooding. Int. J. Transp. Porous Media, 2012a.

GUILLEN, V. et al., Capillary-driven mobility control in macro emulsion flow in porous media. Int. J. Multiphase Flow 43, 62-65, 2012b.

KOKAL, S. Crude-oil emulsoins: A state-of-art review. SPE, p. 5to 13, 2005.

MCAULIFFE, C. Oil in water emulsions and their flow properties in porous media. SPE-AIME, p. 727 to 733 , 1973a.

. Crude oil in water emulsions to improve fluid flow in an oil reservoir. SPE-AIME, p. 721 to $726,1973 \mathrm{~b}$.

PONCE, R. V., CARVALHO, M. S., ALVARADO, V., Oil recoverymodeling of macro-emulsion flooding at low capillary number. Int. J. Petroleum Science and Engineering 119, 112-122, 2014.

PONCE, R. V., CARVALHO, M. S., ALVARADO, V., Water-alternatingmacro emulsion reservoir simulation through capillary-number dependent modeling, artigo em elaboração, 2016.

QUINTELLA, J. R. F., Simulação da Injeção Alternada Água-Emulsão como Processo de Recuperação Avançada de Petróleo, Rio de Janeiro, 2012. 95p. Dissertação de Mestrado, Departamento de Engenharia Mecânica, Pontifícia Universidade Católica do Rio de Janeiro

ROMERO, M.I., CARVALHO, M.S., ALVARADO, V., Experiments and network model of flow of oil-water emulsion in porous media. Phisical Review E 84, 2011.

ROSA, A.J. R., CARVALHO, R.S., XAVIER, J. A., Engenharia de reservatórios de petróleo - Rio de Janeiro: Interciência: PETROBRAS, 2006.

THOMAS, J. E. Fundamentos de engenharia de petróleo. Editora Interciência, Rio de Janeiro, 2001.

YANG,D., DONG,M., Simulation of O/W Emulsion Flow in Alkaline / Surfactant Flood for Heavy Oil Recovery. Canadian International Petroleum Conference, paper 066, 2009. 


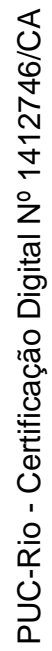

